CRISTIANE MILEO BATISTELA

MEDIDA DE COMPLEXIDADE NO FENÔMENO DE ONDAS DE DEPRESSÃO ALASTRANTE

São Paulo

2012 
CRISTIANE MILEO BATISTELA

MEDIDA DE COMPLEXIDADE NO FENÔMENO DE ONDAS DE DEPRESSÃO ALASTRANTE

\author{
Dissertação apresentada à Escola \\ Politécnica da Universidade de São Paulo \\ para obtenção do título de Mestre em \\ Engenharia Elétrica.
}

São Paulo 
CRISTIANE MILEO BATISTELA

\section{MEDIDA DE COMPLEXIDADE NO FENÔMENO DE ONDAS DE DEPRESSÃO ALASTRANTE}

Dissertação apresentada à Escola Politécnica da Universidade de São Paulo para obtenção do título de Mestre em Engenharia Elétrica.

Área de Concentração:

Engenharia de Sistemas

Orientador:

Prof. Dr. José Roberto Castilho Piqueira

São Paulo 
FICHA CATALOGRÁFICA

Batistela, Cristiane Mileo

Medida de complexidade no fenômeno de ondas de depressão alastrante / C.M. Batistela. -- São Paulo, 2012. $118 / p$.

Dissertação (Mestrado) - Escola Politécnica da Universidade de São Paulo. Departamento de Engenharia de Telecomunicações e Controle.

1. Complexidade I. Universidade de São Paulo. Escola Politécnica. Departamento de Engenharia de Telecomunicações e Controle II. t. 


\section{Agradecimentos}

A Deus, pela vida.

Ao professor Piqueira, por sugerir o tema do trabalho, pela paciência em ensinar, confiança e amizade.

À professora Vera Maura Fernandes de Lima, por conceder os dados dos experimentos para o estudo realizado.

Ao Yuri Cássio Campbell Borges, pelo recurso computacional elaborado para o cálculo da complexidade.

Ao Bruno, por se fazer presente em todos os momentos.

À minha mãe, pelo amor.

Aos demais familiares, pelo incentivo e credibilidade.

Aos amigos da universidade, pela ajuda, incentivo e por partilharem das minhas alegrias e angústias: Luciana, Estela, Naji, Diego, Antônio, Átila, Reginaldo, Raul e Fernando. 


\title{
Resumo
}

O que se desejou apresentar neste trabalho é se a aplicação da medida de complexidade LMC no estudo do fenômeno da depressão alastrante mostra-se eficiente na perspectiva de contribuir para uma melhor compreensão do fenômeno. Para isso, usou-se como modelo experimental a retina de pintinho in vitro. $\mathrm{Na}$ tentativa de obter informações sobre estados de equilíbrio entre a ordem e desordem, propõe-se as análises dos registros de dois dos concomitantes do fenômeno: a alteração lenta do potencial extracelular e do sinal intríseco óptico. Para isso, avaliou-se o efeito de manipulações fármaco-química sobre esses dois concomitantes do fenômeno e através de análises comparativas entre as ondas de controle e as ondas obtidas em presença das diversas substâncias foram discutidas a aplicabilidade do método proposto, mostrando que a medida de complexidade trouxe novas informações sobre a depressão alastrante contribundo para um entendimento melhor do fenômeno.

Palavras-chave: Complexidade. Desordem. Depressão alastrante. Ordem.

\begin{abstract}
What we wanted to present in this work is the application of the LMC measure of complexity in the study of the phenomenon of spreading depression proves efficient in order to contribute to a better understanding of the phenomenon. For this, we used as an experimental model of the chick retina in vitro. In an attempt to obtain information about equilibrium states between order and disorder, it is proposed that the analysis of the records of two of the concomitant phenomena: a slowly changing the extracellular potential and intrinsic optical signal. For this, we evaluated the effect of pharmaco-chemical manipulations on these two concomitant phenomenon and by comparative analyzes of the control waves and the waves obtained in the presence of various substances discussed the applicability of the proposed method, the measure complexity brought new information on the spreading depression to a better understanding of the phenomenon.
\end{abstract}

Keywords: Complexity. Disorder. Spreading depression. Order. 


\section{Lista de figuras}

Figura 2.1- Desenho representando escotomas viajantes feitos por Lashley. 22

Figura 2.2 - Eletrocorticograma do experimento de Leão.

Figura 2.3 - Fotografias da onda de DA na retina de ave.

Figura 2.4 (a) - Diagrama esquemático das camadas da retina.

Figura 2.4 (b) - Diagrama esquemático das principais células encontradas em retina de vertebrados.

Figura 2.5 - Imagem digitalizada da retina de ave.

Figura 2.6 (a) - Registro do perfil do potencial nas camadas da retina e identificação das camadas.

Figura 2.6 (b) - Potenciais de DA nas camadas da retina.

Figura 2.7 - Amostragem do potencial e comportamento dinâmico de alguns íons.

Figura 2.8 - Parte da gravação mostrando a variação do potencial extracelular e da variação do potássio extracelular em experimento de onda circulante.

Figura 2.9 - Evolução temporal do IOS.

Figura 3.1 - Função da entropia binária .

Figura 3.2 - As categorias da complexidade como função da desordem.

Figura 3.3 - Comportamento da complexidade $\Gamma_{\alpha \beta}$ em função da desordem.

Figura 3.4 - Comportamento qualitativo da informação, desequilíbrio e complexidade LMC . 
Figura 3.5 - Complexidade LMC x desordem .

Figura 4.1 - Tamanho e centro da janela. 56

Figura 4.2 - Número de bins. $\quad 57$

Figura 4.3 - Representação da medida de complexidade. 58

Figura 4.4 (a) - Registro do potencial extracelular e respectivo

cálculo da complexidade para as ondas de controle .

60

Figura 4.4 (b) - Registro do IOS e respectivo cálculo da complexidade para as ondas de controle.

Figura 4.4 (c) - Registro do GOS e respectivo cálculo da complexidade para as ondas de controle.

Figura 4.5 (a) - Registro do potencial extracelular e respectivo cálculo da complexidade para as ondas de controle .

Figura 4.5 (b) - Registro do IOS e respectivo cálculo da complexidade para as ondas de controle .

Figura 4.5 (c) - Registro do GOS e respectivo cálculo da complexidade para as ondas de controle.

Figura 4.6 (a) - Registro do potencial extracelular e respectivo cálculo da complexidade para as ondas com protamina 2,0 $\mu \mathrm{g}$.

Figura 4.6 (b) - Registro do IOS e respectivo cálculo da complexidade para as ondas com protamina $2,0 \mu \mathrm{g}$.

Figura 4.6 (c) - Registro do GOS e respectivo cálculo da complexidade para as ondas com protamina $2,0 \mu \mathrm{g}$.

Figura 4.7 (a) - Registro do potencial extracelular e respectivo 
cálculo da complexidade para as ondas com protamina $2,5 \mu \mathrm{g}$.

Figura 4.7 (b) - Registro do IOS e respectivo cálculo da complexidade para as ondas com protamina $2,5 \mu \mathrm{g}$.

Figura 4.7 (c) - Registro do GOS e respectivo cálculo da complexidade para as ondas com protamina $2,5 \mu \mathrm{g}$.

Figura 4.8 (a) - Registro do potencial extracelular e respectivo cálculo da complexidade para as ondas com protamina $5,0 \mu \mathrm{g}$.

Figura 4.8 (b) - Registro do IOS e respectivo cálculo da complexidade para as ondas com protamina $5,0 \mu \mathrm{g}$.

Figura 4.8 (c) - Registro do GOS e respectivo cálculo da complexidade para as ondas com protamina $5,0 \mu \mathrm{g}$.

Figura 4.9 (a) - Registro do potencial extracelular e respectivo cálculo da complexidade para as ondas com ritalina .

Figura 4.9 (b) - Registro do IOS e respectivo cálculo da complexidade para as ondas com ritalina.

Figura 4.9 (c) - Registro do GOS e respectivo cálculo da complexidade para as ondas com ritalina.

Figura 4.10 (a) - Registro do potencial extracelular e respectivo cálculo da complexidade para as ondas com ritalina .

Figura 4.10 (b) - Registro do IOS e respectivo cálculo da complexidade para as ondas com ritalina.

Figura 4.10 (c) - Registro do GOS e respectivo cálculo da complexidade para as ondas com ritalina. 
Figura 4.11 (a) - Registro do potencial extracelular e respectivo cálculo da complexidade para as ondas com ritalina.

Figura 4.11 (b) - Registro do IOS e respectivo cálculo da complexidade para as ondas com ritalina.

Figura 4.11 (c) - Registro do GOS e respectivo cálculo da complexidade para as ondas com ritalina.

Figura 4.12 (a) - Registro do potencial extracelular e respectivo cálculo da complexidade para ondas com anfetamina.

Figura 4.12 (b) - Registro do IOS e respectivo cálculo da complexidade para ondas com anfetamina.

Figura 4.12 (c) - Registro do GOS e respectivo cálculo da complexidade para ondas com anfetamina.

Figura 4.13 (a) - Registro do potencial extracelular e respectivo cálculo da complexidade para ondas com anfetamina.

Figura 4.13 (b) - Registro do IOS e respectivo cálculo da complexidade para ondas com anfetamina.

Figura 4.13 (c) - Registro do GOS e respectivo cálculo da complexidade para ondas com anfetamina.

Figura 4.14 (a) - Registro do potencial extracelular e respectivo cálculo da complexidade para ondas com cafeína.

Figura 4.14 (b) - Registro do IOS e respectivo cálculo da complexidade para ondas com cafeína.

Figura 4.14 (c) - Registro do GOS e respectivo cálculo da complexidade 
para ondas com cafeína.

Figura 4.15 (a) - Registro do potencial extracelular e respectivo cálculo da complexidade para ondas com cafeína.

Figura 4.15 (b) - Registro do IOS e respectivo cálculo da complexidade para ondas com cafeína.

Figura 4.15 (c) - Registro do GOS e respectivo cálculo da complexidade para ondas com cafeína.

Figura 4.16 (a) - Registro do potencial extracelular e respectivo cálculo da complexidade para ondas com cocaína.

Figura 4.16 (b) - Registro do IOS e respectivo cálculo da complexidade para ondas com cocaína.

Figura 4.16 (c) - Registro do GOS e respectivo cálculo da complexidade para ondas com cocaína.

Figura 4.17 (a) - Registro do potencial extracelular e respectivo cálculo da complexidade para ondas com nicotina.

Figura 4.17 (b) - Registro do IOS e respectivo cálculo da complexidade para ondas com nicotina.

Figura 4.17 (c) - Registro do GOS e respectivo cálculo da complexidade para ondas com nicotina.

Figura 4.18 (a) - Registro do potencial extracelular e respectivo cálculo da complexidade para ondas com nicotina.

Figura 4.18 (b) - Registro do IOS e respectivo cálculo da complexidade para ondas com nicotina. 
Figura 4.18 (c) - Registro do GOS e respectivo cálculo da complexidade para ondas com nicotina.

Figura 4.19 (a) - Registro do potencial extracelular e respectivo cálculo da complexidade para ondas com potássio

Figura 4.19 (b) - Registro do IOS e respectivo cálculo da complexidade para ondas com potássio .

Figura 4.19 (c) - Registro do GOS e respectivo cálculo da complexidade para ondas com potássio . 


\section{Lista de tabelas}

Tabela 3.1 - Comportamento da complexidade SDL em função dos parâmetros de ordem e desordem de um sistema.

Tabela 3.2 - Propriedades da complexidade $\Gamma_{1 k}$. 


\section{Lista de Abreviaturas}

BGS - Entropia Boltzmann - Gibbs - Shannon.

$\mathrm{Ca}^{++}$- Íon cálcio.

$\mathrm{Cl}^{-}$- Íon cloro.

DA - Depressão alastrante.

ECoG - Eletrocorticograma.

GOS - Sinal óptico global (Global Óptical Signal).

IOS - Sinal óptico intrínseco (Intinsic Óptical Signal).

IPL - Camada interna plexiforme (Inner Plexiform Layer).

$\mathbf{K}^{+}$- Íon potássio.

LMC - Complexidade López-Ruiz - Mancini - Calbet.

$\mathrm{Na}^{+}$- Íon sódio.

SDL - Complexidade Shiner - Davison - Landsberg.

SNC - Sistema nervoso central. 


\section{Sumário}

1 Introdução geral

2 Depressão alastrante

2.1 Introdução

2.2 Histórico e descrição do fenômeno

2.3 A retina como modelo experimental

2.3.1 A depressão alastrante e a retina

2.4 Fenômenos eletrofisiológicos concomitantes

2.4.1 Potencial extracelular e transiente de potássio associado com a excitação

2.4.2 Mudanças de concentração de íons extracelular e velocidade de propagação

2.5 Fenômenos ópticos concomitantes

2.5.1 Componentes das mudanças intrínsecas ópticas

3.2 Entropia 
4.2 Preparação do eye-cup e procedimentos

4.2.1 Preparação do eye-cup

4.2.2 Equipamentos e produtos químicos

4.2.3 Registros eletrofisiológicos e ópticos

4.3 Recurso computacional

4.4 Análise e medida de complexidade dos sinais

4.4.1 Ondas de controle

4.4.2 Protamina

4.4.3 Ritalina

4.4.4 Anfetamina

4.4.5 Cafeína

4.4.6 Cocaína

4.4.7 Nicotina 
$\begin{array}{ll}\text { 5.2.2 Ritalina } & 106\end{array}$

$\begin{array}{ll}\text { 5.2.3 Anfetamina } & 107\end{array}$

$\begin{array}{ll}\text { 5.2.4 Cafeína } & 108\end{array}$

$\begin{array}{ll}\text { 5.2.5 Cocaína } & 109\end{array}$

$\begin{array}{ll}\text { 5.2.6 Nicotina } & 110\end{array}$

$\begin{array}{ll}\text { 5.2.7 Potássio } & 110\end{array}$

$\begin{array}{ll}\text { 5.3 Perspectivas futuras } & 112\end{array}$

Referências Bibliográficas 115 


\section{Capítulo 1}

\section{Introdução geral}

Sistemas biológicos vêm sofrendo novas interpretações que possibilitam uma melhor compreensão de fenômenos já descritos e fornecem diferentes perspectivas de estudo. Essas contribuições devem-se aos artefatos de cientistas que aplicam novos métodos e modelos para estudos de sistemas variados utilizando conhecimentos de outras áreas. Com essa peripécia, a biologia tem se beneficiado com novas descobertas que vão de sistemas moleculares a sistemas ecológicos (De MATTOS et al., 2007; PIQUEIRA; De MATTOS; VASCONCELOS-NETO, 2009).

De acordo com Piqueira e Nahas (PIQUEIRA; NAHAS, 2011), um dos primeiros cientistas a usar conhecimentos de ciências aparentemente não correlatas para estudos de sistemas biológicos foi Daniel Bernouilli, que estudou a dinâmica populacional de uma doença da época usando um modelo matemático (BERNOUILLI, 1760 apud PIQUEIRA; NAHAS, 2011). Nasce assim, em meados do século XVIII, a visão matemática para estudo, compreensão e evolução de sistemas

biológicos. É possível encontrar na literatura uma descrição histórica da evolução do uso da matemática em estudos biológicos e suas principais contribuições.

O estudo matemático de sistemas biológicos requer a representação do fenômeno ou do sistema a ser descrito a partir de um modelo matemático. Esse modelo pode ser uma representação de diversas formas. Para o estudo da evolução temporal e espacial do sistema, um modelo bastante usado e que tem apresentado grandes contribuições para a descrição do fenômeno, é a representação a partir de um conjunto de equações que descrevem as variações temporais.

Os fenômenos naturais ou biológicos possuem natureza dinâmica, ou seja, escolhem-se grandezas variáveis no tempo e analisam-se suas evoluções. Modelos de natureza dinâmica são descritos por equações dinâmicas que podem ser de tempo contínuo ou discreto. Os modelos biológicos são marcados por certo grau de imprevisibilidade, ou seja, não basta o fornecimento de condições iniciais para a 
previsão exata do estado do sistema num instante qualquer. Esses modelos têm apresentado as melhores descrições a partir de estudos e modelagens não lineares, cuja influência do estado anterior do sistema dinâmico sobre o estado posterior não possui uma relação de proporção, gerando padrões complexos.

O fenômeno em estudo, denominado de depressão alastrante, que será detalhado adiante, pode ser resumido, segundo Fernandes de Lima e Hanke (FERNANDES De LIMA; HANKE, 1997), como uma sequência de eventos metabólicos e alterações eletrofisiológicas que interagem de forma local, disparando um comportamento global, que pode ser medido em qualquer parte da matéria cinzenta central, possibilitando o estudo do fenômeno a partir dos conhecimentos de sistemas complexos.

Sistemas complexos são aqueles compostos de muitos elementos ou subsistemas diferentes interagindo espacialmente ou temporalmente de forma não linear. O comportamento desses subsistemas pode ser estudado de forma isolada apresentando assim suas dinâmicas específicas, entretanto, a combinação desses estudos não traduz o comportamento do sistema como um todo.

Um dos modelos usados para descrever a depressão alastrante a nível molecular e de forma teórica foi o estudo do fenômeno de acordo com a teoria de autômatos celulares e da equação de reação de difusão (PEIXOTO, 1997). Trabalhos mais recentes sobre o estudo de um dos concomitantes do fenômeno também têm contribuído para o entendimento do fenômeno (DUARTE, 2000).

As aplicações das diferentes medidas de complexidade têm sido objeto de aplicações em diversas áreas de estudo (CAMPBELL-BORGES; PIQUEIRA, 2012; PIQUEIRA; De MATTOS; VASCONCELOS NETO, 2009; PIQUEIRA; MORTOZA, 2012) e seus resultados em sistemas distintos são iminentes trazendo grandes contribuições para a compreensão das suas dinâmicas.

Com o objetivo de uma melhor aproximação da realidade complexa e dinâmica dos sistemas biológicos propõe-se, neste trabalho, que tal visão interdisciplinar diferenciada possa contribuir para uma melhor compreensão no estudo do fenômeno de ondas de depressão alastrante, usando como modelo experimental a retina de pintinho in vitro. Na tentativa de obter informações sobre 
estados de equilíbrio entre a ordem e desordem do sistema e como essas grandezas afetam o equilíbrio, propõe-se a análise dos registros de dois dos concomitantes do fenômeno: a alteração lenta do potencial extracelular e do sinal intríseco óptico, sendo que para esse último é possível o estudo em duas escalas diferentes. Para a análise desses registros e da interpretação do fenômeno de depressão alastrante é proposto o uso de uma medida de complexidade na perspectiva de uma melhor compreensão do fenômeno. Para isso, são obtidas algumas ondas de controle e outras ondas em presença de substâncias fármacoquímica e para os dois concomitantes do fenômeno suas respectivas complexidades são calculadas.

Quanto à organização do texto, o capítulo 2 descreve o fenômeno de ondas de depressão alastrante. Além disso, é feita uma breve evolução histórica da pesquisa desse fenômeno e das principais características dos fenômenos concomitantes à passagem da onda. Nesse capítulo apresenta-se uma descrição detalhada da retina de aves e a justificativa de seu uso como modelo experimental. Também nessa seção, descrevem-se a importância das medidas serem feitas na camada interna plexiforme e um detalhamento das variações de um dos fenômenos concomitantes à passagem da onda nesta camada.

No capítulo 3 existe uma descrição do conceito de entropia e seu uso no trabalho proposto. São apresentados os conceitos de ordem e desordem que serão relevantes para a medida de complexidade utilizada. Além disso, é feita uma evolução do conceito de complexidade e suas propostas de uso. Ao final do capítulo são apresentadas as motivações para a importância dada aos parâmetros da ordem e desordem e a justificativa para os valores escolhidos através de sua aplicação em outro estudo de sistema biológico.

O capitulo 4 descreve os procedimentos experimentais adotados, assim como o detalhamento das preparações biológicas e do recurso computacional utilizado para o cálculo da medida de complexidade. Além disso, são apresentados alguns registros obtidos dos experimentos e os seus respectivos gráficos das complexidades calculadas. Para cada produto fármaco-químico utilizado foram feitas as análises detalhadas dos registros experimentais e computacionais obtidos, na 
perspectiva da obtenção de estados cuja ordem e desordem estejam em equilíbrio e quais as condições para que isso ocorra.

No capítulo 5 os resultados das análises do capítulo são discutidos e levantados alguns aspectos relevantes para a explicação do fenômeno de acordo com os resultados obtidos para a complexidade calculada para cada substância utilizada. Nesse capítulo também são sugeridos o estudo detalhado de algumas questões relevantes para trabalhos futuros na tentativa de contribuir para o estudo do fenômeno de depressão alastrante. 


\section{Capítulo 2}

\section{Depressão Alastrante}

\subsection{Introdução}

Nesta seção, o fenômeno de ondas de depressão alastrante (DA) e suas causas serão explicados. Além disso, algumas abordagens experimentais e resultados importantes na evolução da interpretação das ondas DA como ondas em meios excitáveis serão mostrados. A aplicação da teoria de ondas em meios excitáveis para DA sugere que diferentes síndromes ou fenômenos, como epilepsia, enxaqueca entre outras, podem ser explicadas pelo mesmo mecanismo. Segundo Fernandes de Lima e Hanke (FERNANDES De LIMA; HANKE, 1997), ao longo desses anos, foram traçadas três linhas paralelas sobre o estudo desse fenômeno: os fenômenos concomitantes das ondas de DA e seus modelos mecânicos, as interações "neurônio-glia" durante respostas fisiológicas e propagação de ondas e a evolução da teoria da termodinâmica não linear desde a introdução da reação de difusão de Belouzov-Zabotinsky como modelo experimental.

\subsection{Histórico e descrição do fenômeno}

As ondas de DA foram descobertas e preditas em 1940. Elas foram preditas por Lashley, um psicólogo com considerável conhecimento em neuroanatomia e que sofria com enxaqueca, e descobertas por um brasileiro, estudante de doutorado, Aristides Leão. Lashley, com os conhecimentos que tinha sobre córtex visual primário, observou cuidadosamente um dos sinais da síndrome da enxaqueca clássica, os escotomas viajantes, que geralmente precedem a dor de cabeça e publicou um estudo (LASHLEY, 1941 apud FERNANDES De LIMA; GOLDERMANN; 
HANKE, 1999), mostrando que a velocidade de propagação dos escotomas era em torno de $3 \mathrm{~mm} / \mathrm{mim}$, como mostra a figura 2.1. Lashley associou o brilho dos escotomas à fase de intensa excitação e a cegueira transiente após a passagem dos escotomas a uma fase de inibição total.
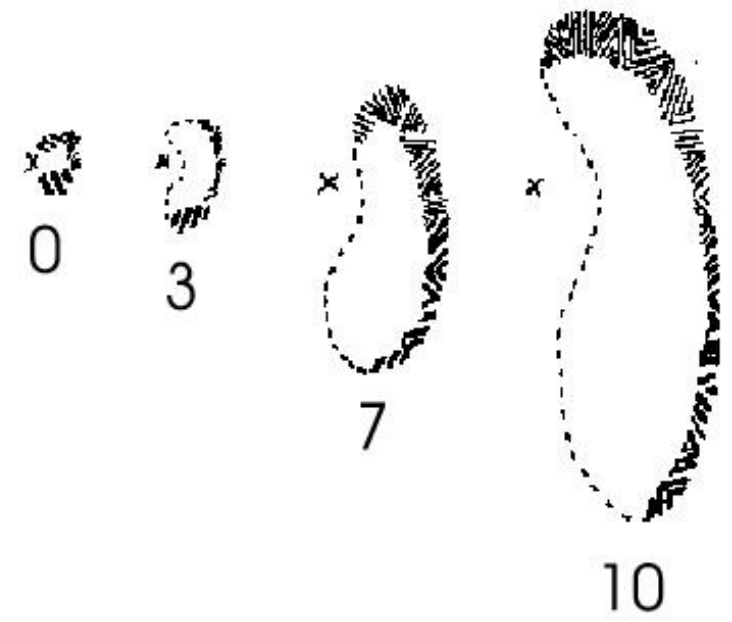

Figura 2.1 - Quatro desenhos sequenciais dos escotomas desenhados por Lashley. As indicações "x" representam o ponto de fixação e os números indicam o tempo em minutos (LASHLEY, 1941 apud FERNANDES De LIMA; GOLDERMANN; HANKE, 1999).

Sem conhecimento sobre os trabalhos de Lashley, o estudante de doutorado do departamento de Fisiologia da Escola Médica de Harvard, Aristides A. Pacheco Leão, buscava novos dados experimentais que permitissem entender o eletrograma cortical que ocorre na epilepsia experimental quando o cérebro é estimulado eletricamente. Leão observou que após os estímulos elétricos em córtex de coelho, havia uma depressão da atividade elétrica espontânea do córtex. Usando vários eletrodos, ele mediu a velocidade de propagação com que tal depressão se espalhava e obteve o mesmo valor encontrado anteriormente por Lashley, de 3 $\mathrm{mm} / \mathrm{mim}$. No experimento feito por Leão, sete eletrodos de registro da atividade elétrica foram colocados em posições diferentes de um mesmo hemisfério do córtex cerebral de um coelho e um eletrodo de estimulação foi instalado no mesmo hemisfério. A figura 2.2 mostra um esquema do protocolo sugerido por Leão. 


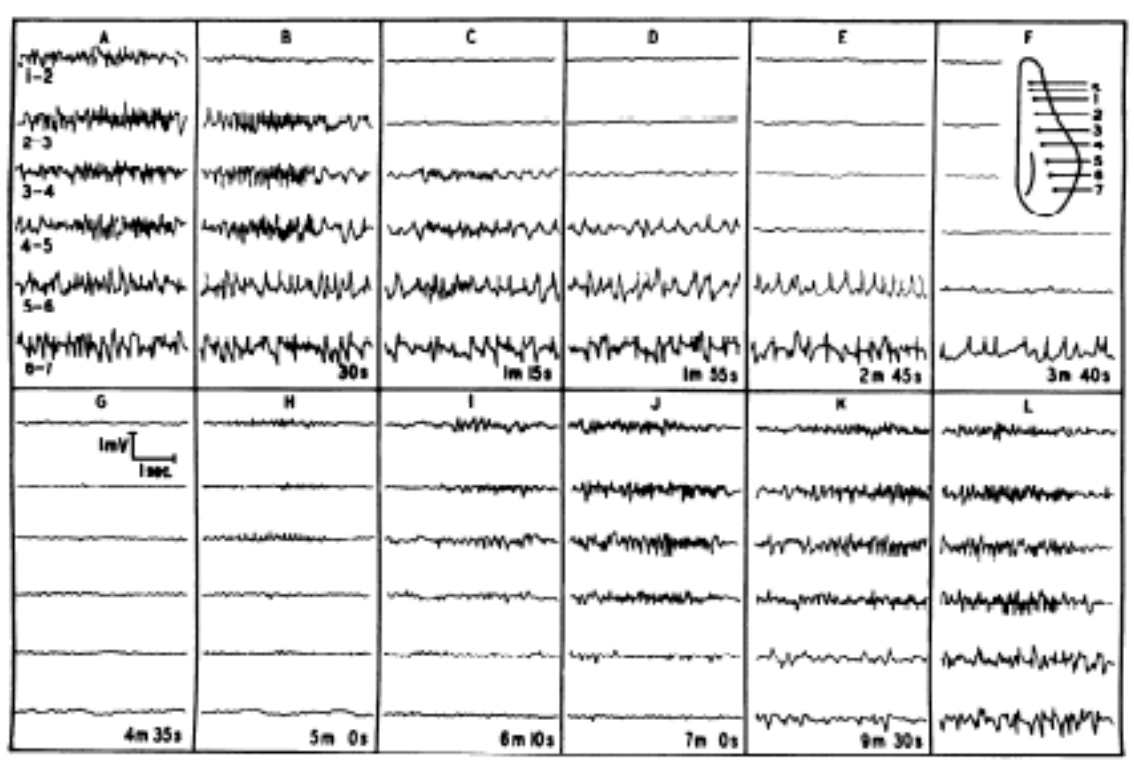

Figura 2.2 - O ECoG do experimento de Leão, mostrando os sete eletrodos de registros no córtex de um coelho (LEÃO, 1944a).

Os registros mostram uma depressão intensa das oscilações elétricas espontâneas cerebrais entre as regiões limitadas pelos eletrodos 1 e 2 a partir do instante 30 segundos até 6 minutos após o estímulo elétrico no córtex, voltando a configuração inicial. Através da análise da figura 2.2 é possível observar que esse mesmo fenômeno ocorre nas demais regiões, evidenciando que a depressão se propaga nas regiões adjacentes, do córtex cerebral. Neste experimento observou-se que a DA se propaga concentricamente da região estimulada para os demais pontos adjacentes atingindo áreas cada vez mais distantes do córtex, enquanto a região estimulada se restabelece progressivamente. Como as ondas de DA possuem essa característica, a ideia de associar ao fenômeno uma medida de complexidade na tentativa de analisar estados de ordem e desordem e uma compreensão de como a DA altera o estado de equilíbrio entre essas grandezas, pode trazer contribuições para o entendimento do fenômeno.

Em 1944 Leão descreve o fenômeno descoberto e chamou-o de depressão alastrante (DA) cortical, cuja principal característica era diminuição da atividade cerebral, quando a região era estimulada eletricamente. Essa diminuição é caracterizada pela alteração lenta do potencial cortical durante a propagação da onda (LEÃO, 1944a; LEÃO, 1944b). Leão também observou que antes do início da redução da atividade cerebral espontânea, houve um disparo da atividade elétrica, 
durante alguns milesegundos precedendo a DA. Naquele momento, ele não considerou esse fato, comentando o ocorrido apenas no final do seu trabalho. Leão não fez nenhum estudo sobre essa avalanche. Hoje, alguns autores sugerem que essas avalanches estão relacionadas com o armazenamento e transmissão de informação (BEGGS; PLENZ, 2004). Nesse estudo inicial, Leão publicou várias outras contribuições para o entendimento do fenômeno, entre elas a descoberta de que DA é uma propriedade da matéria cinzenta, o reconhecimento da importância do processo ondulatório para o entendimento da marcha em síndrome funcional clássica e a associação entre a queda do potencial em DA e a lenta despolarização da anoxia cerebral (LEÃO, 1947).

A relação entre a marcha dos escotomas em aura de enxaqueca clássica, descrita por Lashley, e a propagação de ondas de DA foi sugerida por Milner (MILNER, 1958) e, recentemente, recebeu mais atenção com investigações de Lauritzen (LAURITZEN, 1992 apud FERNADES De LIMA; HANKE, 1997). O ano de 1958 foi um ano de muitas contribuições para o estudo de ondas em meio excitável com a descoberta feita por Gouras, do sinal óptico em ondas de DA (GOURAS, 1958), e as publicações da descoberta da reação de difusão de BelouzovZabotinsky. Nesse mesmo ano, o fenômeno de DA foi identificado na retina, parte mais acessível da matéria cinzenta dos vertebrados (GOURAS, 1958), e desde então, tem sido estudado em retinas de vários animais. Ele testou diversas retinas (de anfíbio, réptil, ave) in vitro antes de escolher a retina de pintinho como a mais fácil de trabalhar.

As similaridades entre o modelo químico $e$ as ondas de DA foram compreendidas por Bures, que introduziu um grupo brasileiro nesse ramo de pesquisa. Através da troca de informações entre esses dois grupos, nasceram duas grandes contribuições: a onda circulante, um tipo de preparação em que se tem um anel de retina através do qual a onda pode se propagar por horas (MARTINSFERREIRA et al., 1974) e a existência de um modelo de onda espiral que foi obtida a partir de uma previsão teórica (GORELOVA; BURES, 1983).

O significado do sinal óptico intrínseco, concomitante com a excitação de ondas em retina descoberto por Gouras, foi muito bem entendido por MartinsFerreira e De Oliveira Castro, que demonstraram, a partir das similaridades entre os 
concomitantes eletrofisiológicos, que o fenômeno observado nas retinas de pintinho eram ondas de DA (MARTINS-FERREIRA; De OLIVEIRA CASTRO, 1971 apud FERNANDES De LIMA; HANKE, 1997) e, partindo disso, foram movidos a explorar as complexidades da onda óptica usando a dispersão da luz para analisar as respostas às manipulações físicas e químicas (MARTINS-FERREIRA; De OLIVEIRA CASTRO, 1966 apud FERNANDES De LIMA; HANKE, 1997). A onda óptica, chamada de sinal óptico intrínseco (IOS), se propaga por todo o tecido e permite a completa visão a olho nu da propagação bidimensional, (veja figura 2.3). O IOS também pode ser observado em outras áreas da matéria cinzenta, mas com magnitude muito menor e por isso o interesse no modelo experimental feito de retina. Outra forma de analisar as ondas de DA seria a utilização das variações dos sinais ópticos, característicos da dispersão da luz associada ao fenômeno, por isso sugere-se neste trabalho a análise da medida de complexidade desses sinais.

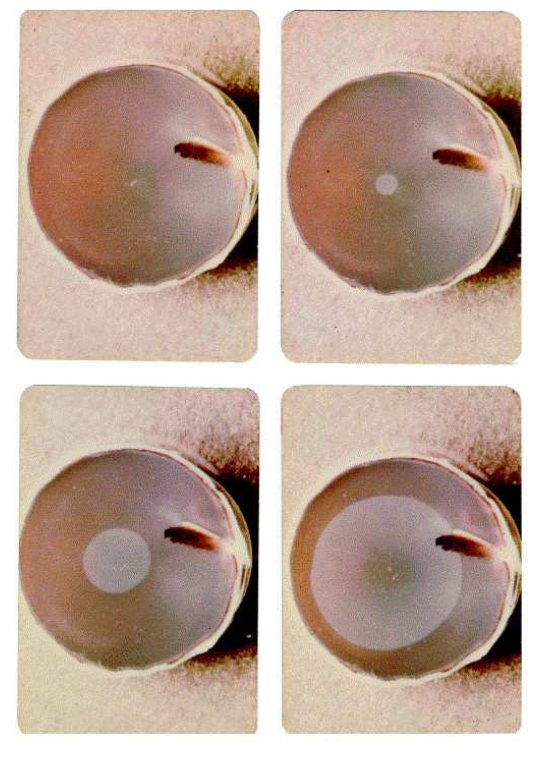

Figura 2.3 - Fotografias, em diferentes intervalos de tempo, da propagação da onda de depressão alastrante acompanhada de um sinal óptico (região mais clara) em retina de ave (MARTINS-

FERREIRA; NEDERGAARD; NICHOLSON, 2000).

A figura 2.3 apresenta fotos da retina de ave vista de cima, sendo que, na primeira foto do canto superior esquerdo, é possível visualizar a região antes do estímulo e verticalmente 17, 40 e 100 s após o estímulo mecânico. É possível notar que a estimulação da onda é feita no centro e, acompanhando a propagação da onda através do IOS, percebe-se que a onda se propaga da região estimulada para os demais pontos adjacentes, como nos registros no córtex de coelho, feitos por 
Leão. Os autores localizaram o máximo IOS na camada interna plexiforme (IPL). A possibilidade da contribuição da "glia" para o IOS em ondas de DA foi sugerida por Van Harreveld (VAN HARREVELD, 1978, 1984 apud FERNANDES De LIMA; HANKE, 1997) e a introdução do conceito da interação "neurônio-glia" na gênese da diminuição do potencial extracelular foi feita por um grupo japonês (TOMITA, 1984 apud FERNANDES De LIMA; HANKE, 1997).

A primeira hipótese mecânica de fatos geradores de ondas DA foi transmitida por Grafstein (GRAFSTEIN, 1956), o qual propôs que o aumento do potássio extracelular poderia despolarizar as membranas neuronais próximas e, além disso, promover a liberação do potássio das membranas. Ela também notou que um campo elétrico podia modular a velocidade de propagação da onda e que os efeitos do campo eram importantes para a propagação. A hipótese do potássio recebeu sustento a partir das medidas feitas das regiões invadidas por DA (MARTINSFERREIRA et al., 1974). No entanto, o envolvimento da atividade sináptica era claro desde a descoberta de Leão de excitação elétrica cortical em DA sustentado pelas descobertas de que o fenômeno poderia ser provocado pela luz (MARTINSFERREIRA; De OLIVEIRA CASTRO, 1966 apud FERNANDES De LIMA; HANKE, 1997), que os concomitantes ópticos e eletrofisiológicos das ondas de DA eram encontrados na IPL, que a excitação e a propagação eram bloqueadas pela alta concentração de magnésio e baixa atividade de cálcio na solução (MARTINSFERREIRA et al., 1974), entre outras contribuições.

\subsection{A Retina como modelo experimental}

Devido à grande quantidade de informação registrada em uma imagem, o olho é um sistema que processa o seu sinal localmente. Esse sinal é processado através da retina, pois na retina os receptores e o tecido neural estão intimamente ligados.

O estudo da retina dos vertebrados permite concluir que a matéria cinzenta e a retina possuem a mesma origem embrionária. Na retina, neurônio, células de 
Müller e epiteliais são derivadas das mesmas células precursoras. A estrutura em camadas da matéria cinzenta central é presente na retina.

$\mathrm{Na}$ retina, os corpos celulares são desprovidos de contatos sinápticos, sendo que sinapses são encontradas apenas nos axônios e dendritos. As duas camadas em que ocorrem sinapses são chamadas de camadas plexiformes. Os corpos celulares são distribuídos em quatro camadas, sendo duas nucleares, uma ganglionar e uma fotorreceptora. Apenas um tipo de célula glial, a célula de Müller, atinge a superfície vítrea até os segmentos internos dos receptores, tendo seus núcleos localizados na camada nuclear interna, como mostra a figura 2.4 (a). As camadas nuclear externa e dos fotorreceptores são constituídas pelos corpos celulares das células receptoras. A camada nuclear interna é constituída pelos corpos celulares das células horizontais, bipolares e amácrinas enquanto que os corpos celulares das células ganglionares são encontrados na camada celular mais proximal, na borda mais interna da retina. As principais células da retina podem ser visualizadas pela representação da figura 2.4 (b).

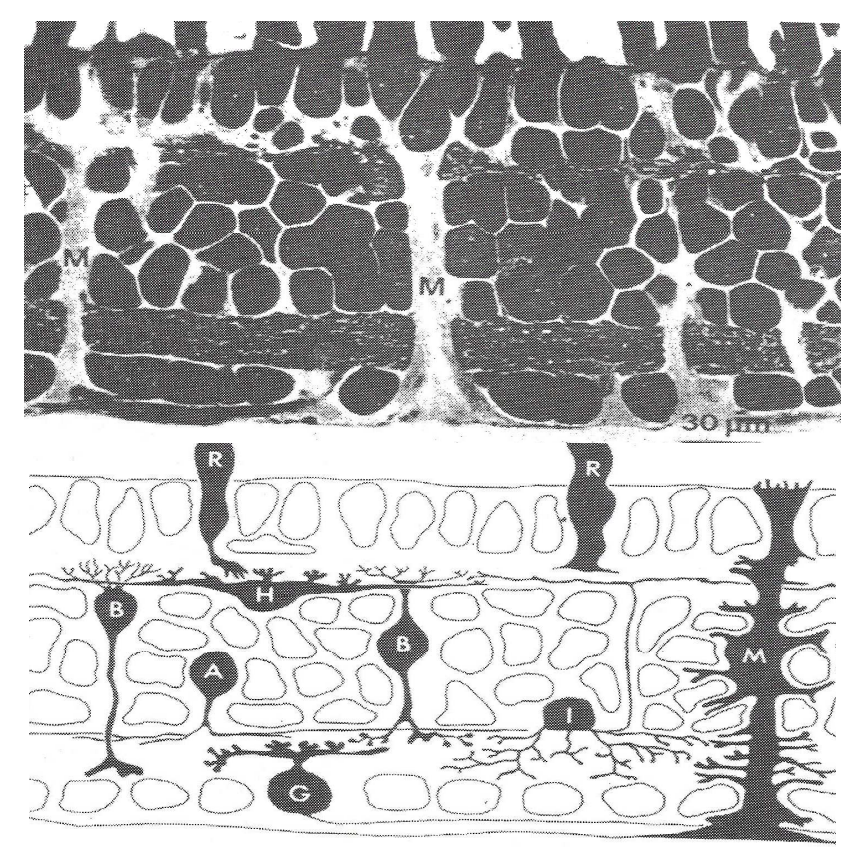

Figura 2.4 - (a) Estrutura em camadas da retina em que (M) representa as células de Müller. (b) Desenho das camadas da retina e os principais tipos de células encontrados em retina de vertebrados $(A=$ células amácrinas, $B=$ células bipolares, $G=$ células ganglionares, $H=$ células horizontais, $I$ = células plexiformes internas, $M=$ células de Müller, $R=$ células receptoras) (Retirado de FERNADES De LIMA; GOLDERMANN; HANKE, 1999). 
Os segmentos exteriores dos receptores, uma região constituída por moléculas sensíveis a luz, são cercados por células de pigmento do epitélio, que compartilham a mesma origem neuroepitelial do resto da retina neural. As células de pigmento do epitélio são assim chamadas pois são preenchidas com pigmento escuro da melanina que absorvem a luz espalhada.

A figura 2.5 mostra as principais camadas da retina de ave, que são relevantes para o estudo do fenômeno de ondas de DA. A luz, após atravessar o sistema de lentes e o humor vítreo, penetra na retina.

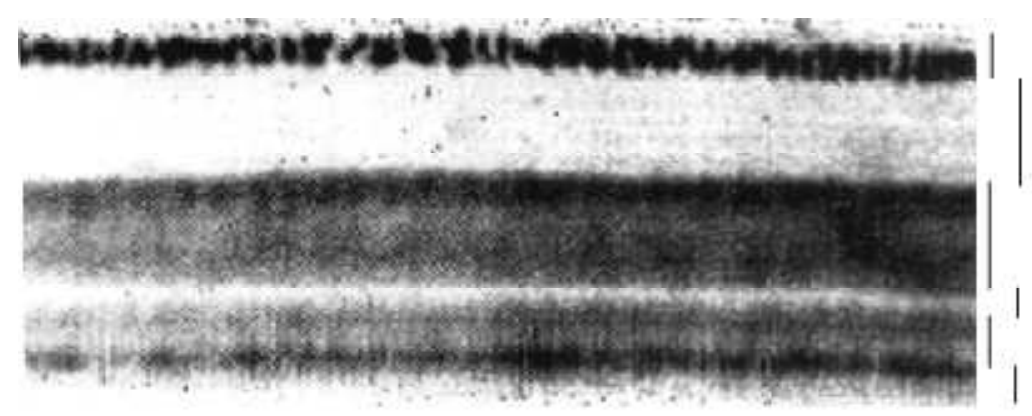

Camada Ganglionar

Camada Plexiforme Interna

Camada Nuclear Interna

Camada Plexiforme Externa

Camada Nuclear Externa

Camada Fotoreceptores

Figura 2.5 - Imagem digitalizada da retina de ave. A estrutura em camadas da retina pode ser vista (Retirado de FERNADES De LIMA; GOLDERMANN; HANKE, 1999).

Do interior para o exterior do olho pode-se agrupar as camadas de acordo com a nomenclatura da figura 2.5. Na retina de aves, as camadas plexiformes são mais largas que nas retinas de anfíbios. A camada plexiforme interna (IPL) possui alta densidade de terminais sinápticos. Segundo Dowling (DOWLING, 1979 apud FERNADES De LIMA; HANKE, 1997), todas as sinapses que ocorrem na retina, estão restritas às duas camadas plexiformes, ocorrendo nessas camadas sinápticas às interações entre os três tipos principais de células, que podem ser obsevadas na Figura 2.4 (b). As células fotorreceptoras fornecem o sinal de entrada para a camada plexiforme externa, na qual ocorre uma interação sináptica entre os dendritos das células bipolares e os processos das células horizontais.

Segundo Duarte (DUARTE, 2000), as células bipolares são as células de saída da camada plexiforme externa. Todas as informações visuais passam da camada plexiforme externa para a interna através das células bipolares. As células 
horizontais possuem processos que se estendem ao longo da camada plexiforme externa, tendo seus processos restritos a essa camada. Essas células transmitem horizontalmente os sinais das células receptoras para os dendritos das células bipolares. As células bipolares, por sua vez, são as células de entrada da camada plexiforme interna. Seus terminais sinápticos, localizados no interior dessa camada, fazem contato com os dendritos das células ganglionares e os processos das células amácrinas. Essa camada é constituída por uma alta densidade de interface entre meio intra e extracelulares.

As células ganglionares e seus axônios são as saídas da camada interna plexiforme e de toda a retina. As células amácrinas transmitem sinais em duas direções, diretamente das células bipolares para as células ganglionares ou horizontalmente entre os axônios das células bipolares, os dendritos das células ganglionares ou outras células amácrinas. Os processos das células amácrinas são confinados no interior da camada plexiforme interna.

\subsubsection{A Depressão alastrante e a retina}

A DA já foi detectada em várias estruturas neurais, inclusive na retina, não sendo um fenômeno exclusivo do córtex. Existem várias justificativas para a utilização da retina de ave, como modelo experimental, in vitro, para o estudo da DA (MARTINS-FERREIRA et al., 1974). Algumas vantagens encontradas na retina devem-se a possibilidade de isolar uma parte do sistema nervoso central (SNC) com menos dano que em qualquer outra região. Sua estrutura laminar é comparável a outras regiões do SNC e, especificamente na retina de aves, que é desprovida de vasos sanguíneos, a integridade funcional é mantida pela movimentação de fluidos em sua interface com o meio de perfusão. Na retina, a onda de DA é idêntica àquela observada no córtex, apresentando as mesmas características, como variação lenta do potencial, velocidade de propagação da mesma ordem de grandeza, variação do volume do tecido durante o fenômeno tendo a vantagem de ser acompanhado através do sinal óptico que acompanha a propagação da onda. 
As variações lentas do potencial extracelular são causadas pelo fluxo iônico através da região extracelular associado à propagação da onda. Esse potencial extracelular é decorrente de correntes passando pelas células gliais que estão despolarizadas pela liberação do potássio durante a DA e as correntes estão relacionadas com o tamponamento espacial, não sendo esse o único fenômeno responsável pelo potencial celular (FERNADES De LIMA; HANKE, 1997). A possibilidade do potencial extracelular ser negativo deve-se também ao potencial de Nernst, que tem como origem a permeabilidade das células gliais, exclusiva ao íon potássio $\left(\mathrm{K}^{+}\right)$.

O potencial extracelular é medido em relação a uma referência na solução nutriente. Do Carmo e Martins-Ferreira (Do CARMO; MARTINS-FERREIRA, 1984) identificaram o perfil do potencial extracelular ao longo de toda espessura da retina de ave. A amplitude máxima negativa do potencial ocorre na IPL, como mostra a figura 2.6. As formas de onda típicas do potencial também são mostradas nesta figura. A fase negativa da onda de DA tem amplitude máxima de 20 a $25 \mathrm{mV}$.
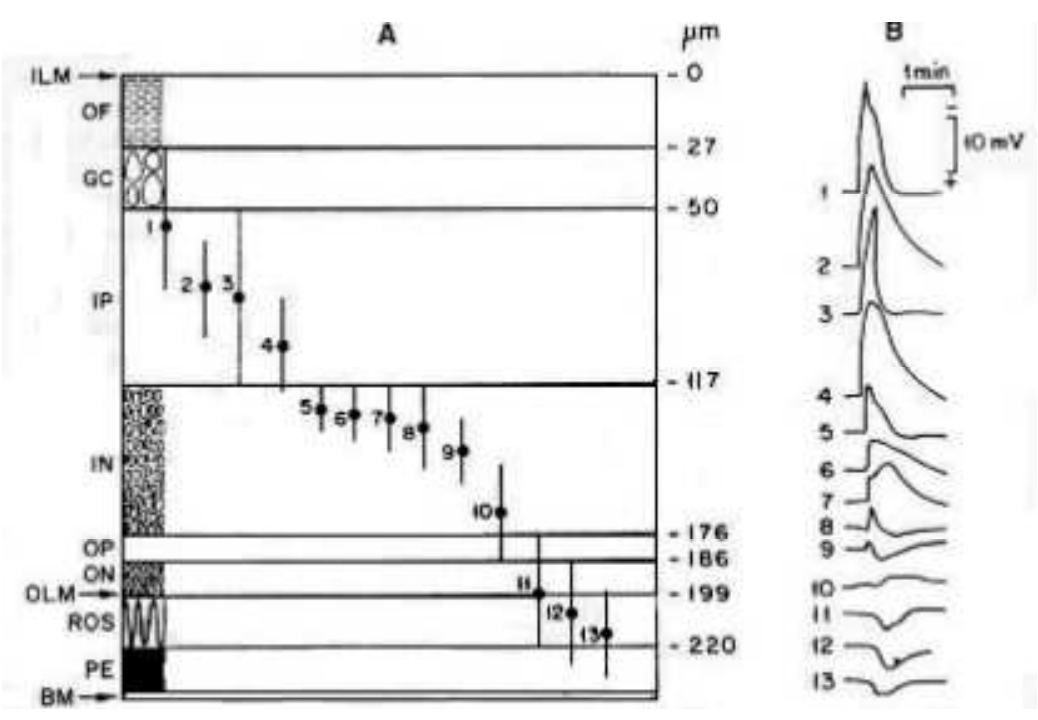

Figura 2.6 - Registro do perfil de potencial das camadas da retina. (A) - As camadas estão identificadas como: ILM, membrana limitante interna; OF, camada de fibras ópticas; GC, camadas de fibras ganglionares; IP, camada plexiforme interna; IN, camada nuclear interna; OP, camada plexiforme externa; ON, camada nuclear externa; OLM, membrana limitante externa; ROS, segmentos receptores externos; PE, pigmentos epitíleos; BM, membrana de Brunch. (B) - Potencias da DA registrados nos pontos correspondentes em A. Deflexões para cima da linha de base são negativas e para baixo da linha de base são positivas (Modificado de Do CARMO; MARTINS- 
Os movimentos dos íons durante as ondas de DA podem ser monitorados através das concentrações iônicas. Na região à frente da onda, a concentração do íon $\mathrm{K}^{+}$aumenta no espaço extracelular, enquanto dos íons $\mathrm{Ca}^{++}, \mathrm{Na}^{+}, \mathrm{Cl}^{-}$diminuem (Do CARMO; MARTINS-FERREIRA, 1984). A figura 2.7 mostra a dinâmica das concentrações dos íons $\mathrm{Ca}^{++}, \mathrm{Na}^{+}, \mathrm{Cl}^{-}$e $\mathrm{K}^{+}$durante uma onda de DA. Nessa mesma figura, pode-se observar o efeito dos íons $\mathrm{TEA}^{+}$e a-NS, que permitem avaliar as mudanças do volume no espaço extracelular. Esses mesmos autores consideraram que esses íons não permeavam as membranas e que em baixas concentrações e em equilíbrio com o meio, eles indicavam o movimento de água do espaço extra para intracelulares, que provocam variações no volume extracelular (Do CARMO; MARTINS-FERREIRA, 1984).
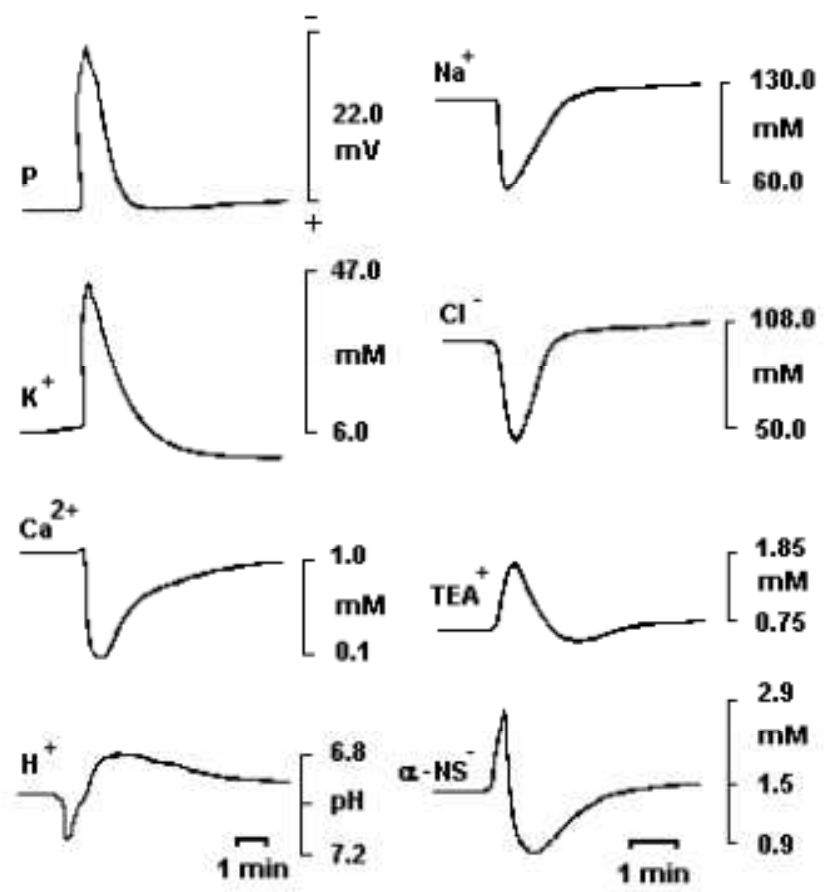

Figura 2.7 - Amostragem do potencial (P) e comportamento dinâmico dos íons $\mathrm{Ca}^{++}, \mathrm{Na}^{+}, \mathrm{Cl}^{-}, \mathrm{K}^{+}, \mathrm{TEA}^{+}$ e a-NS no meio extracelular durante a DA, medido na IPL (Retirado de FERNADES De LIMA; HANKE, 1997).

\subsection{Fenômenos eletrofisiológicos concomitantes}

As principais características das ondas DA são a diminuição do potencial medido na superfície ou dentro do espaço extracelular da matéria cinzenta e um 
aumento da concentração de íons potássio no espaço extracelular. Outras alterações também caracterizam o fenômeno como mudança da concentração de cálcio e mudanças complexas do $\mathrm{pH}$ tanto na parte intra quanto na parte extracelular. Pode-se observar que também existe um movimento de água entre espaços intra e extracelular acompanhado de trocas iônicas com concomitante expansão e contração do volume extracelular.

\subsubsection{Potencial extracelular e transiente de potássio associado com a excitação}

Num preparo de onda-circulante (FERNANDES De LIMA et al., 1993; MARTINS-FERREIRA et al., 1974) com as ondas de DA em estado auto-sustentado é possível mostrar que a transição de potássio pode ser separada da queda do potencial extracelular. Para isso, usa-se cloreto de bário adicionado na solução de perfusão, que bloqueia o canal glial de potássio. A concentração extracelular de potássio é diretamente afetada pela presença de bário, ocorrendo primeiro um aumento de potássio, um acentuado decréscimo e posterior aumento e, o fato mais importante, é o da concentração de potássio atingir um valor menor que a da concentração de perfusão e a consequente ocorrência de uma lenta troca positiva do potencial em intervalo sucessivos das ondas. Na presença de bário, o potencial extracelular durante as ondas de DA pode ser invertido. A fonte dessa mudança deve-se à liberação do potássio do canal da membrana sináptica.

Na figura 2.8 há um exemplo dessa situação. Um segmento de uma gravação é mostrado indicando que o nível basal de potássio extracelular está em queda em intervalos sucessivos. Nesse intervalo de tempo, a dinâmica do potássio mudou significativamente enquanto o pico da amplitude estava decrescendo e a duração era variável de onda para onda. As mudanças nas ondas de potássio extracelular foram acompanhadas pela transição do potencial negativo para o positivo durante as ondas a partir de uma diminuição de potássio extracelular. 


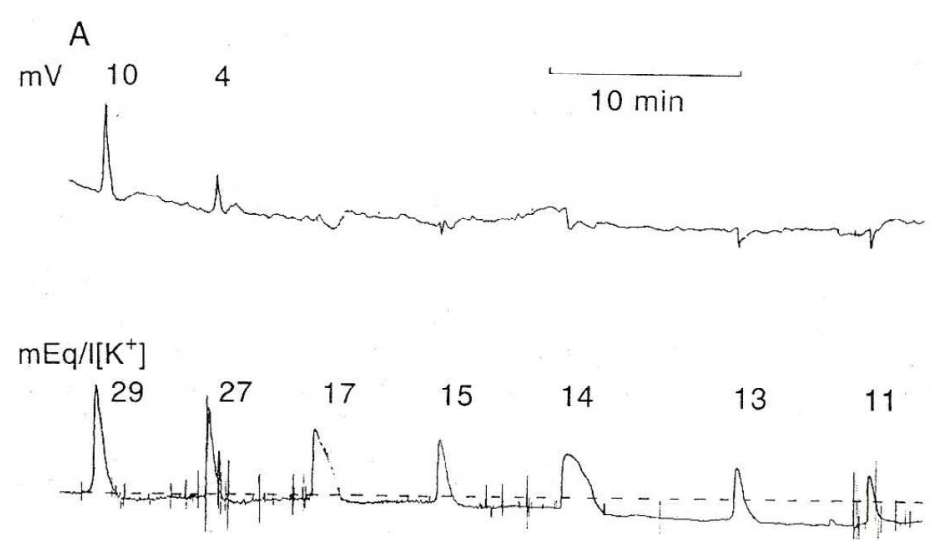

Figura 2.8 - Parte da gravação de experimento de onda circulante. Potencial extracelular (primeira figura) e concentração de potássio extracelular (segunda figura). Os números em cima do pico indicam o valor do pico (Retirado de FERNADES De LIMA; HANKE, 1997).

Os experimentos com ondas circulantes mostram que a propagação da excitação é compatível com muitos estados complexos macromoleculares que permitem a passagem de íons através das membranas. De acordo com Peixoto (PEIXOTO, 1997) e de forma muito simplificada, pode-se dizer que o aumento da concentração de potássio no meio extracelular, acima de um nível máximo, conhecido como ceiling level e estimado em $10 \mathrm{mM}$, acelera o processo de saída de potássio e liberação de transmissores dos terminais sinápticos. O processo autocatalítico de liberação de potássio, inicia-se com a entrada de sódio nos terminais sinápticos e isso ocorre devido ao aumento da condutância dos canais de potássio. Dependendo da intensidade do processo, as células de Müller (também conhecidas como células gliais), que neste caso funcionam como reservatório e controladoras de potássio (GROSSMAN; SEREGIN, 1977), não conseguem manter através das bombas de $\mathrm{Na}-\mathrm{K}$, a diferença de concentração de $\mathrm{K}^{+}$entre os meios intra e extracelulares e, consequentemente, passam a ficar despolarizadas, aumentando 0 processo de feedback positivo nos terminais sinápticos. A glia efetua a limpeza do excesso do $\mathrm{K}^{+}$do meio extracelular e, nesse caso, o humor vítreo desempenha o papel de maior importância como potencial sorvedouro de $\mathrm{K}^{+}$. No meio extracelular ocorre ainda a difusão de potássio, promovendo a propagação da onda e, a partir daí, inicia-se o arranjo dos outros íons como $\mathrm{Ca}^{++}, \mathrm{Na}^{+}, \mathrm{Cl}^{-}$e água entre os espaços intra e extra celulares para que o equilíbrio osmótico e a eletroneutralidade do meio seja estabelecida. 


\subsubsection{Mudanças de concentração de íons extracelular e velocidade de propagação}

Outros transientes iônico que devem ser relacionados com excitabilidade do tecido são o cálcio e o pH durante a propagação das ondas. Experimentos com cloreto de bário mostraram que ao contrário do transiente potássio, a queda rápida do cálcio durante as ondas de DA não podem ser dissociadas da onda de potencial (FERNANDES De LIMA, et. al, 1993) e que o pH pode ser medido na presença de bário. Preparação de ondas circulantes foram feitas em que a concentração de cálcio na solução de perfusão variava de 1 para $0.1 \mathrm{mEq} / \mathrm{l}$ e observou-se que a atividade de cálcio na IPL não mudou após a solução ter sido alterada, demorando 10 min. para o nível de cálcio na IPL atingir $0.6 \mathrm{mEq} / \mathrm{l}$. Nessas circunstâncias foi observada uma troca lenta negativa no potencial extracelular. Aumentando-se a concentração do cálcio na solução de perfusão, de 1 até $3 \mathrm{mEq} / \mathrm{l}$, poderia alterar a atividade interna plexiforme tão rápido quanto o aumento dos íons potássio seguido das mudanças de concentração de potássio na solução de perfusão, sugerindo que diferenças na taxa de difusão tiveram pouca relação com a lenta queda de cálcio seguindo a mudança de concentração da perfusão.

A redução da concentração de sódio na perfusão acelerou a diminuição de cálcio no meio extracelular sugerindo que o transporte ativo foi subjacente à concentração extracelular de cálcio levando o sistema para longe do equilíbrio. A melhor hipótese para a explicação da rápida queda de cálcio durante a DA se dá devido à rápida despolarização da glia através dos canais de potássio. A diminuição do cálcio pelos processos gliais desliga a extrusão do potássio dos terminais sinápticos.

O cloreto de bário e a baixa perfusão de cálcio, ambos os processos, diminuem a velocidade de propagação. O cálcio extracelular possui uma profunda relação com os terminais sinápticos e na condutividade dos terminais que promove a ligação entre os neurônios na IPL. O bário afeta principalmente o fluxo iônico no espaço extracelular impedindo a corrente de potássio pela glia. $O$ campo elétrico 
criado pela atividade do canal glial possui um efeito direto nos terminais sinápticos que são delimitados pelos processos gliais (FERNADES De LIMA; HANKE, 1997).

\subsection{Fenômenos ópticos concomitantes}

Nesta seção, os resultados de experimentos realizados serão descritos usando técnicas de vídeo imagem aplicadas ao sinal intrínseco de ondas de DA. Experimentos mais complexos, com a aquisição do sinal óptico em várias faixas de frequência (por exemplo, vermelho e azul), e medidas de cálcio intracelular medindo a fluorescência extrínsica, também podem ser realizados na retina.

\subsubsection{Componentes das mudanças intrínsecas ópticas}

Em 1971, após o sinal intrínsico óptico (IOS) ter sido descoberto por Gouras, Martins-Ferreira e De Oliveira Castro (De OLIVEIRA CASTRO; MARTINSFERREIRA, 1985 apud FERNANDES De LIMA; HANKE, 1997; MARTINSFERREIRA; De OLIVEIRA CASTRO, 1966 apud FERNANDES De LIMA; HANKE, 1997) descreveram dois principais componentes do IOS, que daqui em diante serão chamados de "IOS clássico". Na figura 2.9, esses componentes são mostrados por duas ondas sucessivas excitadas mecanicamente, nas quais podem-se observar um primeiro e segundo pico devido ao aumento da dispersão da luz, que ocorrem devido a uma diminuição da transparência da retina, e estão presentes nas duas ondas. A evolução temporal dessas ondas, seus componentes e suas diferenças em relação a respostas físicas e manipulações químicas sugerem diferentes processos em suas origens. $O$ primeiro pico está relacionado com 0 concomitante eletrofisiológico das ondas de DA e possui uma forte dependência espectral, sendo mais forte para ondas de comprimento pequeno (azul) se comparada com comprimento de onda longa (vermelha). O segundo pico é influenciado por fatores metabólicos e quase não possui uma dependência espectral. Além dessas 
mudanças ópticas, os autores também associam a dispersão da luz à morte celular e alterações na transparência do tecido (FERNANDES De LIMA; HANKE, 1997).

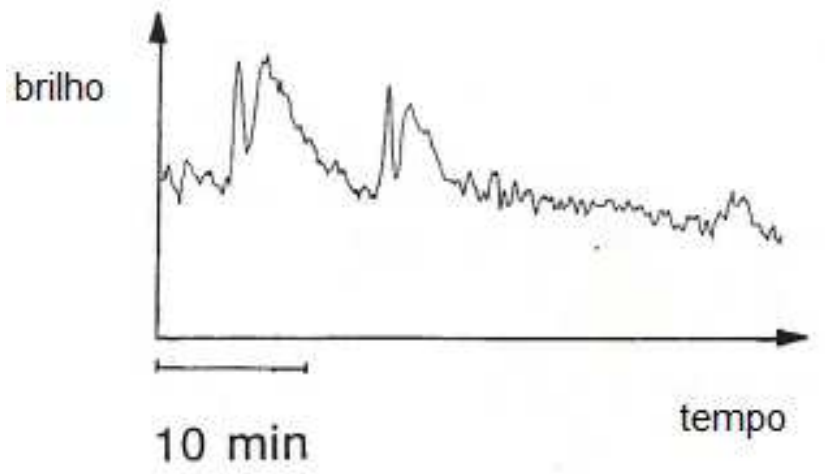

Figura 2.9 - Evolução temporal do IOS de duas ondas excitadas mecanicamente (Retirado de FERNADES De LIMA; HANKE, 1997).

O uso das técnicas de vídeo imagem teve outras contribuições além de confirmar as descobertas de Martins-Ferreira. Além da confirmação da predominância de onda curta no primeiro pico da IOS, foi descoberto um componente que precede em tempo e em espaço o IOS clássico e consiste numa dispersão da luz vermelha e será chamada de "IOS inicial".

O clássico e "IOS inicial" podem ser separados usando diferentes manipulações experimentais. Cloreto de bário bloqueia o "IOS inicial", diminui a velocidade de propagação e possui pouco efeito no brilho do "IOS clássico", enquanto o glicerol adicionado na solução de perfusão deprime o "IOS clássico" e permite o "IOS inicial" não alterando a velocidade de propagação da onda. A diferença espectral, a frequência espacial e a resposta para manipulações experimentais, sugerem diferentes processos físicos para a dispersão clássica e "inicial" concomitante com DA.

O "IOS inicial" possui uma relação com a atividade da membrana, e a lenta evolução temporal e longa latência são características da contribuição da membrana glial para o IOS de outras regiões. A sensibilidade da dispersão clássica a manipulações experimentais que afetam as variações volumétricas no espaço extracelular e movimentos da membrana sugerem um rearranjo estrutural. Pode-se dizer que na IPL, no qual está localizado o máximo IOS, existem dois processos da membrana com alta razão superfície-volume: terminais sinápticos e processos gliais. 
As mudanças nas propriedades ópticas dos tecidos durante a propagação das ondas DA podem refletir nas mudanças das propriedades ópticas das membranas ou mudanças no nível estrutural da membrana. O "IOS inicial", caracterizado pela dispersão do vermelho, parece estar relacionado com sinais ópticos da membrana, chamado de despolarização glial. 


\section{Capítulo 3}

\section{Entropia e Complexidade}

\subsection{Introdução}

Desde que Shannon propôs sua Teoria da Informação (SHANNON, 1948), o conceito de entropia informacional tem sido usado para estabelecer medida de complexidade. Neste capítulo, será feita uma breve revisão sobre entropia de Shannon e sobre o conceito de complexidade e suas medidas clássicas. Será lembrado quando um sistema apresenta entropia máxima e quais as implicações desses valores nas medidas de complexidade. Uma breve revisão bibliográfica das medidas de complexidade clássica SDL e LMC será apresentada, e serão usadas em nosso estudo. Um aspecto estrutural da medida de complexidade a ser discutido é como a complexidade de um sistema pode evoluir e quanto um sistema pode ser complexo.

Como um dos objetivos do trabalho é analisar se a variação da medida de complexidade associada ao fenômeno de onda de DA, contribui para um melhor entendimento do fenômeno, será apresentado no final do capítulo um resultado encontrado por Piqueira, De Mattos e Vasconcelos-Neto (PIQUEIRA; De MATTOS; VASCONCELOS-NETO, 2009; PIQUEIRA; De MATTOS, 2011) que justificará a escolha dos parâmetros escolhidos ao longo do trabalho.

\subsection{Entropia}

O conceito de entropia é fundamental na teoria da informação, mas a noção desse conceito apareceu primeiramente na Termodinâmica quando o físico $\mathrm{R}$. 
Clausius postulou a Segunda Lei da Termodinâmica que aponta para o aumento da entropia de um sistema. Nesse momento, a entropia foi usada para distinguir processos reversíveis e irreversíveis. Uma nova concepção da entropia foi dada em Mecânica Estatística, que atribui a entropia ao logaritmo da contagem de quantos estados microscopicamente distintos apresentam uma mesma descrição macroscópica de um sistema. Como exemplo, pode-se considerar um sistema físico macroscópico constituído por $N$ partículas. Cada partícula pode ocupar um dos $m$ estados microscópicos possíveis que são caracterizados pela energia $E_{i}(i=1 \ldots m)$. Chamando de $N_{i}$ o número de partículas que ocupam o estado com energia $E_{i}$, é possível rearranjar essas partículas com suas energias de $W$ maneiras. $O$ trabalho de L. Boltzmann em mecânica estatística mostra que a entropia pode ser calculada por

$$
S \equiv k \ln W,
$$

em que $S$ é a medida de entropia.

Com o desenvolvimento das telecomunicações no pós-guerra, a entropia volta a ser reinterpretada por C. Shannon, nascendo assim a Teoria da Informação cujo conceito central é a entropia que indica como armazenar e transmitir informação de maneira mais econômica.

Recentemente tem sido estabelecida a noção de entropia em sistemas dinâmicos, buscando um detalhamento de como esses sistemas caminham para o equilíbrio, e ainda surgiu o conceito de entropia não-extensiva em que variáveis envolvidas não são independentes.

\subsubsection{Entropia de Shannon}

Com o intuito de quantificar os recursos mínimos necessários para armazenar informação produzida por uma fonte, de tal forma que a informação pudesse ser 
reconstruída posteriormente, C. Shannon, propôs que a entropia em bits por símbolo era esse recurso mínimo.

Suponha que $X$ seja uma variável aleatória e deseja-se medir a quantidade de informação associada a essa variável aleatória que descreve um evento. Quanto mais improvável é um evento, mais informação obtém-se com sua ocorrência. A definição de entropia de Shannon, para a medida de informação de uma variável aleatória $X$, com $N$ elementos com probabilidades $p_{i}$, é uma função, representada por $H$, que obedece a três condições:

(i) A quantidade de informação em um evento $X$, depende apenas das probabilidades $p_{i}$;

(ii) $H\left(p_{1}, p_{2}, \ldots, p_{N}\right)$ é uma função contínua no conjunto das probabilidades $p_{i}$;

(iii) $H\left(p_{x}, p_{y}\right)=H\left(p_{x}\right)+H\left(p_{y}\right)$.

A definição formal (SHANNON, 1948) mostra que a única função que satisfaz essas condições é uma função do tipo:

$$
H(X)=k \sum_{i=1}^{N} p_{i} \log _{a} p_{i}
$$

sendo $k$ e $a$ constantes positivas. A função $H$, que Shannon, chamou de entropia é formalmente idêntica à função de entropia definida por Boltzmann, representada pela eq. (3.1), entretanto a eq. (3.2) não possui limite assintótico, sendo definida para qualquer fonte possuindo um número finito de símbolos.

Nos casos mais extremos, tem-se que:

$$
\begin{gathered}
P(X)=1 \Rightarrow H(X)=0 \\
e \\
P(X)=0 \Rightarrow H(X)=\infty
\end{gathered}
$$


o que faz sentido, pois um evento que ocorre com certeza tem informação nula, e não existe informação associada a um evento que não ocorre. A entropia de Shannon pode ser vista como uma medida da informação após o conhecimento de $X$, ou como uma medida da incerteza sobre $X$ antes do conhecimento do seu valor. O conteúdo da informação não influencia na medida da quantidade de informação, por isso a entropia de uma variável aleatória é defina como uma função das probabilidades dos diferentes possíveis valores que a variável adquire.

A Entropia de Shannon pode ser definida formalmente como:

Seja uma variável aleatória $X$ com vetor de probabilidade $\left(p_{1}, \ldots, p_{n}\right)$. A entropia de Shannon da variável aleatória é definida como

$$
H(X) \equiv H\left(p_{1}, \ldots p_{n}\right) \equiv-\sum_{x \in X} p_{x} \log p_{x} \equiv \sum_{x \in X} p(x) I(x)
$$

sendo x um símbolo da variável aleatória $X$ e $I(x)$ é associado à medida de informação.

Associando a "função informação" à ideia descrita pela eq. (3.5), a interpretação da terceira condição estabelecida para a definição da função entropia, pode ser traduzida como a informação obtida quando dois eventos independentes ocorrem com suas respectivas probabilidades é igual a soma da informação obtida com cada evento independente.

Como visto na eq. (3.5), a entropia de Shannon depende somente da distribuição de probabilidade. Para que a entropia faça sentido, é necessário definir que se $p(x)=0$, a entropia será $0 \log 0=0$. Se $X$ assumir algum valor com probabilidade 1, então nenhuma informação é ganha após a observação de $X$ e pela definição $H(X)=0$. Se $X$ for equiprovável $\left(p_{x}=\frac{1}{N}\right)$, para todo $x, H(X)=\log N$. Aqui $\log$ é tomado na base 2, que é mais adequado para o uso em teoria de informação para que a unidade de medida de entropia seja bit/símbolo. 
Considere um sistema com dois eventos complementares $x_{1}, x_{2}$ com probabilidades $p\left(x_{1}\right)=q$ e $p\left(x_{2}\right)=1-q$. Pela definição a entropia da fonte $X=$ $\left\{x_{1}, x_{2}\right\}$ é dada por

$$
\begin{aligned}
& H(X)=-x_{1} \log p\left(x_{1}\right)-x_{2} \log p\left(x_{2}\right) \\
& H(X)=-q \log q-(1-q) \log (1-q)
\end{aligned}
$$

Em teoria de informação, a entropia de uma variável aleatória com dois valores possíveis recebe o nome de entropia binária. É possível mostrar que a função entropia binária tem o valor máximo de $H(X)=1$, quando a distribuição de probabilidade for equiprovável. A função da entropia binária está representada na figura 3.1, sendo possível observar as propriedades descritas.

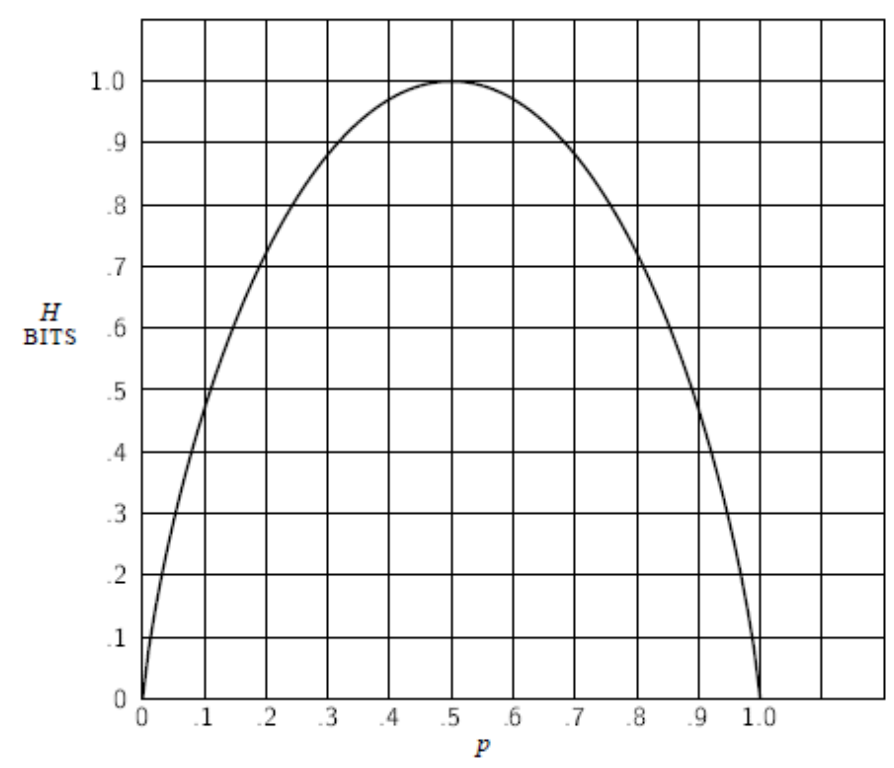

Figura 3.1 - Entropia no caso de duas possibilidades com probabilidade $(p)$ e $(1-p)$ (SHANNON, 1948).

A entropia binária possui uma propriedade importante que traduz 0 comportamento da entropia quando misturamos duas ou mais distribuições de 
probabilidade. Além disso, é possível perceber através da figura 3.1 que a função entropia binária é côncava, conceito muito explorado nos resultados mais profundos em informação.

\subsection{Complexidade}

Muitos autores têm discutido as multiplicidades e variedades das definições de complexidade da literatura (BENNETT, 1990; LÓPEZ-RUIZ; MANCINI; CALBET, 1995; SHINER; DAVISON; LANDSBERG, 1999; WACKERBAUER et al., 1994).

A noção de complexidade em física iniciou-se considerando um sistema isolado de gás ideal e de um cristal perfeito como exemplos mínimos de complexidade. Um cristal perfeito apresenta seus átomos arranjados de acordo com regras de simetria e portanto são completamente ordenados. O sistema isolado de gás ideal é uma representação de desordem total. A informação necessária para descrever o cristal é mínima, enquanto para descrever o gás ideal, é máxima. Esses dois exemplos constituem o extremo na escala de ordem e informação, indicando que o conceito de complexidade não pode ser apenas em função da ordem e informação.

Segundo Shiner, Davison e Landsberg (SHINER; DAVISON; LANDSBERG, 1999), as definições atuais dividem a complexidade em três grandes grupos. A primeira dessas definições associa a complexidade a uma função monotonicamente crescente da desordem (categoria I). Exemplos dessas definições são as complexidades algorítmicas e as variações de entropias (SHANNON, 1948). Tão numerosa quanto à primeira definição está à categoria que caracteriza a complexidade como uma função convexa da desordem (categoria II), em que a complexidade é mínima para sistemas completamente ordenados ou desordenados e é máxima para algum nível entre ordem e desordem. Para essa definição pode-se citar como exemplo a profundidade lógica e termodinâmica. E por fim, algumas definições tratam a complexidade como o mesmo que ordem (categoria III), essa classificação identifica complexidade com o nível de auto-organização. 
Essas três categorias de complexidade são representadas na figura 3.2.

1

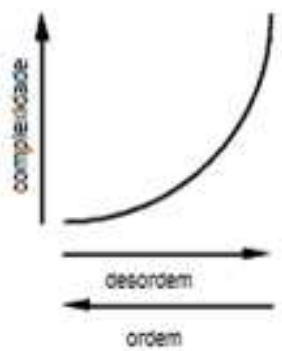

II

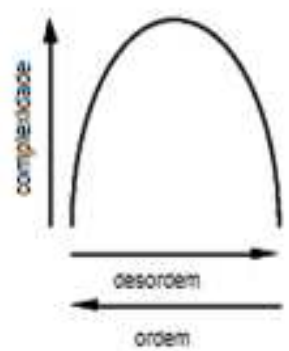

III

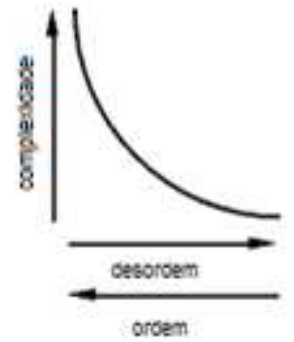

Figura 3.2 - As três categorias da complexidade como uma função da desordem (SHINER; DAVISON; LANDSBERG, 1999).

Com o objetivo de descobrir se a evolução de sistemas biológicos ou outros sistemas complexos tendem a otimizar a complexidade ou de saber como esses sistemas evoluem se a complexidade for otimizada, Shiner, Davison e Landsberg, (LANDSBERG; SHINER, 1998; SHINER; DAVISON; LANDESBERG, 1999) propuseram outra medida de complexidade, a complexidade Shiner - Davison Landsberg (SDL), que de acordo com os parâmetros escolhidos, pode prevalecer o comportamento de uma das três categorias da figura 3.2.

O problema da otimização pode ser resolvido com a teoria da otimização (controle ótimo) que, devido à dificuldade computacional, apresenta uma desvantagem em relação à complexidade SDL. Feldman e Crutchfield (FELDMAN; CRUTCHFIELD, 1998) chegaram independentemente aos mesmos resultados da complexidade SDL, para um conjunto de parâmetros, através de um procedimento que eles chamaram de reparação não-extensiva de outra medida de complexidade, a complexidade López-Ruiz - Mancini - Calbet (LMC).

\subsubsection{Complexidade SDL}

Para conceituar a medida de complexidade SDL é necessário expressar o conceito de ordem e desordem de um sistema. Muito frequentemente, a entropia é 
tomada como uma medida da desordem do sistema. Se o número de estados de um sistema aumenta, a entropia e consequentemente a desordem também aumentam. Sabe-se que o crescimento da complexidade é indesejável como resultado somente do aumento em seu tamanho. Landsberg (LANDSBERG, 1984) propôs a definição de desordem como

$$
\Delta \equiv \frac{s}{S_{\max }}
$$

Essa definição de desordem implica no fato de $0 \leq \Delta \leq 1$, sendo que para um sistema totalmente organizado a desordem é nula e assume o valor máximo para um sistema totalmente desorganizado.

$\mathrm{Na}$ eq. (3.8) $S$ é a entropia de Boltzmann - Gibbs - Shannon (BGS) (SHANNON, 1948), dada por

$$
S \equiv-k \sum_{i=1}^{N} p_{i} \ln p_{i}
$$

sendo $p_{i}$ a probabilidade de ocorrência do $i$-ésimo estado dos $N$ possíveis estados do sistema e $k$ é a constante de Boltzmann apropriado ao sistema físico. No caso mais simples, a de um sistema isolado, a entropia máxima é alcançada numa distribuição equiprovável de probabilidade em que $p_{i}=1 / N$, sendo $1 \leq i \leq N$, temse que:

$$
S_{\text {max }}=k \ln N
$$


Devido a não-extensividade de $\Delta, S$ pode ser trocada pela entropia de Shannon:

$$
S=-\sum_{i=1}^{N} p_{i} \log _{2} p_{i}
$$

Dada à normalização de $\Delta$ para que a não-extensividade possa ser atingida, pode-se definir ordem como

$$
\Omega \equiv 1-\Delta
$$

Após a definição de ordem, é possível perceber que ordem e desordem são quantidades compreendidas entre 0 e 1 e estão livres do efeito do tamanho, sendo possível que a entropia aumente de acordo com o aumento do tamanho dos sistema.

Shiner - Davison - Landsberg (SHINER - DAVISON - LANDSBERG, 1999) definiram a complexidade SDL, como uma medida dependente da ordem e desordem de um sistema para que as três categorias representadas na figura 3.2 pudessem ser quantificadas. A complexidade SDL pode ser expressa por

$$
\Gamma_{\alpha \beta} \equiv \Delta^{\alpha} \Omega^{\beta}
$$

em que $\alpha$ e $\beta$ indicam os graus de importância da desordem e da ordem respectivamente. De acordo com os parâmetros de ordem e desordem escolhidos é possível observar as três categorias de medidas de complexidade. A tabela 3.1, mostra os comportamentos da medida de complexidade SDL em função dos parâmetros. 
Tabela 3.1 - Comportamento da complexidade SDL em função dos parâmetros de ordem e desordem de um sistema.

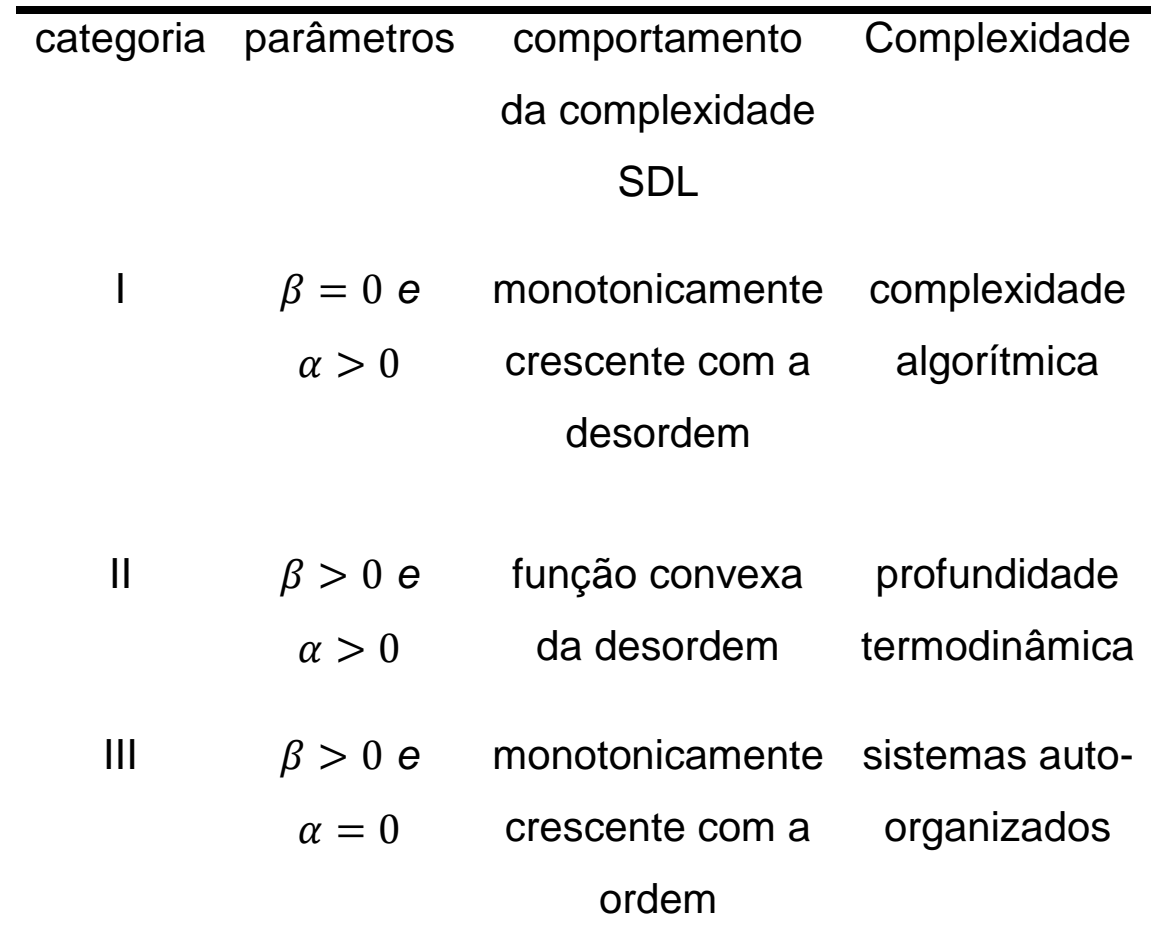

Os diversos comportamentos da complexidade em função da entropia podem ser explicados através dos valores que os parâmetros que controlam a importância da ordem e desordem assumem. Quando $\beta=0$, o parâmetro de ordem deixa de fazer parte da medida de complexidade e essa passa a ser uma função da desordem apresentando o comportamento da categoria I. Já quando $\alpha=0$, a complexidade passa a ser uma medida da ordem do sistema apresentando o comportamento da categoria III. Situações de interesse de estudo são regidas pelo comportamento da categoria II em que $\alpha>0$ e $\beta>0$, em que a medida de complexidade é uma função convexa da desordem. Como neste trabalho, pretendese obter informações sobre o estado de equilíbrio entre ordem e desordem do sistema associado ao fenômeno de ondas de DA, a medida de complexidade mais adequada é obtida para parâmetros de ordem e desordem positivos, descritos pelo comportamento da categoria II. O comportamento da complexidade $\Gamma_{\alpha \beta}$ em função dos parâmetros $\alpha$ e $\beta$ pode ser confirmado pela figura 3.3. 


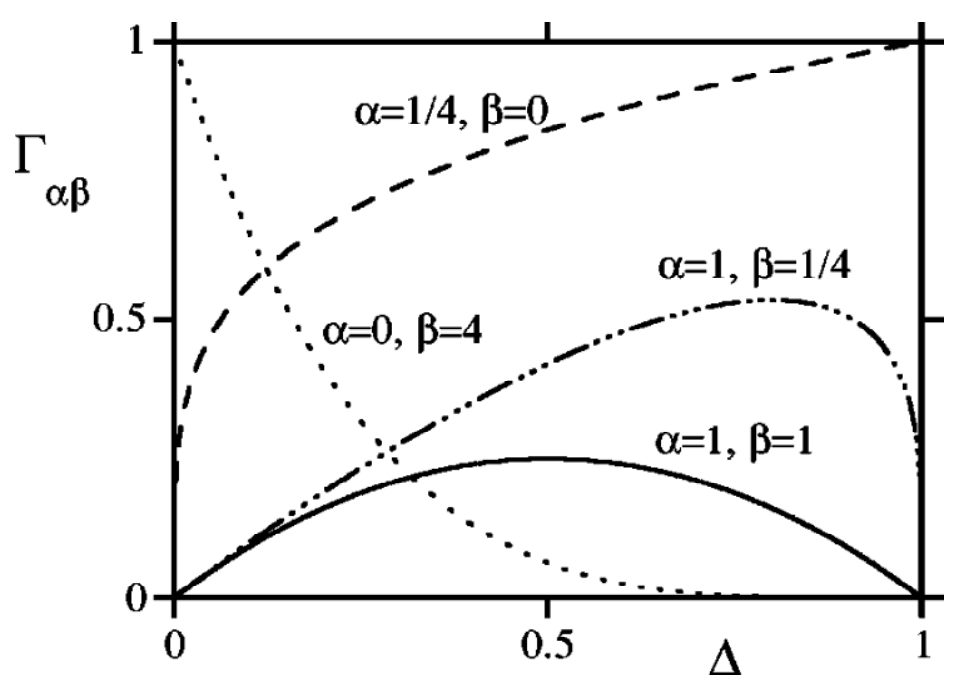

Figura 3.3 - Comportamento da função $\Gamma_{\alpha \beta}$ em função da desordem $\Delta$, mostrando as três categorias de complexidade. Categoria I expressa por $\alpha=\frac{1}{4} e \beta=0$; Categoria II expressa por $\alpha=1, \beta=1$ e $\alpha=$ 1 e $\beta=\frac{1}{4}$; Categoria III expressa por $\alpha=0$ e $\beta=4$ (SHINER - DAVISON - LANDSBERG, 1999).

Tomando $\Gamma_{\alpha \beta}$ como medida de complexidade e $\alpha$ e $\beta$ valores positivos para expressar a complexidade como uma função convexa da desordem, pode-se perceber que a ordem de um sistema é uma medida da distância do equilíbrio. Para a eq. (3.13) a medida da complexidade é uma expressão da distância do equilíbrio e da desordem de um sistema, sendo que a complexidade deixa de existir para sistemas em equilíbrio, implicando máxima desordem ou se ele for ordenado indicando a máxima distância do equilíbrio.

\subsubsection{Complexidade LMC}

Observando a organização de um cristal perfeito e a desorganização de um gás ideal, López-Ruiz, Mancini e Calbet, perceberam que era razoável definir a complexidade LMC como uma composição de duas grandezas, a informação e o desequilíbrio. O desequilíbrio é definido como a distância da distribuição equiprovável dos estados acessíveis de um sistema. No gás ideal, o desequilíbrio é mínimo, enquanto no cristal perfeito o desequilíbrio pode ser máximo, indicando que 
essa medida não pode ser associada diretamente com a complexidade LMC. O desequilíbrio pode ser definido como

$$
D=\sum_{i=1}^{N}\left(p_{i}-\frac{1}{N}\right)^{2}
$$

e a informação é definida pela eq. (3.11).

$\mathrm{Na}$ figura 3.4, tem-se o comportamento qualitativo do desequilíbrio, da informação e de uma sugestão de medida de complexidade.

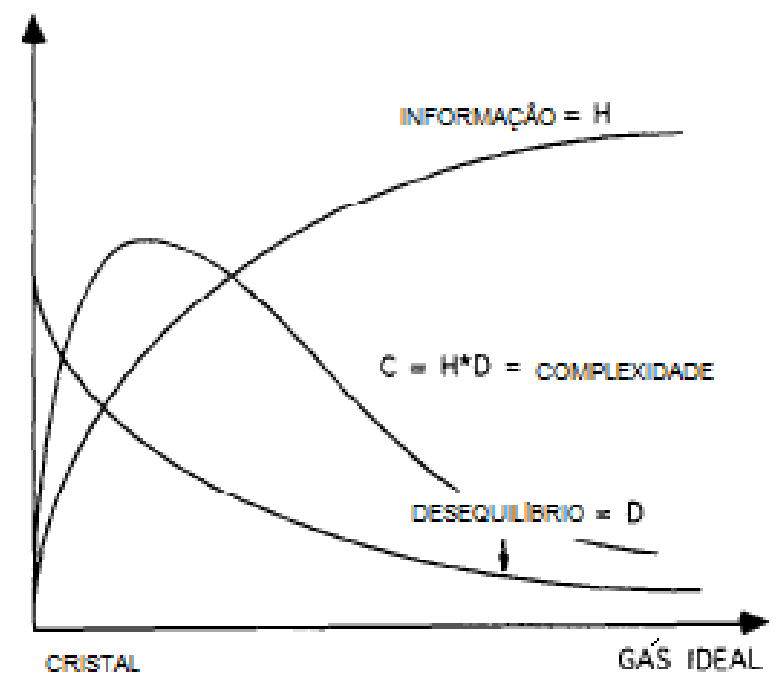

Figura 3.4 - Comportamento qualitativo da informação, desequilíbrio e complexidade LMC em um cristal perfeito e um gás ideal (LÓPEZ-RUIZ; MANCINI; CALBET, 1995).

A figura 3.4 sugere que o produto da informação e do desequilíbrio apresenta um comportamento que pode ser usado como medida da complexidade LMC, sendo nula para sistemas totalmente organizados ou desorganizados. 
A definição da complexidade LMC não normalizada (LÓPEZ-RUIZ; MANCINI; CALBET, 1995) é dada por

$$
C=H D=-\left(K \sum_{i=1}^{N} p_{i} \log p_{i}\right)\left(\sum_{i=1}^{N}\left(p_{i}-1 / N\right)^{2}\right) .
$$

A eq. (3.15) mostra a noção intuitiva que a complexidade deve ser nula nos extremos (gás ideal e cristal perfeito), pois para estados acessíveis igualmente prováveis, como no caso do gás ideal, o desequilíbrio é mínimo, implicando em $C=0$. Já para um cristal perfeito, como alguns estados acessíveis possuem prioridade sobre outros, a informação é minima, indicando complexidade baixa.

A normalização da eq. (3.15) é feita considerando a informação máxima, dada pela eq. (3.10), obtendo a desordem definida na medida SDL.

A relação entre a complexidade LMC normalizada e SDL (SHINER DAVISON - LANDSBERG, 1999) é uma aproximação de primeira ordem da $\Gamma_{11}$, mantendo o comportamento da convexidade.

Em todos os casos, a função definida para a medida de complexidade é compatível com o fato de que nem ordem total e nem desordem completa são sistemas complexos. Escolhendo os coeficientes $\alpha$ e $\beta$ de forma conveniente, a medida da complexidade pode ser usada para expressar a organização de um sistema, pois calculando $\Gamma_{\alpha \beta}$ e observando a escala temporal é possível analisar a evolução da complexidade.

Como em sistemas em que a entropia é máxima ou nula não há complexidade, é necessária uma análise mais detalhada para investigar como os parâmetros de ordem e desordem afetam o resultado da complexidade. Sem perda de generalidade, Piqueira e De Mattos, (PIQUEIRA; De MATTOS, 2011) propuseram uma análise para a complexidade em que $\alpha=1$ e $\beta=k$, em que $k>0$, expressando a eq. (3.13) como

$$
\Gamma_{1 k}=(1-\Delta)(\Delta)^{k} .
$$


Piqueira, De Mattos e Vasconcelos-Neto (PIQUEIRA; De MATTOS; VASCONCELOS-NETO, 2009) usaram a complexidade $\Gamma_{11}$ para a medida de complexidade biológica. Em relação ao referido sistema, a complexidade parecia ser controlada pelas condições ambientais, pois quando essas condições eram favoráveis, o sistema estava organizado entre o nível de ordem e desordem e quando as condições não eram favoráveis à complexidade tendia a valores extremos. A variação dos parâmetros de ordem e desordem não produziram mudanças qualitativas nos resultados. Esses fatos podem ser verificados pelas propriedades da eq. (3.16). Analisando a tabela 3.2, é possível avaliar o comportamento do sistema em função da complexidade.

Tabela 3. 2 - Propriedades da complexidade $\Gamma_{1 k}$.

\begin{tabular}{|c|c|c|c|}
\hline desordem & entropia & complexidade & sistema \\
\hline$(\Delta)$ & $(S)$ & $\left(\Gamma_{1 k}\right)$ & \\
\hline$\Delta=0$ & $S=0$ & $\begin{array}{l}\Gamma_{1 k}=0, \forall k>0 \\
\text { complexidade nula }\end{array}$ & $\begin{array}{l}\text { totalmente } \\
\text { ordenado }\end{array}$ \\
\hline$\Delta=1$ & $S=S_{\max }$ & $\begin{array}{l}\qquad \Gamma_{1 k}=0, \forall k>0 \\
\text { complexidade nula }\end{array}$ & $\begin{array}{c}\text { totalmente } \\
\text { desordenado }\end{array}$ \\
\hline$\Delta=\Delta_{\max }$ & & $\Gamma_{1 k}=\left(\Gamma_{1 k}\right)_{\max }$ & complexidade \\
\hline$\left(\Delta_{\max }=\frac{k}{k+1}, \forall>0\right)$ & & $\left(\Gamma_{1 k}\right)_{\max }=\left(\frac{k}{k+1}\right)^{k}-\left(\frac{k}{k+1}\right)^{k+1}$ & \\
\hline
\end{tabular}

A consequência da terceira propriedade em que a desordem é máxima pode ser relacionada aos valores que $k$ assume e para a medida de complexidade os parâmetros de ordem e desordem podem assumir importâncias variáveis: 
- mesma importância dada a ordem e a desordem ou seja, se $k=1 \Rightarrow$ $\Delta_{\max }=.5 ;\left(\Gamma_{1 k}\right)_{\max }=.25$;

- maior importância a ordem ou seja, se $0<k<1 \Rightarrow \Delta_{\max }<.5$; $\left(\Gamma_{1 k}\right)_{\max }>$ .25 ;

- maior importância a desordem ou seja $k>1 \Rightarrow .5<\Delta_{\max }<1$; $\left(\Gamma_{1 k}\right)_{\max }<$ .25 .

O comportamento da complexidade em função da desorganização de um sistema que varia de acordo com o parâmetro $k$ pode ser representado como mostra figura 3.5.

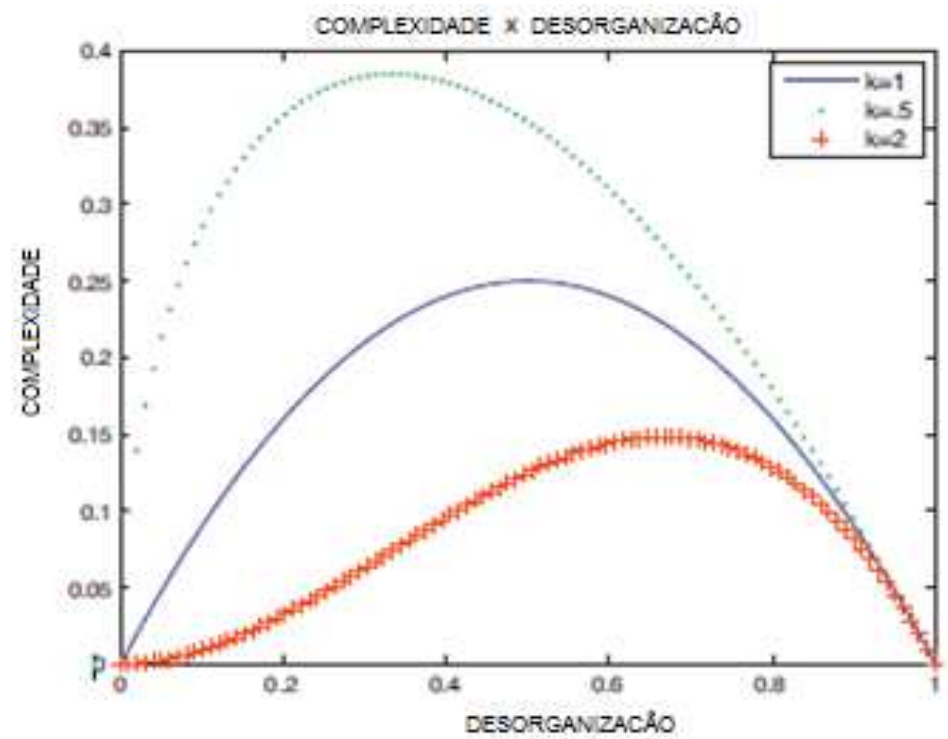

Figura 3.5 - Medida da complexidade LMC x desordem (PIQUEIRA; De MATTOS, 2011). 


\section{Capítulo 4}

\section{Materiais e métodos}

\subsection{Introdução}

Neste capítulo serão descritas as preparações biológicas e os materiais utilizados durante o experimento, assim como o procedimento utilizado. Também será feita uma breve descrição do recurso computacional utilizado para o cálculo da medida de complexidade. Como explicado no capítulo 2, os principais concomitantes das ondas de DA, o potencial extracelular e o sinal óptico, foram adquiridos e usados para os cálculos da medida de complexidade. Ao final do capítulo serão apresentados e discutidos os resultados calculados.

\subsection{Preparação do eye-cup e procedimentos}

Os dados utilizados para os cálculos da medida de complexidade foram adquiridos dos experimentos realizados pela Vera Maura Fernandes de Lima e Michaela Sieber. Os experimentos foram realizados no Instituto de Zoofisiologia da Universidade de Hohenheim, Alemanha, seguindo as normas de éticas locais, sob a supervisão de Wolfgang Hanke. As descrições detalhadas da preparação do eyecup e dos procedimentos utilizados para a realização do experimento foram retiradas do artigo de Piqueira et al. (PIQUEIRA et al., submetido Physica D). 


\subsubsection{Preparação do eye-cup}

O modelo experimental utilizado foi a retina de pintinho. Foram utilizados animais em idade entre 5 e 21 dias. Os pintinhos foram decapitados e seus olhos dissecados. A câmara anterior foi cortada no equador e o humor vítreo removido, enquanto a câmara posterior foi imersa na solução Ringer. As retinas foram colocadas no fundo de uma placa de Petri, caracterizando o eye-cup, onde a perfusão foi mantida a uma taxa constante. A solução Ringer usada para a perfusão continha $\mathrm{NaCl}$ a $100 \mathrm{mM}, \mathrm{KCl}$ a $6 \mathrm{mM}, \mathrm{MgSO}_{4}$ a $1 \mathrm{mM}, \mathrm{NaHCO}_{3}$ a $30 \mathrm{mM}$, glicose a $30 \mathrm{mM}$, TRIS a $10 \mathrm{mM}$ e $\mathrm{CaCl}_{2} .2 \mathrm{H}_{2} \mathrm{O}$ a $1 \mathrm{mM}$. O pH é ajustado em 7,4 e antes do início das medidas, as retinas descansaram por 30 minutos.

\subsubsection{Equipamentos e produtos químicos}

O setup era composto de uma gaiola de Faraday tal que uma câmera e um fotomultiplicador tinham seus pontos focais posicionados na região central da retina por meio de um microscópio. Sinais elétricos foram adquiridos com microeletrodos de vidro (diâmetro da ponta cerca de $10 \mu \mathrm{m}$, preenchidos com solução de potássio) controlado a partir de sinais ópticos de posição. O posicionamento dos eletrodos foi destinado à camada IPL, como explicado no capítulo 2. O potencial elétrico em relação à solução foi medido, usando um amplificador de alta impedância conectado ao microeletrodo de vidro e outro de referência na solução de banho. A taxa de perfusão foi mantida a $1 \mathrm{ml} / \mathrm{min}$ e a temperatura em torno de $30^{\circ} \mathrm{C}$.

Os produtos químicos testados foram diluídos na solução Ringer e perfundidos na mesma taxa de amostragem utilizada para a aquisição das ondas controle. Todos os produtos químicos, inclusive aqueles necessários para a preparação da solução Ringer eram da marca Sigma, Aldrich ou Marck. 


\subsubsection{Registros eletrofisiológicos e ópticos}

Os dados do setup foram armazenados usando o LabView ${ }^{R}$. As séries temporais relativas aos sinais de saída do fotomultiplicador e dos eletrodos foram, simultaneamente, armazenadas como séries temporais e a saída da câmera foi registrada em um arquivo de DVD. Juntamente com a saída da câmera, foi possível acompanhar a saída do eletrodo e do brilho médio de uma matriz 10×10 de pixel, posicionado sobre a ponta do eletrodo, e, simultaneamente, a saída do fotomultiplicador. A série temporal do brilho médio fornece o perfil óptico das ondas de DA em microescala (GOS), de comprimento de uma matriz quadrada de $50 \mu \mathrm{m}$, enquanto a saída do fotomultiplicador fornece o perfil óptico em escala macroscópica (IOS), de uma área circular de $1 \mathrm{~mm}$ de diâmetro. A série temporal da saída do eletrodo fornece o potencial elétrico.

\subsection{Recurso computacional}

O programa usado para o cálculo da complexidade foi elaborado por Yuri Cássio Campbell Borges (CAMPBELL-BORGES; PIQUEIRA, 2012). Nesse programa, a complexidade SDL temporal-janelada é usada para calcular a complexidade de apenas uma série temporal e usa-se uma janela para analisar diferentes partes da série.

Inicialmente o programa pede o nome do arquivo a ser lido. Cada arquivo possui três séries temporais. Cada série representa os valores obtidos das respectivas grandezas medidas. A primeira série é constituída pelos valores do potencial extracelular, a segunda é a medida do brilho médio em macroescala, conhecida como sinal óptico intrínseco (IOS), sendo a última série representada pelas medidas do perfil óptico em microescala, também chamada de sinal óptico global (GOS). 
Escolhe-se a série temporal a ser analisada. Após a leitura dos dados, o programa pedirá o tamanho da janela desejado. A janela escolhida é quadrada garantindo que todos os pontos tenham a mesma importância para o cálculo da complexidade, como mostra a figura 4.1. Variando-se o tamanho da janela, obtém se dinâmicas diferentes. Aumentando - se o tamanho da janela, a dinâmica será mais rápida, ao passo que se tornará mais lenta quanto menor for essa janela.

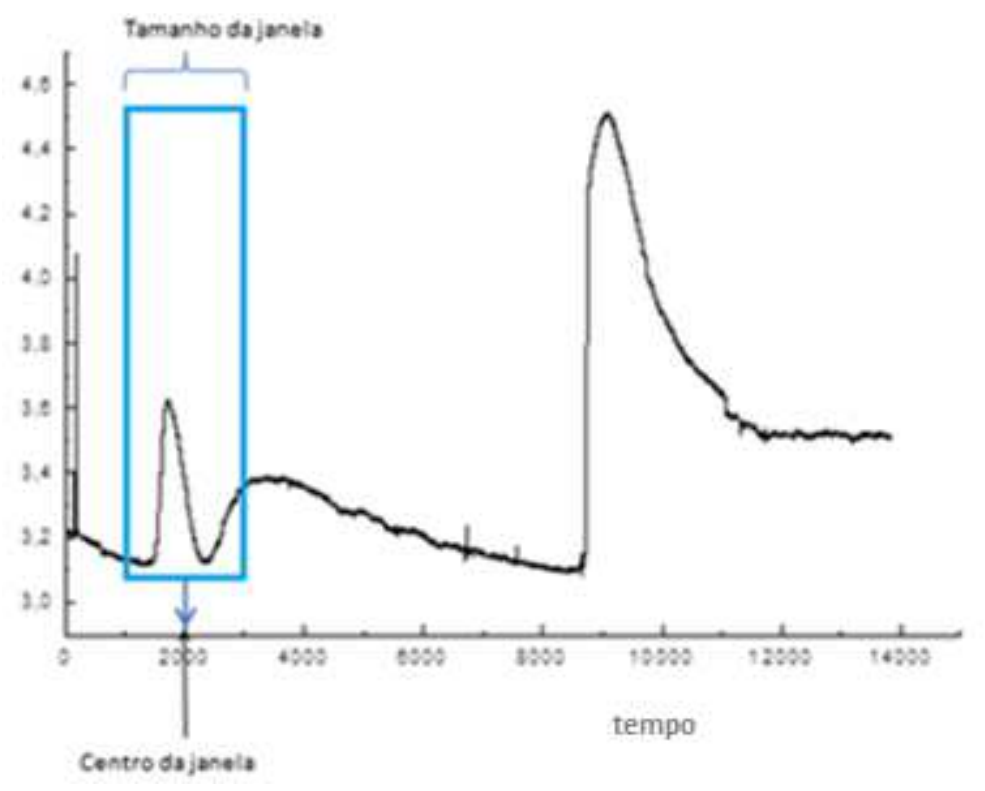

Figura 4.1 - Tamanho e centro da janela (Fonte: Yuri Cássio Campbell Borges).

Após a definição do tamanho da janela, outro parâmetro importante a ser escolhido é o número de estado do sistema, representado pela variável chamada de "bins". Para essa partição, o programa armazena o maior e o menor valor da série e divide essa diferença em intervalos iguais, definidos pelo número de bins, como mostra a figura 4.2. Variando-se o número de bins, pode-se obter uma dinâmica mais detalhada do processo, sendo que um número maior de bins é capaz de mostrar mais detalhes do processo em análise. O número de estados foi definido pela amplitude e como essa definição pode afetar o resultado da medida de complexidade, essa escolha levou em consideração valores que não alterassem de qualitativamente a complexidade calculada. 


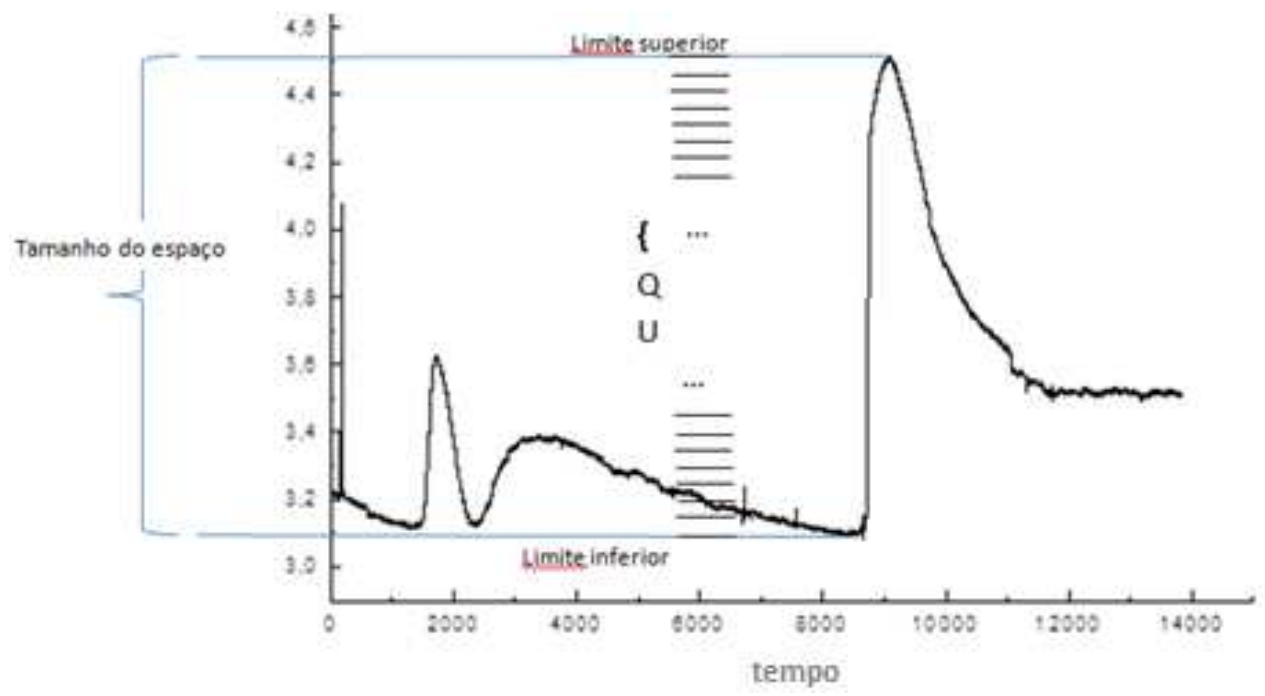

Figura 4.2 - Representação do número de estados do sistema através de partições representadas pelo número de bins (Fonte: Yuri Cássio Campbell Borges).

Esse padrão é obedecido para todas as janelas, computando-se assim, para todas as janelas e partições, a complexidade de acordo com os parâmetros de ordem $(\beta)$ e desordem $(\alpha)$ estabelecidos. Os melhores parâmetros para a ferramenta matemática utilizada foram encontrados escolhendo-se uma janela de tamanho 2000 e o número de partições caracterizado por 32 divisões. De acordo com os resultados obtidos por Piqueira, De Mattos e Vasconcelos-Neto, (PIQUEIRA; De MATTOS; VASCONCELOS-NETO, 2009) a complexidade calculada neste trabalho foi obtida atribuindo-se a mesma importância dada à ordem e à desordem ou seja, calculou-se $\Gamma_{11}$ para toda as séries temporais.

Após a execução do programa, a imagem fornecida está representada na figura 4.3. A parte inferior da figura mostra a representação da série temporal a ser analisada e a parte superior da figura mostra a representação da medida da complexidade janelada $\Gamma_{11}$ da respectiva série temporal. 

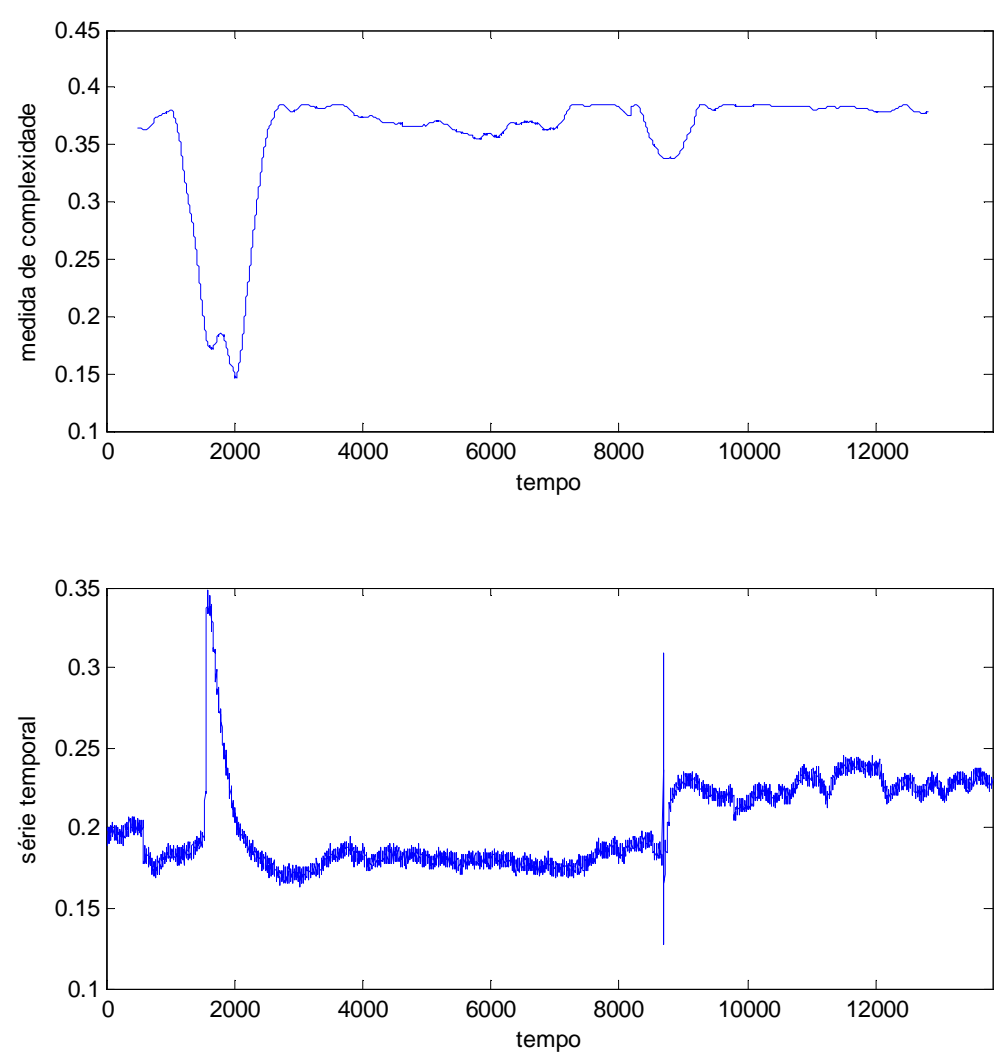

Figura 4.3 - Representação da série temporal e de sua respectiva medida de complexidade.

\subsection{Análise e medida de complexidade dos sinais}

As ondas de DA analisadas eram isoladas e circulares. Para o estudo, foram realizados diversos experimentos e suas variações de potencial e sinal óptico foram adquiridos. Os dados dos registros foram usados para calcular a complexidade associada ao fenômeno. As análises das respostas dos potenciais e dos perfis ópticos, nas escalas micro e macroscópicas, foram realizadas em duas etapas: a primeira delas consiste numa análise comparativa entre as ondas de controle e as obtidas com as diversas substâncias, e a segunda parte é composta por uma comparação entre os registros adquiridos e suas respectivas complexidades calculadas de cada onda obtida em presença das diversas substâncias fármacoquímica.

Para a obtenção das ondas de controle foram realizados quarenta e três experimentos e suas variações de potencial e sinal óptico foram adquiridos. Os 
dados dos registros foram usados para calcular a complexidade associada ao fenômeno.

As ondas foram obtidas em presença de diversas substâncias: potássio, nicotina, protamina, ritalina, cafeína, cocaína e anfetamina. Ao todo, foram realizados quarenta e nove experimentos com substâncias fármaco-química na tentativa de relacionar o fenômeno de ondas DA em retina com cada substância específica.

Com os dados das séries temporais, as respectivas medidas de complexidade LMC foram calculadas e os gráficos dessas medidas são representados na parte superior de cada série obtida, como mostra a figura 4.3. Os registros dos sinais ópticos estão em uma escala arbitrária, assim como a escala temporal.

\subsubsection{Ondas de controle}

Parte do experimento consistiu na obtenção de ondas de controle para estabelecer um padrão de comparação para as ondas obtidas em presença das diversas substâncias analisadas. Para as ondas de controle foram obtidos os registros das variações do potencial e dos sinais ópticos em escala micro e macroscópicas e suas respectivas complexidades foram calculadas.

A análise dos registros do potencial mostra que quando o potencial varia de forma abrupta, a complexidade é alta e, em muitos dos registros, é até máxima, indicando que esse comportamento é traduzido como o estado de equilíbrio entre ordem e desordem. Quando o sinal oscila entre valores próximos, caracterizando um aumento de ordem ou desordem, a complexidade diminui, sendo nula quando há o predomínio de uma dessas grandezas. As medidas de complexidade permanecem entre valores intermediários quando o registro do potencial oscila em torno de valores diferentes, como pode ser observado na figura 4.4 (a). 

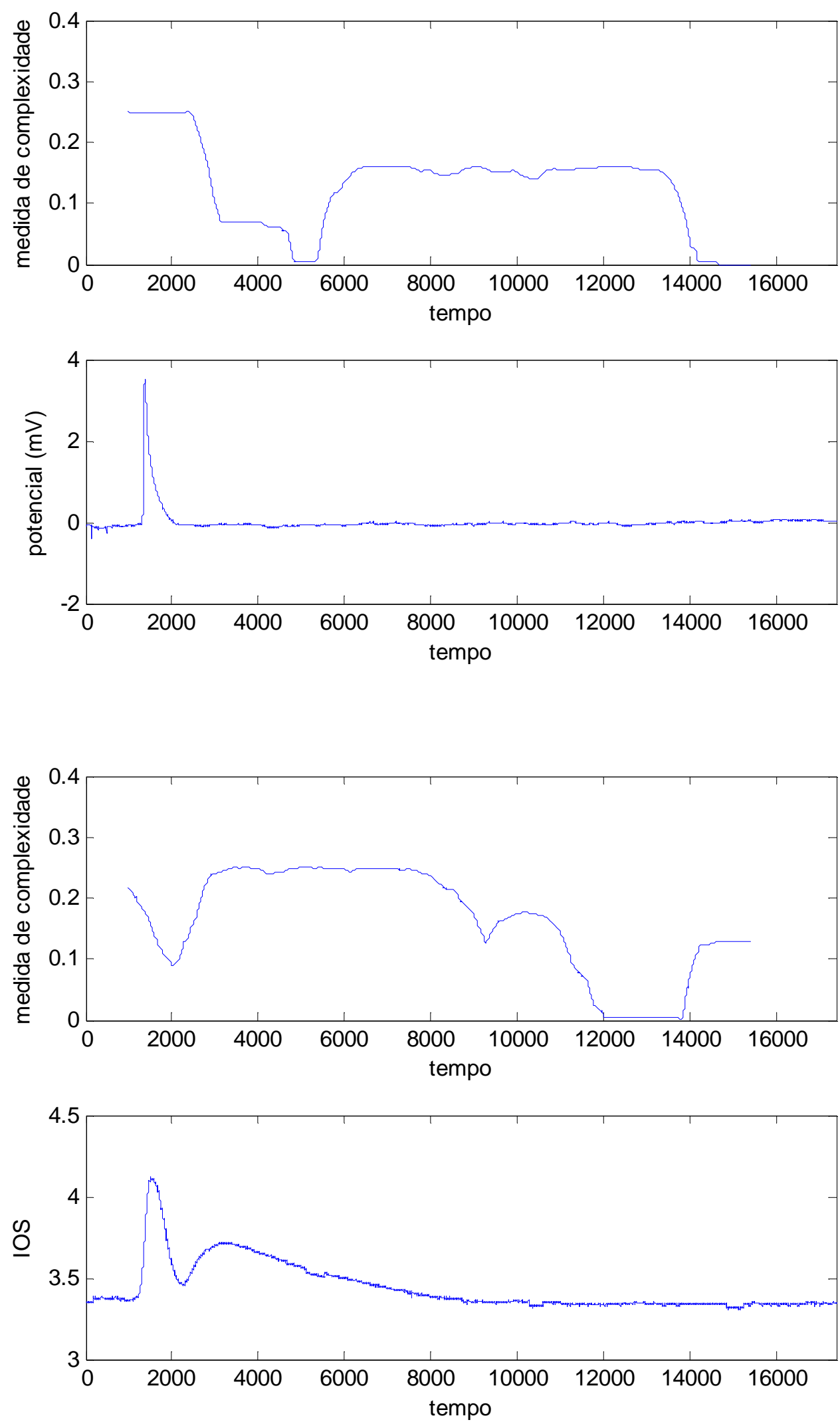

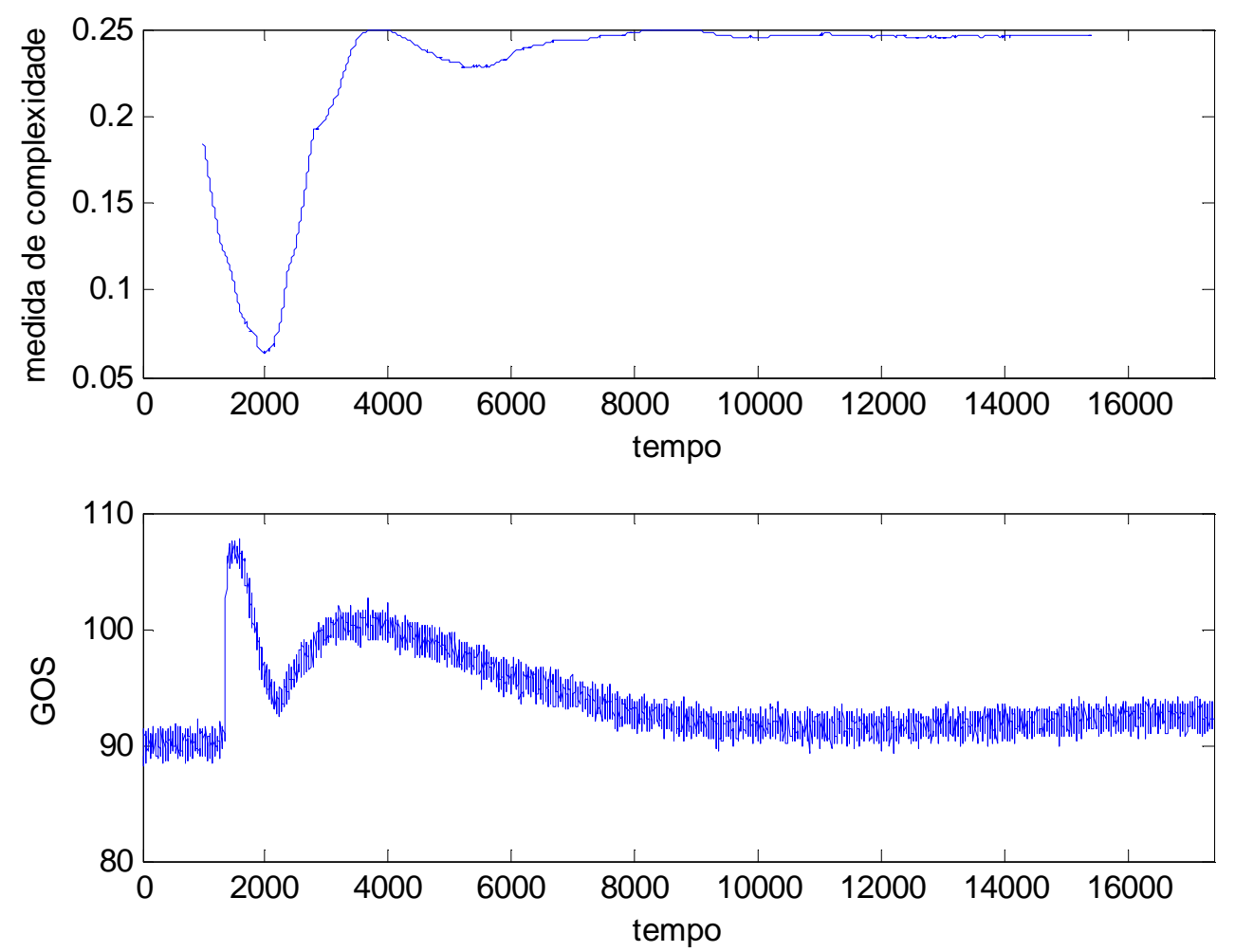

Figura 4.4 - Registros das ondas de controle. (a) Registro do potencial extracelular e respectivo cálculo da complexidade. (b) Registro do IOS e respectivo cálculo da complexidade. (c) Registro do GOS e respectivo cálculo da complexidade.

Outro comportamento que traduz o equilíbrio entre ordem e desordem é descrito pela figura 4.5 (a). Pode-se notar que em alguns trechos a complexidade calculada é máxima mesmo em trechos não caracterizados pela variação abrupta do potencial. Indicando que a variação do sinal em torno de valores diferentes também aumenta o equilíbrio da ordem e desordem. 

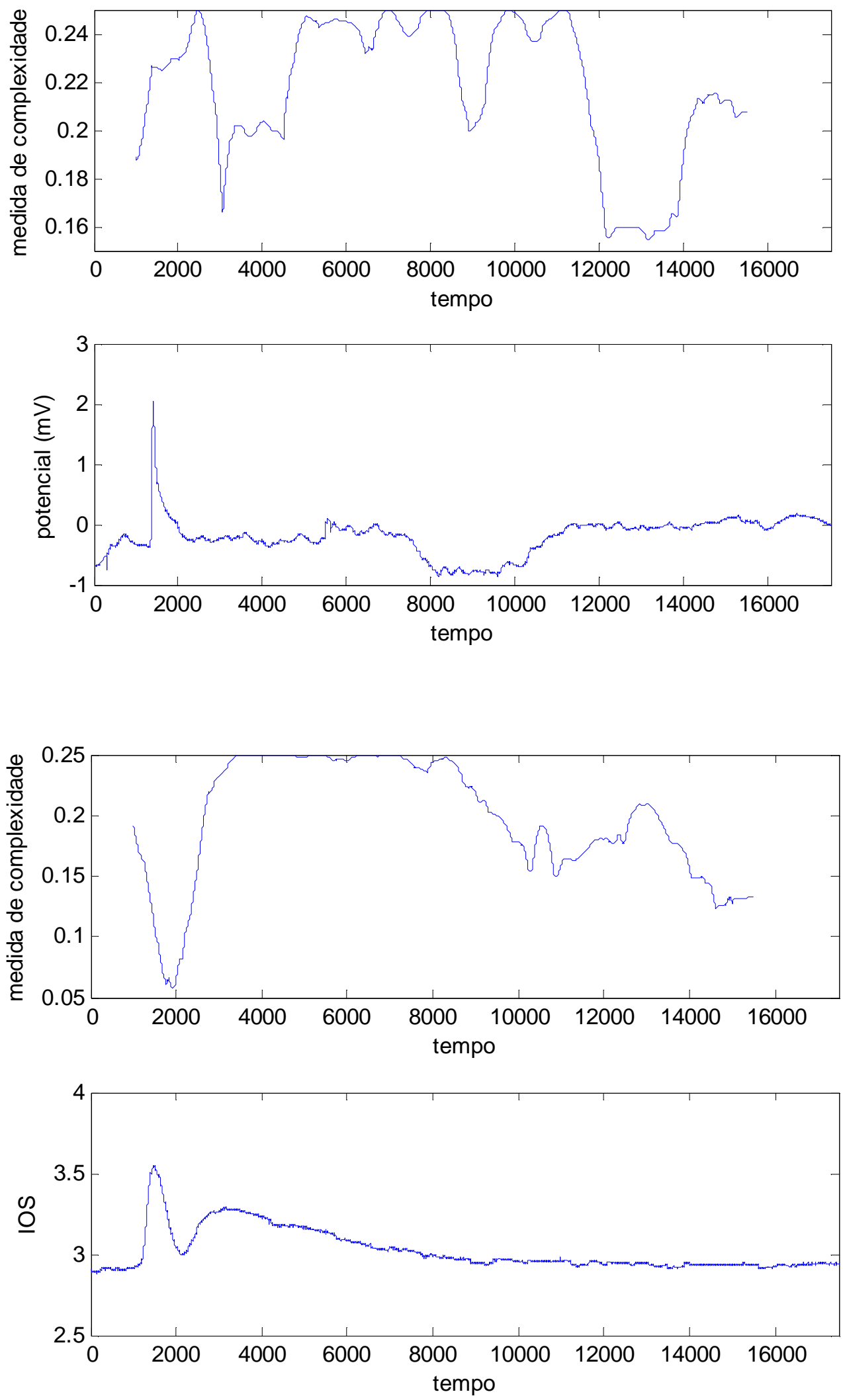

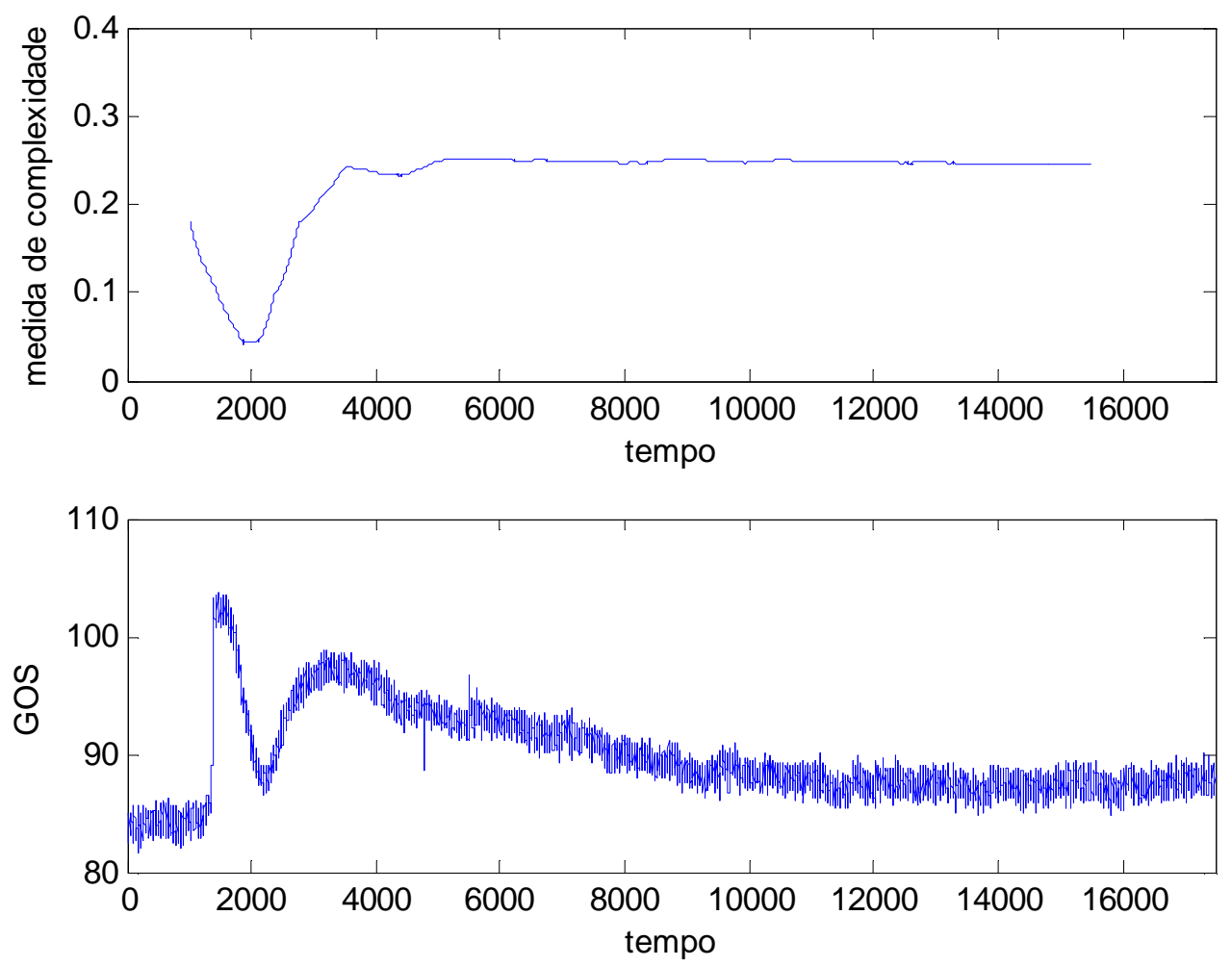

Figura 4.5 - Registros das ondas de controle. (a) Registro do potencial extracelular e respectivo cálculo da complexidade. (b) Registro do IOS e respectivo cálculo da complexidade. (c) Registro do GOS e respectivo cálculo da complexidade.

Nos registros em micro e macroescalas é possível observar a relação do primeiro componente óptico com o potencial e do segundo componente com a resposta da atividade metabólica, como descrito no capítulo 2. Para os gráficos GOS percebe-se que a relação do potencial com o sinal óptico, caracterizado por uma variação abrupta desses valores, contribui para o predomínio da ordem ou desordem, comportamento comprovado pela diminuição da complexidade. Já a influência da atividade metabólica, descritas nos registros por variações não abruptas em torno de valores diferentes e próximos contribui para o aumento da complexidade, sendo nesse caso, máxima, caracterizando o equilíbrio entre a ordem e desordem. A complexidade permaneceu máxima para o restante do registro cujo sinal oscila muito pouco em torno de valores próximos indicando que essa pequena variação contribui para o equilíbrio, figuras 4.4 (c) e 4.5 (c).

Para os registros em macroescalas (IOS) percebe-se que as regiões do registro relacionadas com o potencial também apresentam as menores medidas de 
complexidade em razão do desequilíbrio provocado pelo predomínio da ordem ou desordem característico do fenômeno. As regiões dos perfis relacionadas com as respostas metabólicas são caracterizadas pelo equilíbrio dessas grandezas correspondendo à máxima complexidade do sistema. No restante do perfil não é esse o comportamento observado, pois as oscilações do sinal em torno de valores próximos contribuem para a diminuição da complexidade, sendo essa uma diferença qualitativa dos sinais em escalas diferentes, conforme mostram as figuras 4.4 (b e c) e 4.5 (b e c).

\subsubsection{Protamina}

Em parte dos experimentos, as ondas foram obtidas em presença de protamina, sendo realizados três experimentos em quantidades distintas de massa, sendo de 2,0 $\mu \mathrm{g}, 2,5 \mu \mathrm{g}$ e 5,0 $\mu \mathrm{g}$. Para cada experimento foram registrados o sinal do potencial e dos perfis ópticos.

A análise comparativa dos registros das ondas de controle e das ondas obtidas em presença de protamina sugerem algumas diferenças qualitativas. Para os registros obtidos com a menor massa, observa-se que para as ondas de controle a variação abrupta do potencial contribui para o aumento da complexidade do sistema, enquanto a oscilação do potencial em torno de valores muito próximos diminui a complexidade do sistema, assumindo valores intermediários. Para os registros de protamina, observa-se o comportamento contrário, sendo a complexidade máxima nos trechos de pequenas oscilações, ela assume valores intermediários e mínimos para os trechos de oscilações abruptas, figura 4.6 (a).

Para os registros ópticos, também é possível perceber um comportamento contrário. Nas ondas de controle em microescala, o perfil relacionado com 0 potencial apresenta valores de complexidade intermediários, enquanto nas ondas obtidas em presença de protamina, esses trechos são os relacionados com as maiores medidas de complexidade. Nessa mesma escala, enquanto para as ondas de controle o perfil relacionado à atividade metabólica contribui para que a complexidade seja máxima, nas ondas de protamina esses valores contribuem para 
que a complexidade assuma valores intermediários e muitas vezes valores bem baixos, indicando que a presença de protamina para a obtenção do fenômeno diminui o equilíbrio entre ordem e desordem do sistema, figura 4.6 (c).

Para os registros em macroescala, as ondas de controle apresentam um comportamento semelhante aos registros em microescala com as pequenas diferenças descritas anteriormente, já as ondas de protamina possuem um comportamento qualitativo semelhante, sendo acentuada a diminuição da complexidade relacionada à atividade metabólica e nesses trechos nota-se que a complexidade chega a ser nula, caracterizando ordem ou desordem total, figura 4.6 (b).

Para os registros do potencial obtidos em presença de protamina de quantidade em massa intermediária é possível notar que a complexidade assume valores máximos em alguns trechos caracterizados pela variação do sinal que antecede e sucede a variação abrupta do sinal do potencial, diferentemente das ondas de controle. Para os sinais ópticos as diferenças são muito semelhantes aos registros de quantidade menor de massa, tendo complexidade máxima para a região do perfil relacionado ao potencial e valores de intermediário a baixo para respostas metabólicas.

Os registros de protamina com a quantidade de massa maior apresentam complexidade máxima para o perfil do potencial relacionado aos trechos cujos sinais apresentam oscilações em torno de valores diferentes e próximos, sendo a complexidade intermediária para as variações abruptas, que comparadas às ondas de controle indica que nesses picos de potencial ocorre uma diminuição da complexidade caracterizando o aumento de ordem ou desordem do sistema. Para os registros ópticos, nota-se uma maior semelhança qualitativa dos registros das ondas de controle, pois a complexidade é máxima para os trechos relacionados às atividades metabólicas e assume valores menores na região do perfil relacionado ao potencial, como nos registros de controle.

A comparação entre os registros das ondas obtidas em presença de protamina mostra que os perfis de onda em microescala (GOS) e em macroescala (IOS) apresentam comportamentos semelhantes, como mostram as figuras 4.6 (b e c), 4.7 (b e c) e 4.8 (b e c). É possível notar que o potencial está relacionado com o 
primeiro componente óptico do perfil e que o segundo componente óptico está relacionado com a resposta da atividade metabólica, como descrito no capítulo 2.

De acordo com os registros obtidos é possível observar que, quanto maior a massa de protamina, maior os picos de potencial medido. A mudança de quantidade de massa de 2,0 $\mu \mathrm{g}$ para 2,5 $\mu \mathrm{g}$ produz uma alteração não só nos valores dos picos do potencial como nos perfis ópticos, que apresentam comportamentos qualitativos aparentemente semelhantes. Essa semelhança é aparente, sendo confirmada comparando-se os gráficos das medidas de complexidade dos respectivos potenciais e dos perfis ópticos, como mostram as figuras 4.6 (a) e 4.7 (a), e dos perfis ópticos, figuras 4.6 (b e c) e 4.7 (b e c).

O experimento em presença da menor massa apresenta complexidade máxima para grande parte do registro do potencial como mostra a figura 4.6 (a), indicando que há um equilíbrio entre a ordem e desordem do sistema. Quando o potencial varia de forma abrupta, representado na figura pelos picos, caracterizando certa desordem ou ordem ao sistema, a complexidade diminui. Nos demais trechos em que se pode constatar que o potencial oscila entre valores próximos, a complexidade não só aumenta como é máxima, indicando que essas pequenas variações contribuem para o equilíbrio entre a ordem e desordem do sistema.

Observando a figura 4.7 (a), é possível verificar que a complexidade é máxima nos instantes que antecedem e sucedem a grande variação do potencial, indicando que esses trechos são marcados pelo equilíbrio da ordem e desordem. A complexidade diminui nos trechos relacionados com os picos de potencial. Nos demais pontos do registro caracterizados por variações do sinal em torno de valores próximos, a complexidade assume valores intermediários. Esse mesmo comportamento é observado para o experimento com massa de 5,0 $\mu \mathrm{g}$, como mostra a figura 4.8 (a), sendo que neste último experimento existem alguns outros trechos caracterizados pelo equilíbrio da ordem e desordem, contribuindo para 0 aumento da complexidade. 

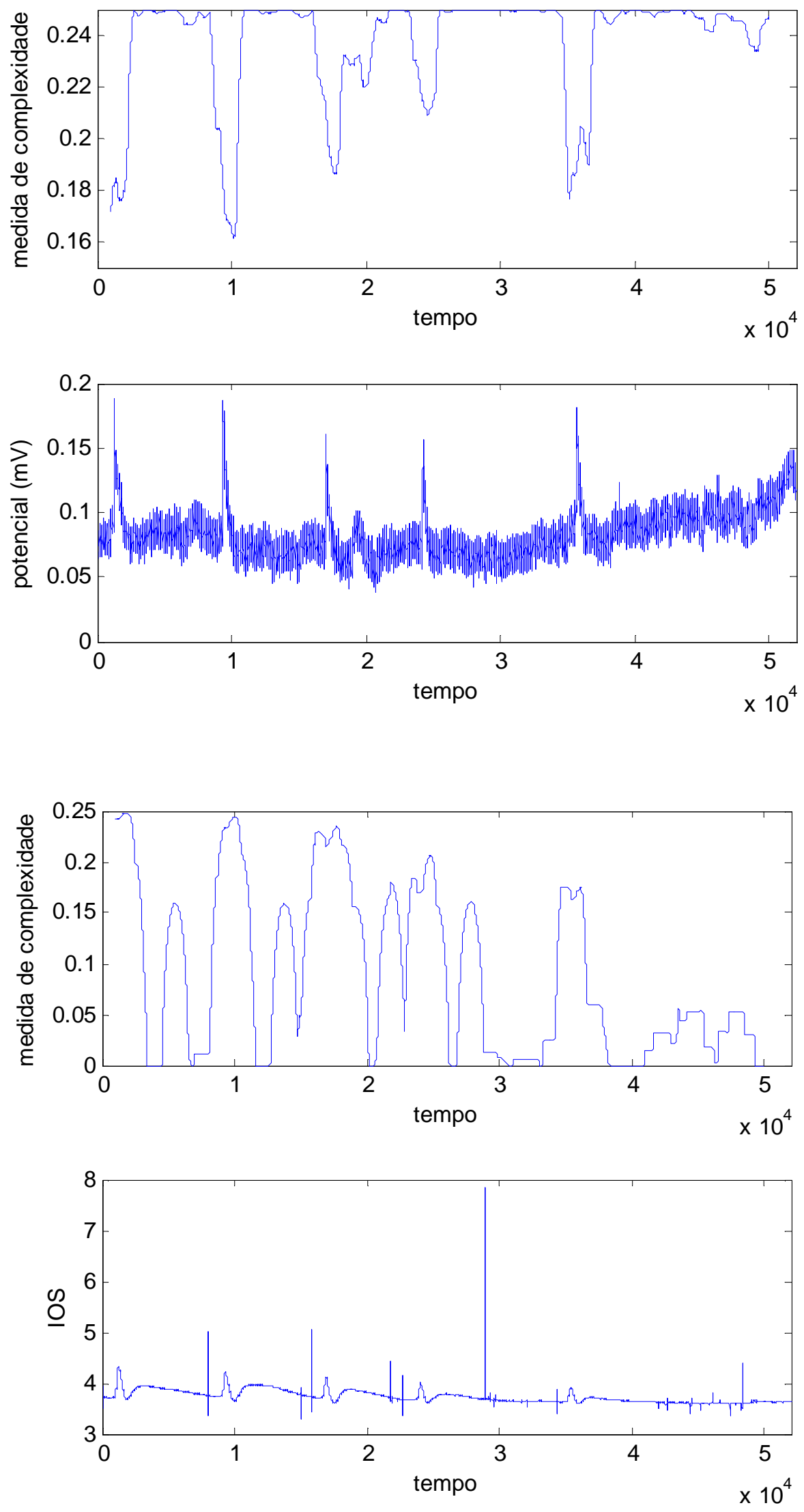

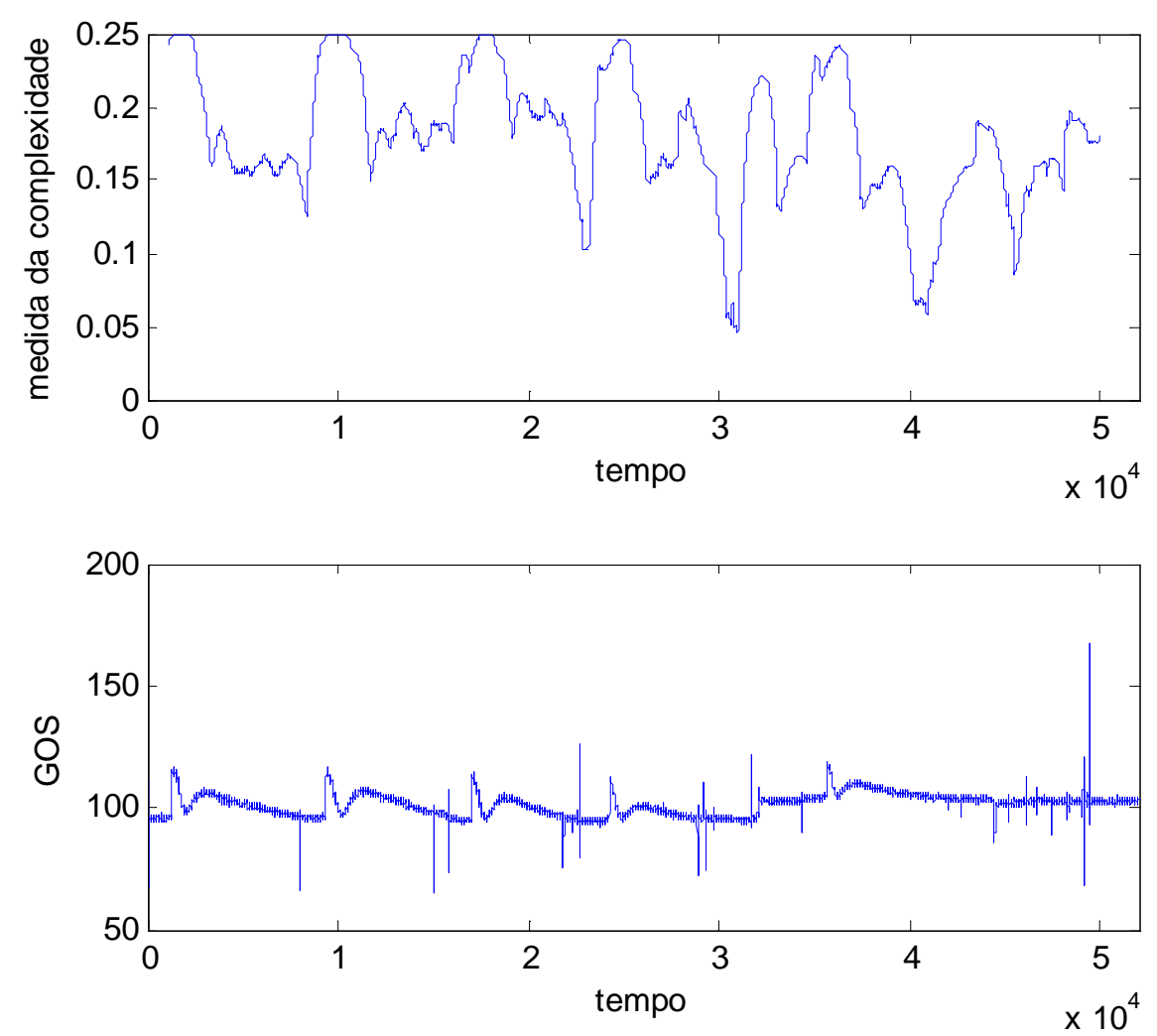

Figura 4.6 - Registros com protamina 2,0 $\mu \mathrm{g}$. (a) Registro do potencial extracelular e respectivo cálculo da complexidade. (b) Registro do IOS e respectivo cálculo da complexidade. (c) Registro do GOS e respectivo cálculo da complexidade.

Analisando os perfis ópticos, IOS e GOS, para os experimentos em presença de protamina com massas de 2,0 $\mu \mathrm{g}$ e 2,5 $\mu \mathrm{g}$, é possível perceber que a complexidade é máxima para o primeiro componente óptico que possui uma relação direta com o potencial, como explicado no capítulo 2. Essas quantidades de massas de protamina produziram alterações significativas no sinal óptico que possui relação com a atividade metabólica e nesses trechos pode-se notar que a complexidade apresenta valores intermediários, como pode ser verificado pela análise das figuras 4.6 ( $b$ e c) e 4.7 ( $b$ e c), indicando a ocorrência do predomínio da ordem ou da desordem. 

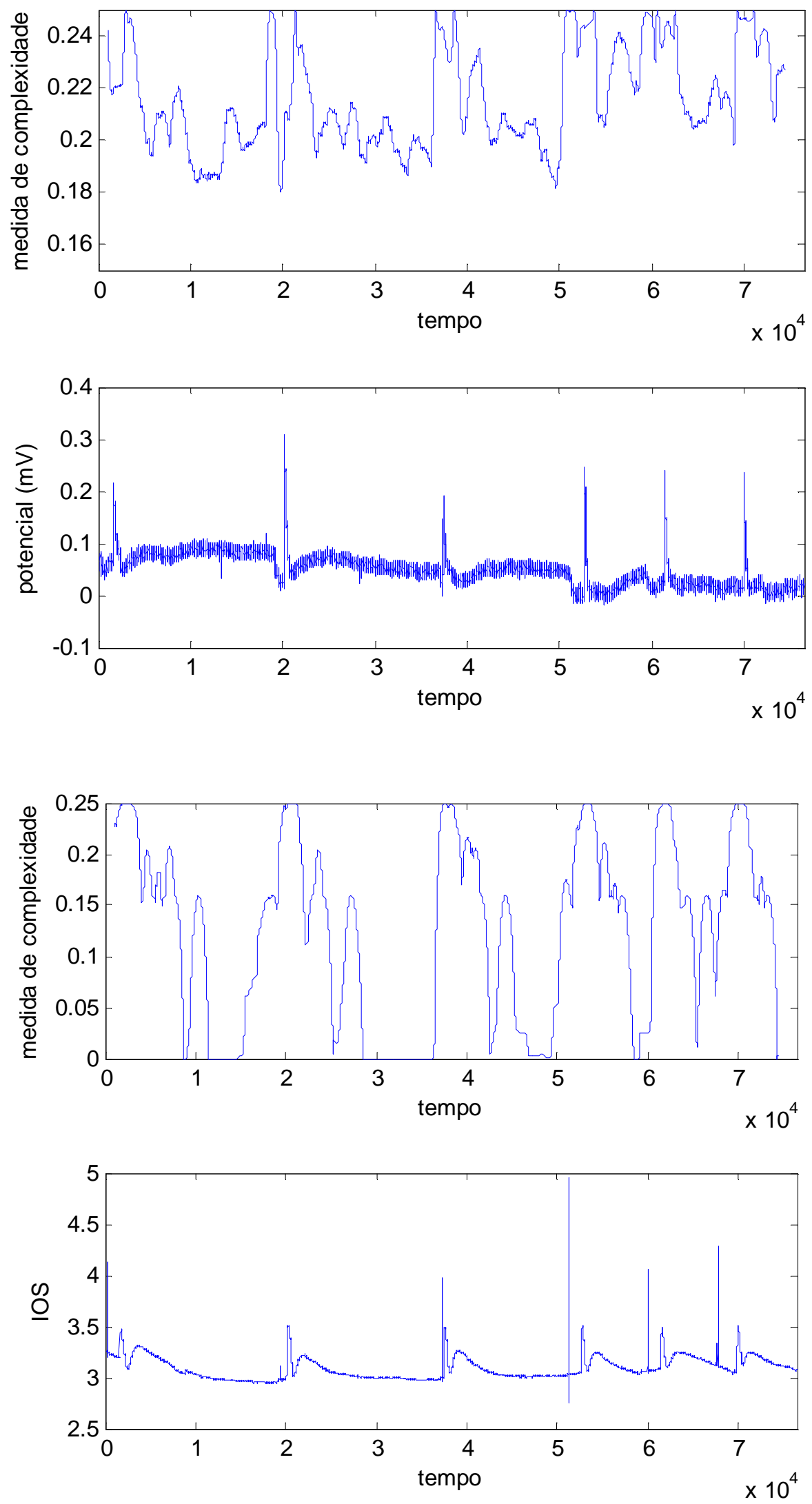

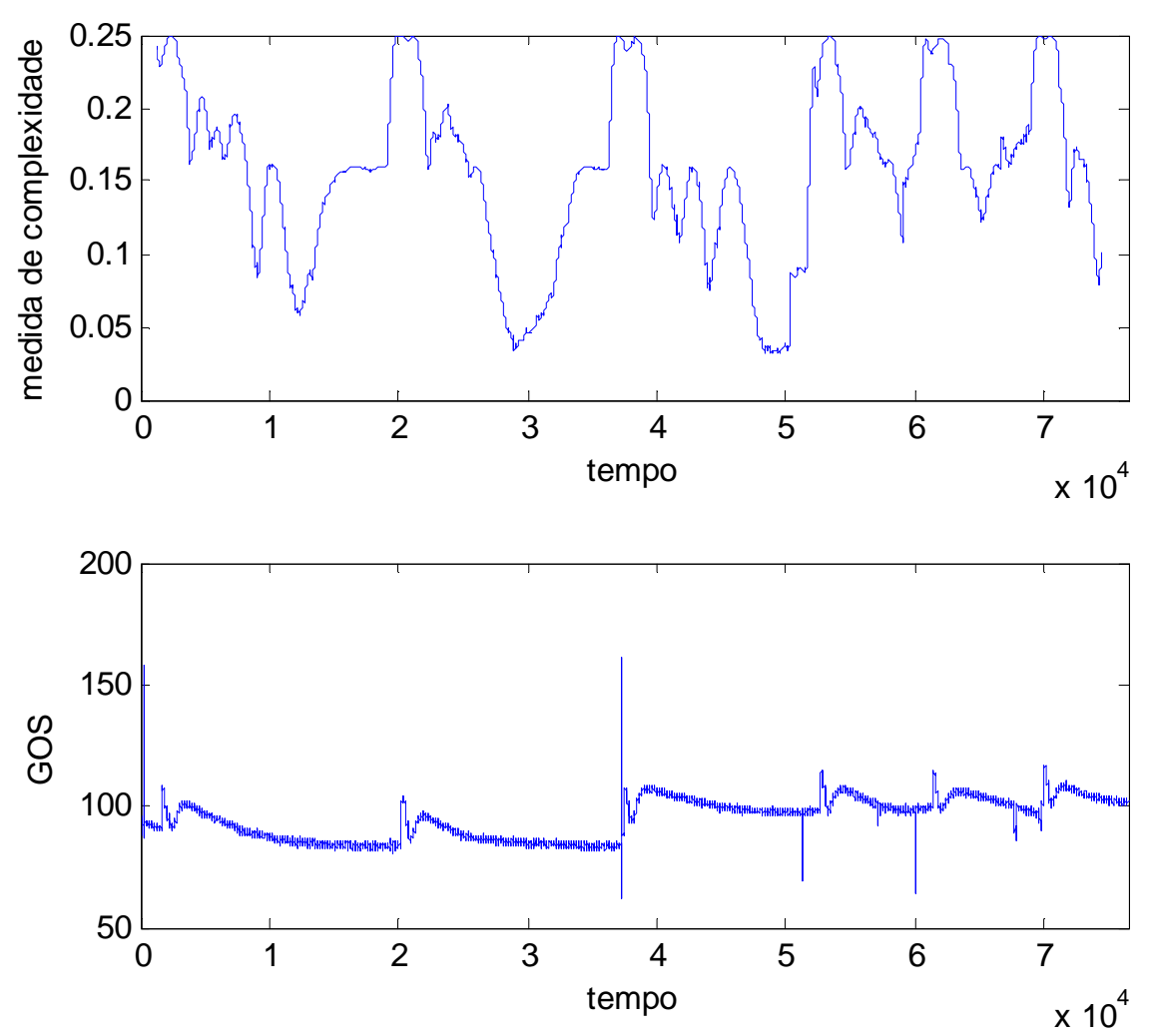

Figura 4.7 - Registros com protamina 2,5 $\mu \mathrm{g}$. (a) Registro do potencial extracelular e respectivo cálculo da complexidade. (b) Registro do IOS e respectivo cálculo da complexidade. (c) Registro do GOS e respectivo cálculo da complexidade.

A análise dos gráficos das medidas de complexidade dos registros ópticos obtidos no experimento feito com protamina 5,0 $\mu \mathrm{g}$ sugere que o aumento de massa produziu uma mudança qualitativa nos perfis ópticos. A complexidade calculada para as séries dos perfis ópticos apresentou valores máximos para as regiões relacionadas às atividades metabólicas, indicando que nesses trechos, há um equilíbrio entre a ordem e desordem do sistema, não sendo esse o comportamento observado para os experimentos com massas menores, como pode ser observado analisando as figuras 4.8 ( $b$ e c c). Nas regiões referentes às variações do potencial, caracterizadas pelo predomínio da ordem ou desordem, a complexidade apresenta uma queda. 

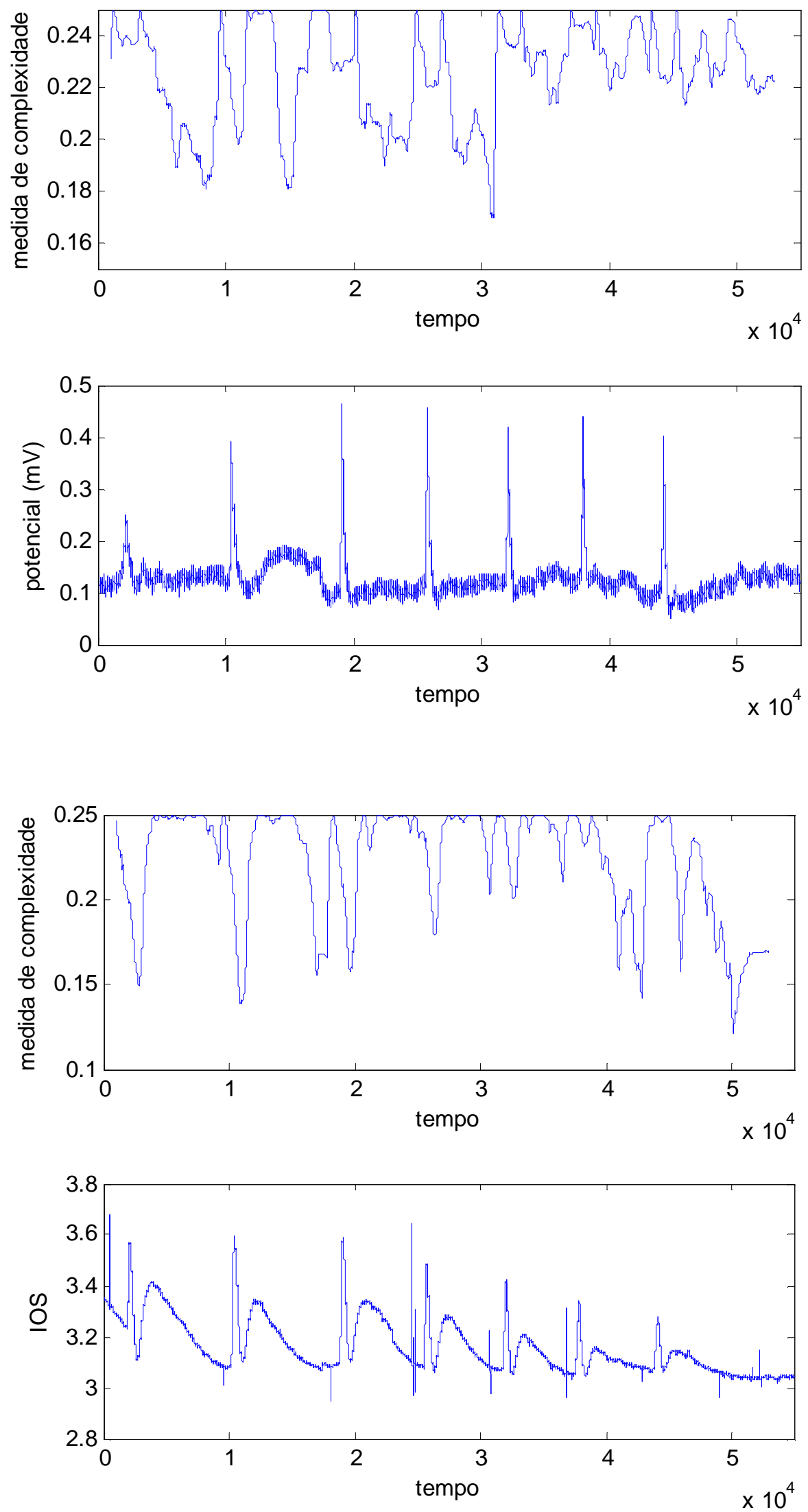

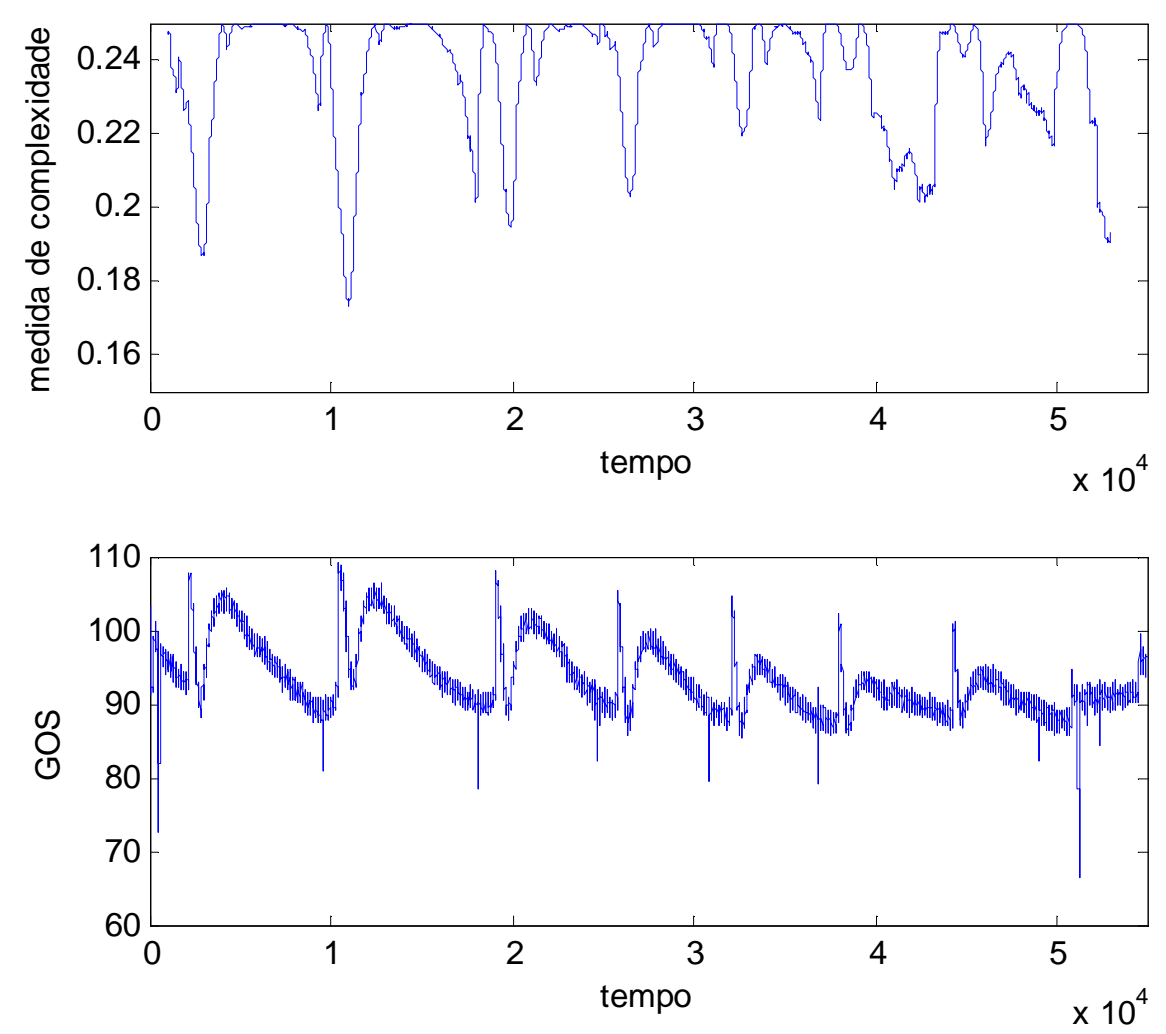

Figura 4.8 - Registros com protamina 5,0 $\mu \mathrm{g}$. (a) Registro do potencial extracelular e respectivo cálculo da complexidade. (b) Registro do IOS e respectivo cálculo da complexidade. (c) Registro do GOS e respectivo cálculo da complexidade.

\subsubsection{Ritalina}

Em parte dos experimentos, as ondas foram obtidas em presença de ritalina e foram realizados cinco experimentos. Para cada experimento, foram obtidos os registros do potencial e dos perfis ópticos e suas respectivas complexidades calculadas. A comparação entre os registros das ondas obtidas em presença de ritalina e as ondas de controle sugere algumas diferenças qualitativas, sendo a mais notória nos perfis ópticos em microescala, caracterizada pela presença da sequência de platôs após a região relacionada com a atividade metabólica. Esse comportamento associado à presença da ritalina contribui para o equilíbrio entre a ordem e desordem do sistema não só nesses trechos, mas no restante do registro, figura 4.9 (c). 
Outra diferença é observada ao analisar os registros em macroescala. Para as ondas de controle é possível observar que os gráficos das complexidades calculadas para os registros em micro e macroescalas possuem forte relação, sofrendo algumas alterações qualitativas nos trechos de pequenas oscilações do sinal, registradas no final do perfil. Nos registros obtidos em presença da ritalina, percebe-se pouca semelhança qualitativa entre os registros ópticos em escalas diferentes, sendo traduzido pelas diferenças na complexidade calculada.

A comparação entre as ondas obtidas em presença da ritalina mostra que para os registros do potencial é possível observar que a complexidade é máxima quando há equilíbrio entre a ordem e desordem do sistema. Pelas análises realizadas é possível notar que a variação brusca do potencial, mesmo aumentando a desordem ou ordem do sistema, contribui, juntamente com a ordem ou desordem, para o aumento da complexidade. Também é possível observar que pequenas variações nos sinais dos potenciais, produzem aumento significativo na medida de complexidade, mantendo a complexidade entre os valores de máximo e mínimo. 0 sistema apresenta complexidade mínima quando não há muita variação do potencial, indicando o predomínio da ordem ou desordem do sistema, como pode ser observado nas figuras 4.9 (a) e 4.10 (a).
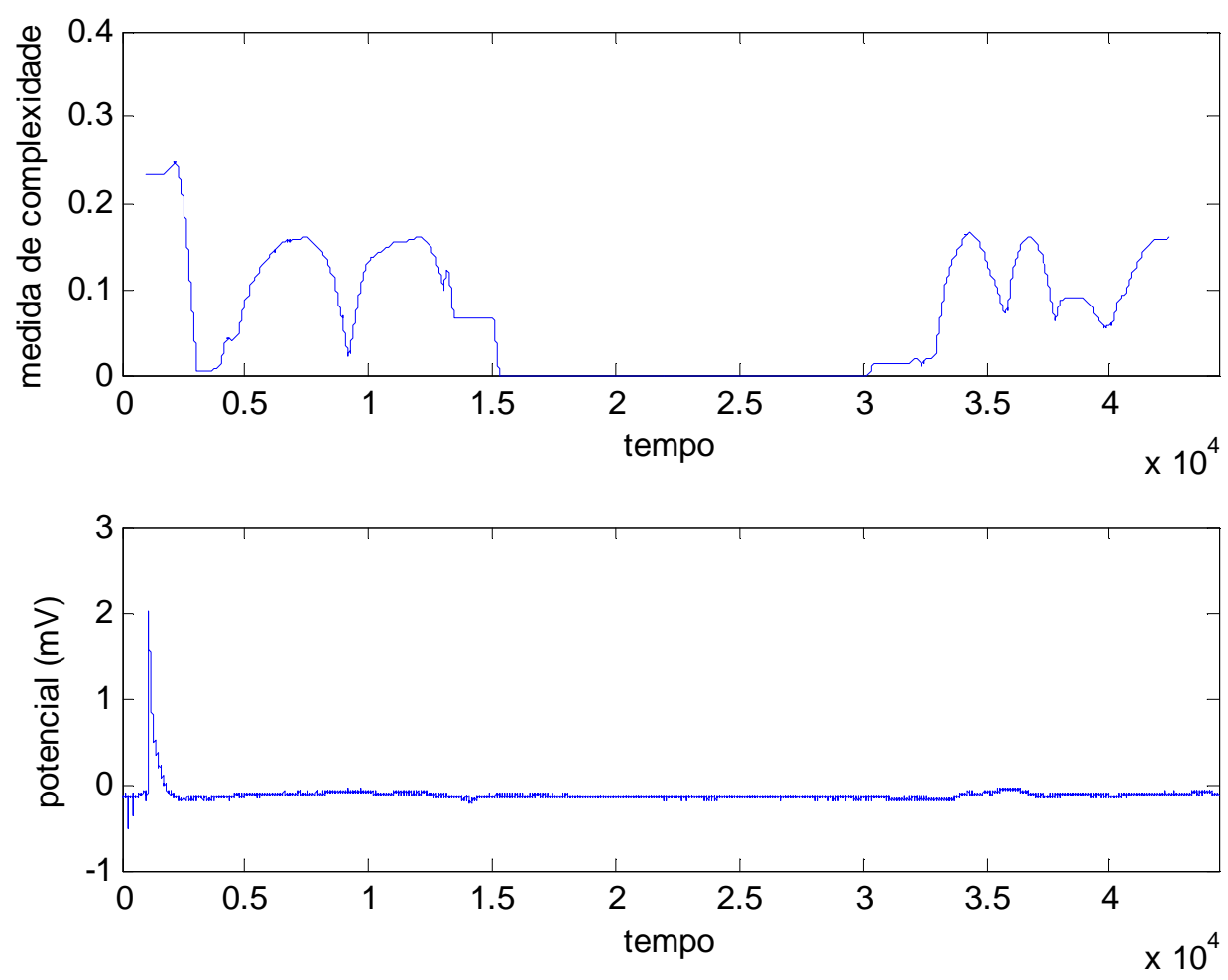

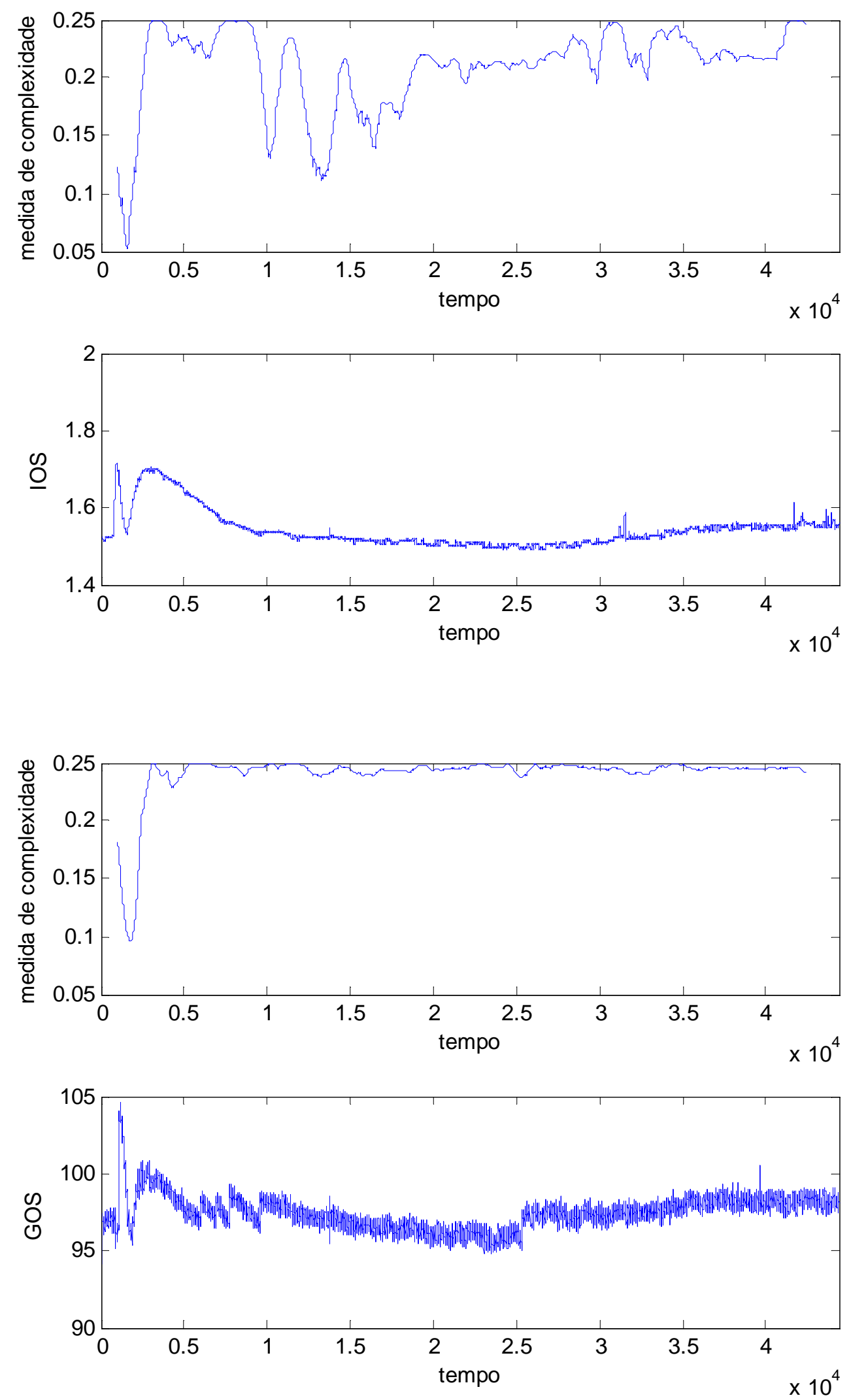

Figura 4.9 - Registros com ritalina. (a) Registro do potencial extracelular e respectivo cálculo da complexidade. (b) Registro do IOS e respectivo cálculo da complexidade. (c) Registro do GOS e respectivo cálculo da complexidade. 
Para os registros dos perfis ópticos em micro (GOS) e macroescalas (IOS) é possível observar algumas semelhanças qualitativas, como mostram as figuras 4.9 (b e c) e 4.10 (b e c). Para esses gráficos percebe-se a relação entre o potencial e o primeiro componente óptico do perfil e a relação entre a atividade metabólica e o segundo componente óptico do perfil, como explicado no capítulo 2. Percebem-se diferenças qualitativas ao analisar os respectivos gráficos das medidas de complexidade. Para os gráficos de IOS, a complexidade é máxima nos trechos em que o perfil óptico possui relação com a atividade metabólica, por ser caracterizado pelo equilíbrio entre ordem e desordem, e possui valores mínimos quando há uma brusca variação do sinal, caracterizado pelo primeiro pico registrado no perfil, que possui forte relação com o potencial, e nos trechos em que ocorre o predomínio da ordem ou da desordem do sistema, figuras 4.9 (b) e 4.10 (b).

Analisando os registros em microescala (GOS), percebe-se que a ritalina contribui para o aumento da complexidade em grande parte dos trechos que estão relacionados com respostas da atividade metabólica, sendo marcados pelo equilíbrio entre desordem e ordem e, após esse pico no perfil óptico, é possível observar que a complexidade é mantida nos valores máximos, indicando que o perfil é caracterizado pelo equilíbrio entre a ordem e desordem, figuras 4.9 (c) e 4.10 (c). A complexidade é mínima no trecho do perfil relacionado com a variação do potencial, cujo comportamento contribui para o aumento da ordem ou desordem. Nesses trechos de complexidade mínima, observa-se que o sinal varia de forma muito abrupta, enquanto que pequenas oscilações em torno de valores muito próximos contribuem para o aumento da complexidade. 

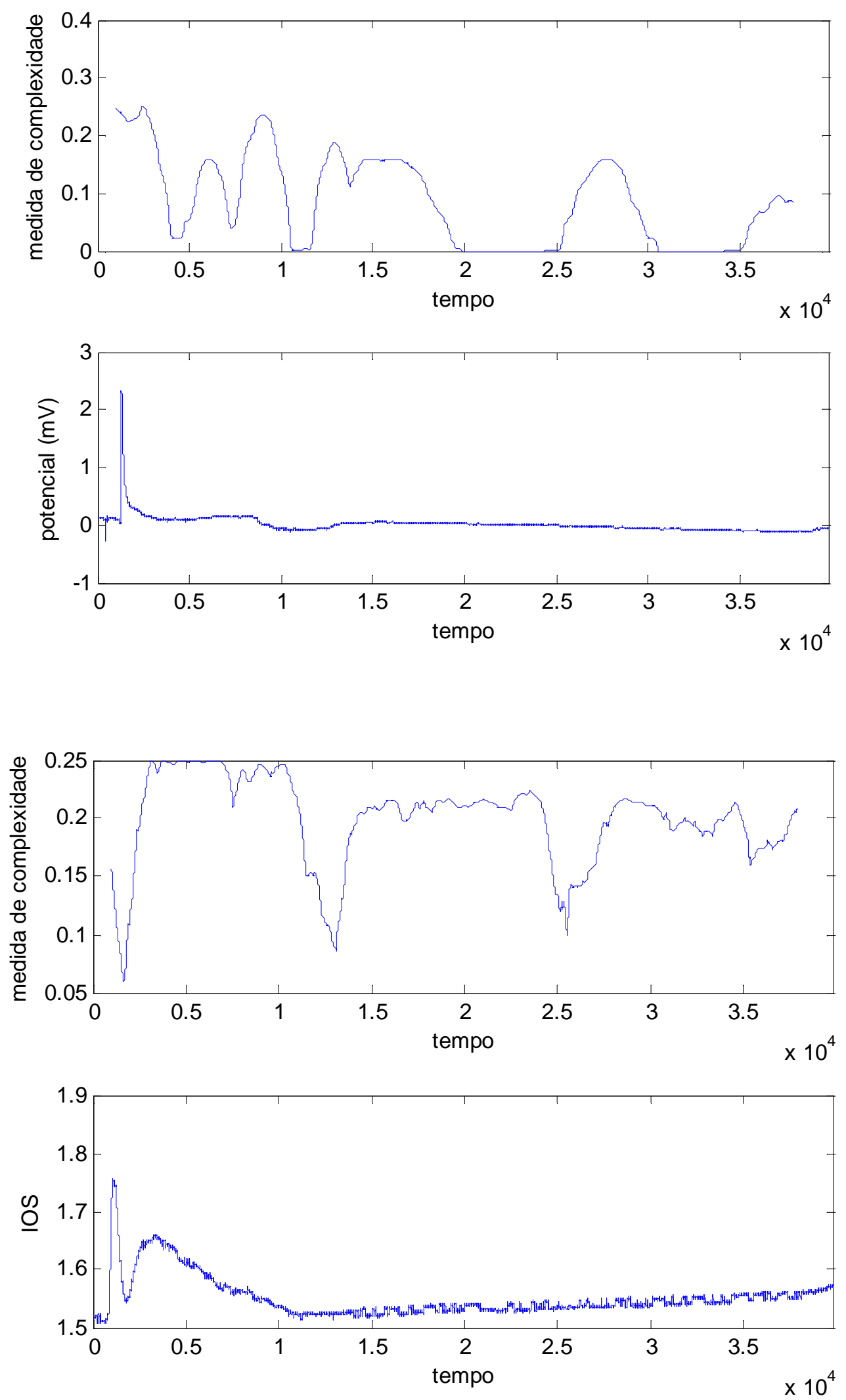

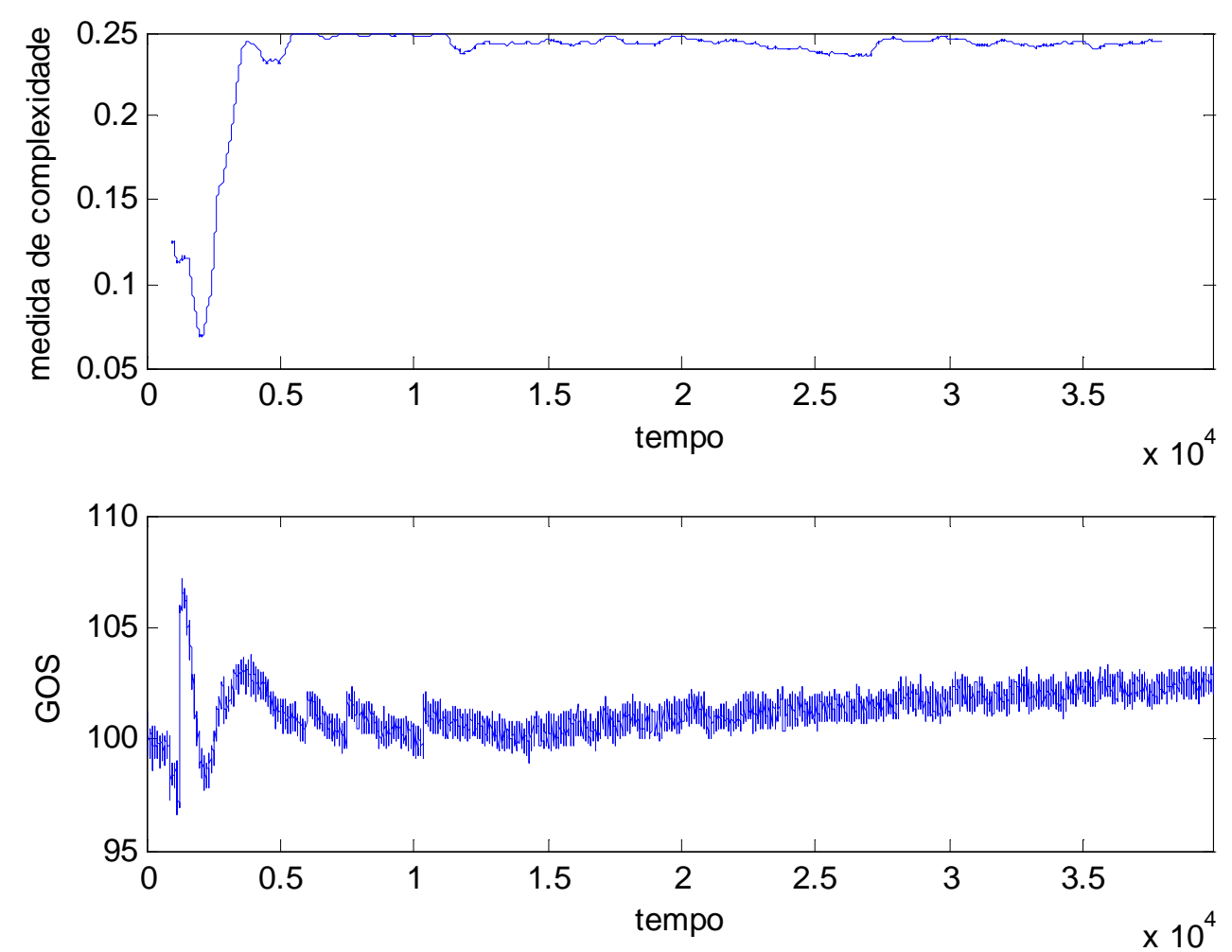

Figura 4.10 - Registros com ritalina. (a) Registro do potencial extracelular e respectivo cálculo da complexidade. (b) Registro do IOS e respectivo cálculo da complexidade. (c) Registro do GOS e respectivo cálculo da complexidade.

Dentre todos os registros obtidos dos experimentos, um deles, representado pela figura 4.11, chamou a atenção por apresentar todas as características descritas anteriormente, e por ser o único dos experimentos cujos registros ópticos, em micro e macroescalas apresentam semelhanças qualitativas, confirmadas pelos gráficos das medidas de complexidade, figuras 4.11 ( $\mathrm{b}$ e c), possibilitando a análise do sistema a partir de uma visão macroscópica. 

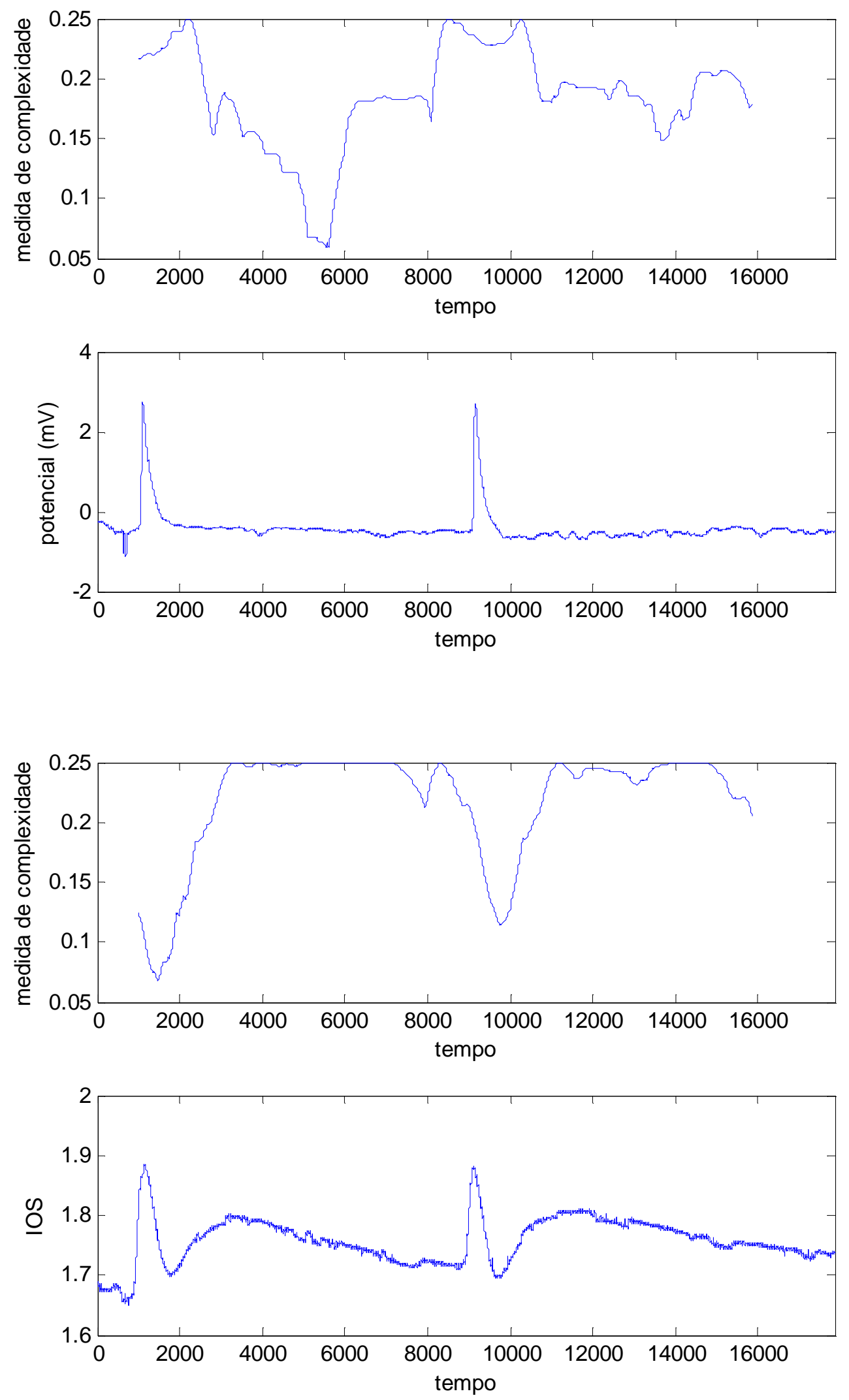

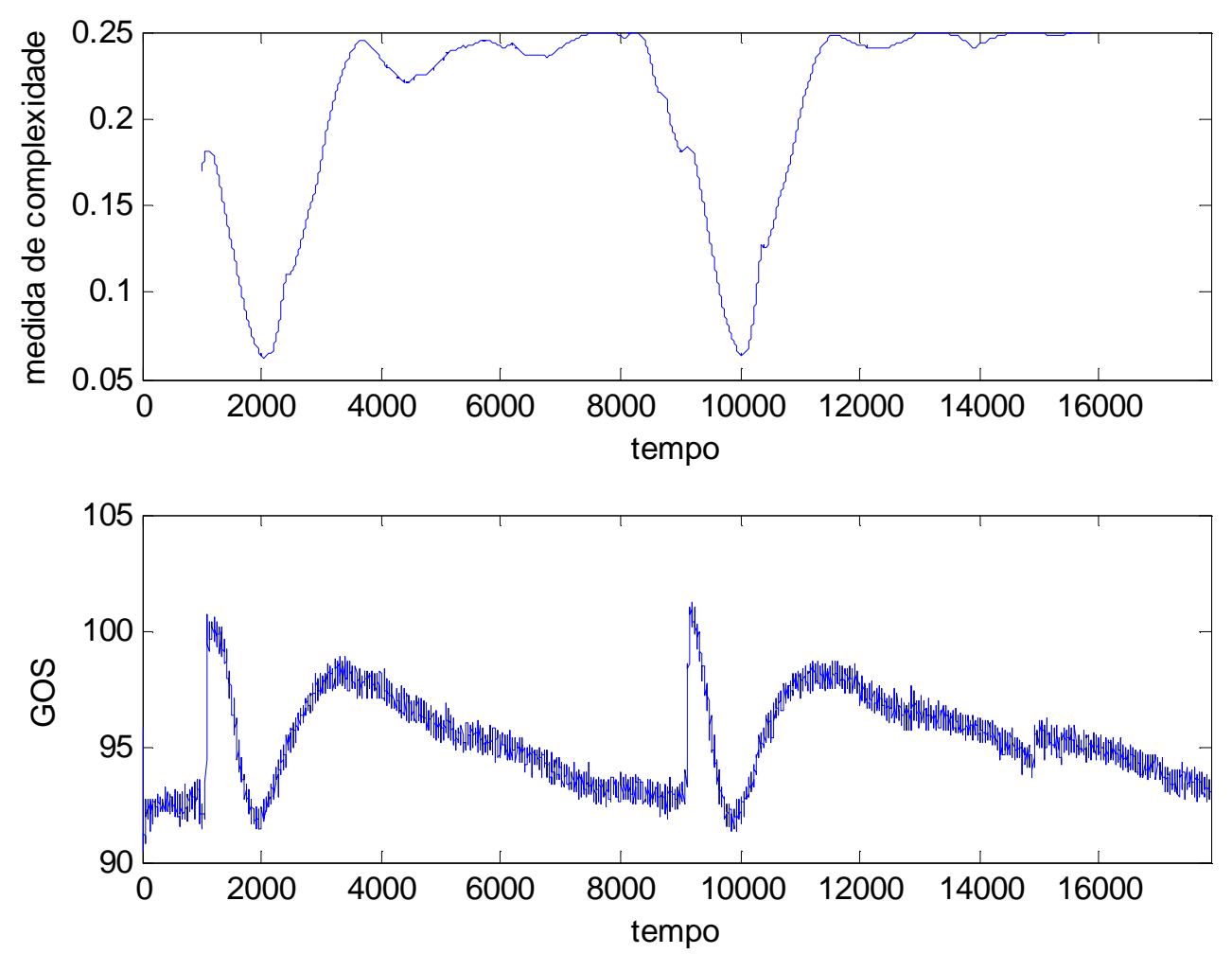

Figura 4.11 - Registros com ritalina. (a) Registro do potencial extracelular e respectivo cálculo da complexidade. (b) Registro do IOS e respectivo cálculo da complexidade. (c) Registro do GOS e respectivo cálculo da complexidade.

\subsubsection{Anfetamina}

Para o estudo do fenômeno de DA com anfetamina, foram realizados sete experimentos. As análises foram feitas observando-se as variações do potencial e dos perfis ópticos em micro e macroescalas.

Comparando-se as ondas de controle com as ondas obtidas em presença de anfetamina é notável uma diferença nos registros em microescalas na região caracterizada após o trecho do perfil relacionado com a atividade metabólica. Nos registros de controle observa-se que nessas regiões a complexidade é máxima enquanto nos registros de anfetamina esses valores diminuem, indicando que a anfetamina aumenta a ordem ou desordem durante o fenômeno, embora a característica qualitativa seja mantida. 
Outra diferença nos registros em microescala atribuída a presença da anfetamina é observada logo após a atividade metabólica representada por uma sequência de platôs que contribui para que a complexidade permaneça máxima. Característica essa que não é encontrada nos registros em macroescala e percebese que nessas regiões equivalentes a complexidade diminui, figuras 4.12 (b e c ).

A comparação entre os registros obtidos para as ondas de DA em presença de anfetamina mostra que para os registros do potencial, a variação abrupta desse sinal, contribui para o aumento da medida de complexidade. Na maior parte dos registros, os trechos caracterizados pelos picos de potencial, ou variações abruptas, são aqueles que apresentam complexidade máxima indicando que essas variações equilibram a ordem e desordem do sistema. Outras regiões dos registros que apresentam um comportamento relevante são aqueles cujas pequenas variações do potencial em torno de valores diferentes contribuem para que a complexidade permaneça entre valores próximos do máximo, indicando que essas pequenas oscilações adicionam ao sistema certo grau de ordem ou desordem contribuindo para a diminuição da complexidade. Nos trechos em que a variação do potencial é mínima, marcada pelo predomínio de organização ou desorganização total, a complexidade também o é, como pode ser observado analisando as figuras 4.12 (a) e $4.13(a)$. 

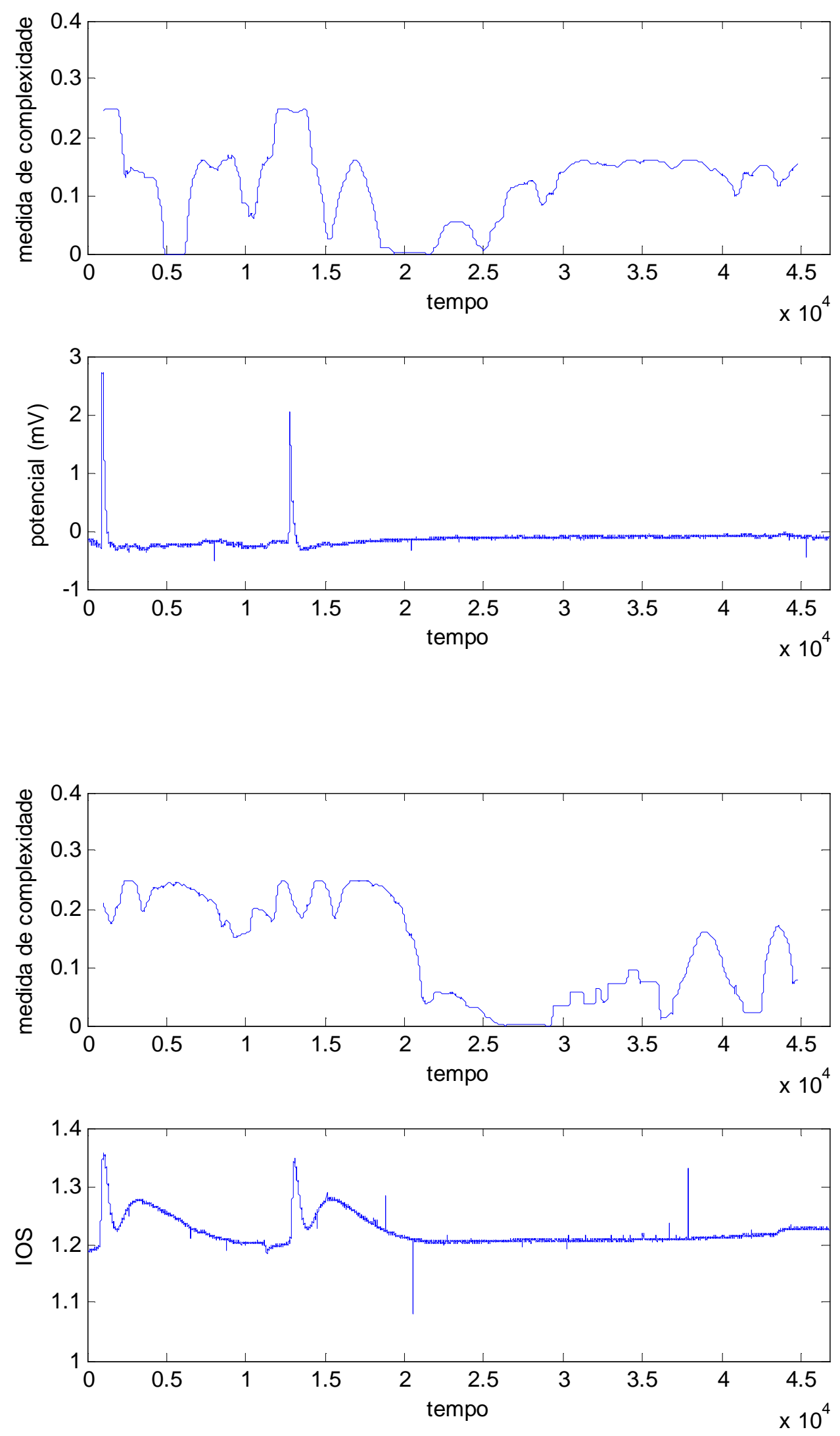

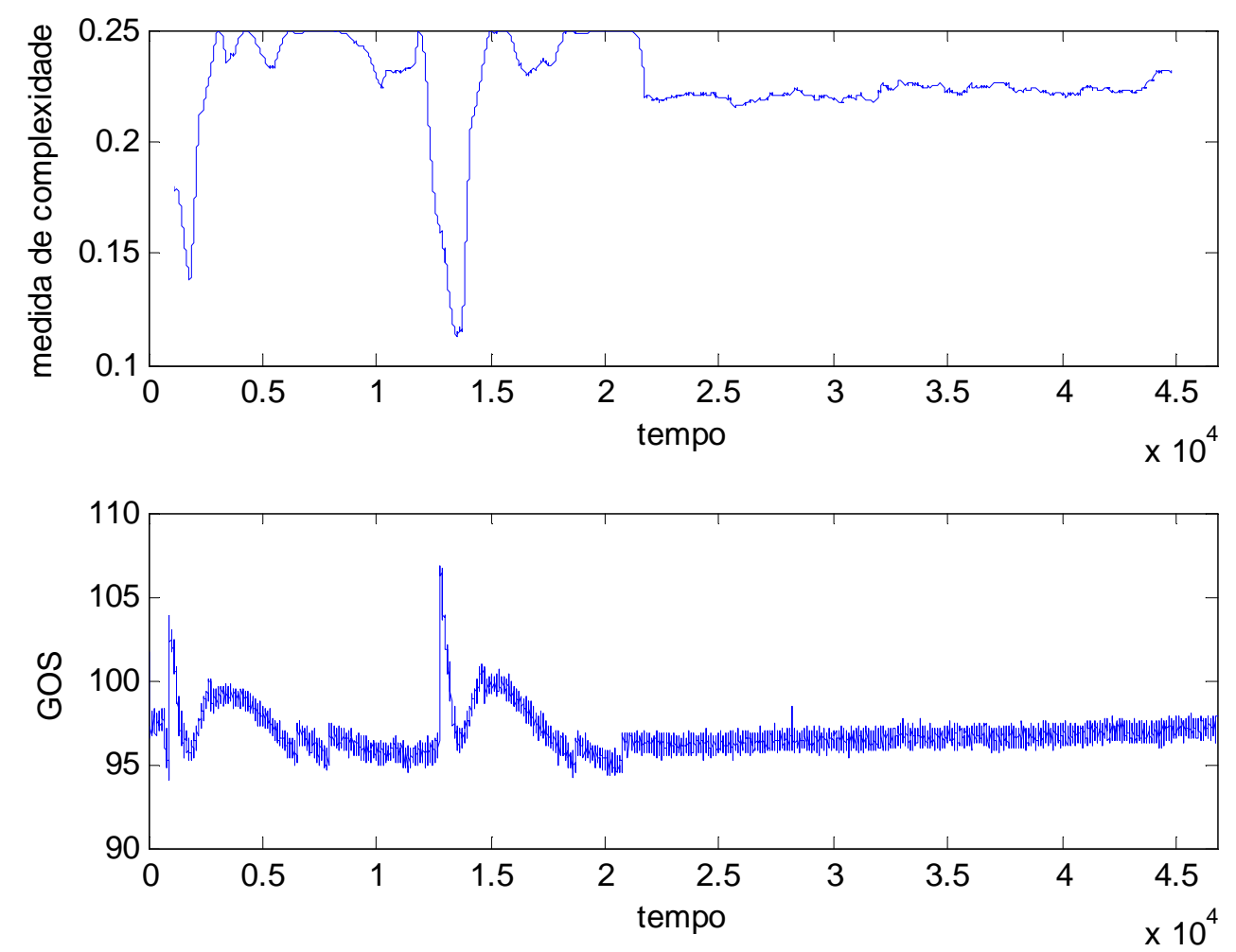

Figura 4.12 - Registros com anfetamina. (a) Registro do potencial extracelular e respectivo cálculo da complexidade. (b) Registro do IOS e respectivo cálculo da complexidade. (c) Registro do GOS e respectivo cálculo da complexidade.

Para os registros ópticos, percebe-se a relação do primeiro componente do perfil com o potencial e do segundo componente do perfil com a resposta metabólica, como descrito no capítulo 2. As semelhanças dos registros em micro e macroescalas são aparentes, como pode ser observados analisando-se as complexidades que apresentam comportamentos qualitativos distintos, figuras 4.12 (b e c) e 4.13 (b e c). 

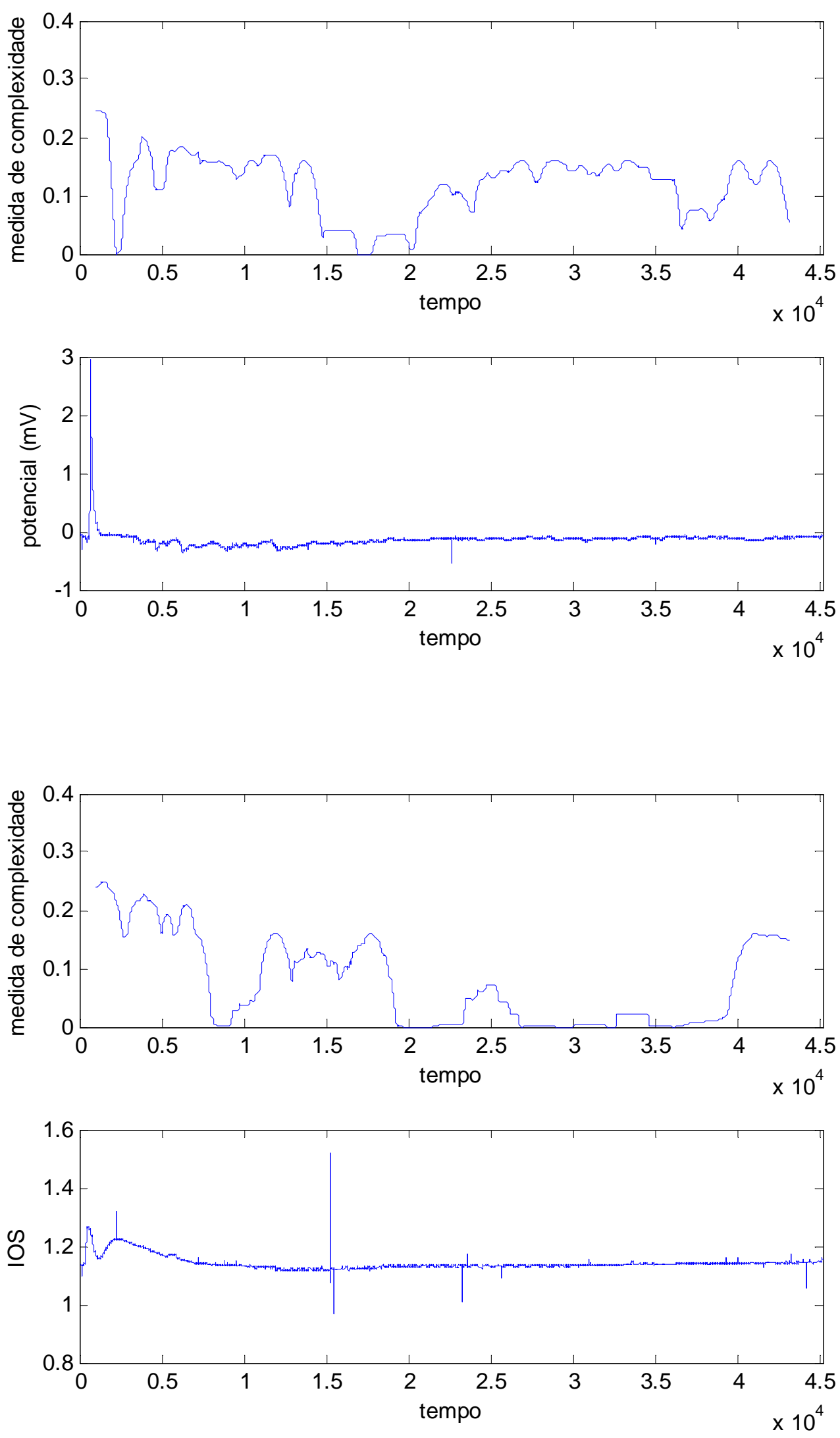

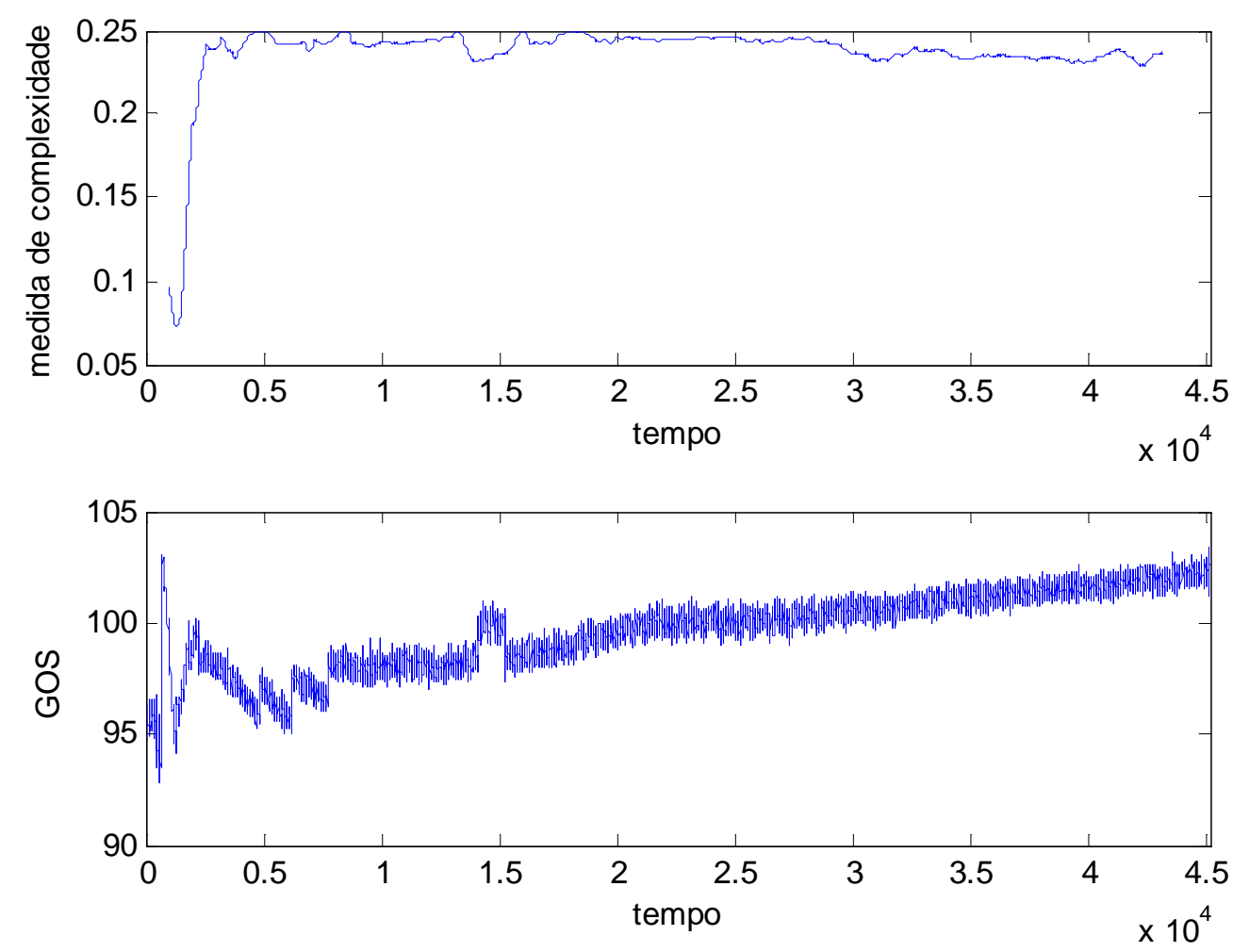

Figura 4.13 - Registros com anfetamina. (a) Registro do potencial extracelular e respectivo cálculo da complexidade. (b) Registro do IOS e respectivo cálculo da complexidade. (c) Registro do GOS e respectivo cálculo da complexidade.

Para os registros em macroescala (IOS), é possível observar que a complexidade é máxima nos trechos caracterizados pelas atividades metabólicas, mostrando que a anfetamina contribui para o equilíbrio da ordem e desordem do sistema, influenciando a resposta metabólica. Uma diminuição da medida de complexidade é observada nos trechos do perfil relacionados ao potencial, mostrando fortes indícios de que a variação abrupta do sinal óptico relacionado ao potencial contribui para o aumento da ordem ou desordem do sistema. Nos trechos dos registros com pouca variação do IOS, a complexidade é baixa, assumindo em alguns instantes valores extremos, marcados pelo alto grau de organização ou desorganização do sistema, figuras 4.12 (b) e 4.13 (b).

Para os registros em microescala (GOS), percebe-se que o trecho do perfil relacionado com o potencial contribui para a diminuição da medida de complexidade, possivelmente devido ao aumento da ordem ou desordem do sistema, enquanto o 
trecho do perfil relacionado à resposta metabólica é caracterizado pelo equilíbrio da ordem e desordem do sistema, contribuindo para que a complexidade seja máxima. Além disso, para os perfis registrados é possível observar que, após o pico relacionado com as atividades metabólicas, o sinal óptico em microescala apresenta pequenas variações que contribuem para que a medida de complexidade seja muito próxima do máximo, como pode ser observado nas figuras 4.12 (c) e 4.13 (c). Já nos trechos em que o sinal oscila em torno de valores muito próximos a complexidade diminui, embora permaneça com valores próximos do máximo, indicando que essa pouca variação contribui para que haja um aumento da ordem ou desordem do sistema.

\subsubsection{Cafeína}

Para o fenômeno de ondas de DA em presença de cafeína foram realizados nove experimentos e, a partir dos dados adquiridos, foram calculadas as respectivas medidas de complexidade.

Através da comparação dos registros das ondas de controle com os registros das ondas obtidas em presença de cafeína percebem-se diferenças nos perfis ópticos em microescalas com a presença dos platôs caracterizados nos registros de anfetamina. Diferentemente desses, a sequência de platôs não é tão bem definida. Essa mudança no perfil não altera qualitativamente a complexidade do sistema, pois a complexidade permanece máxima nesses trechos e no restante do registro.

Em um dos registros da cafeína não é notável a presença desses platôs e percebe-se que a influência da cafeína na resposta metabólica é alta, comportamento confirmado pelos altos valores de complexidade. Nesse mesmo registro, é possível notar que a complexidade deixa de ser máxima devido à ausência desse comportamento.

A comparação entre os registros obtidos das variações do potencial das ondas obtidas em presença da cafeína indica que quando esse sinal varia bruscamente, há um aumento na medida de complexidade, sendo que em muitas 
das medições a complexidade calculada apresentou o valor máximo nesses trechos. A complexidade calculada apresenta-se mínima em trechos nos quais o potencial possui variações pequenas, indicando o predomínio da ordem ou desordem do sistema.

Observando os resultados da figura 4.14 (a), pode-se notar que essa variação brusca do potencial não é o único fator responsável pelo aumento da complexidade, pois em outros trechos, a complexidade também apresenta valores altos sem a presença desse comportamento. Nesses trechos, caracterizados pela variação do potencial em torno de valores diferentes, a complexidade assume valores intermediários, indicando que essa característica tende a equilibrar a ordem e a desordem do sistema, ocorrendo efetivamente nos trechos de pico de potencial ou das variações abruptas.
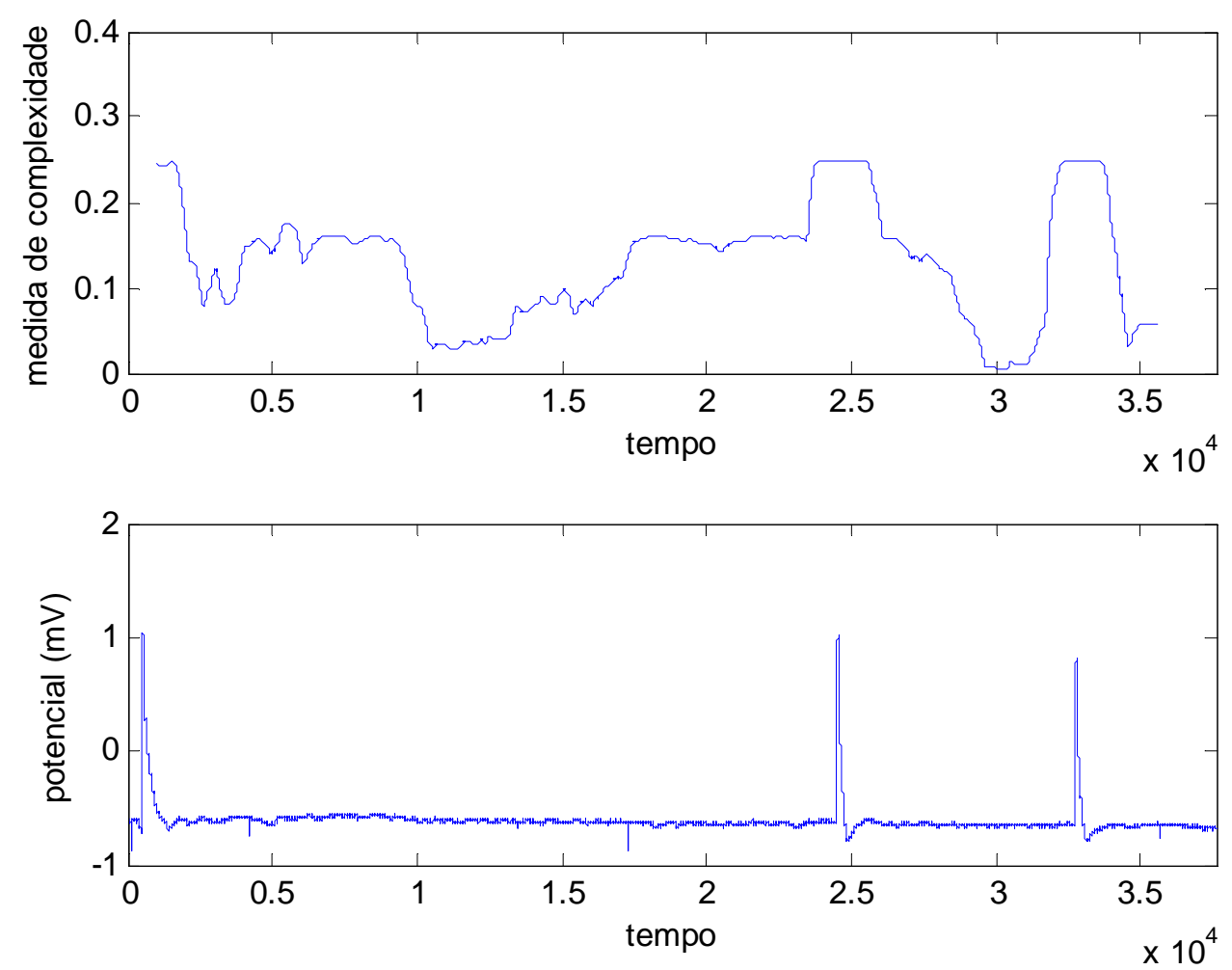

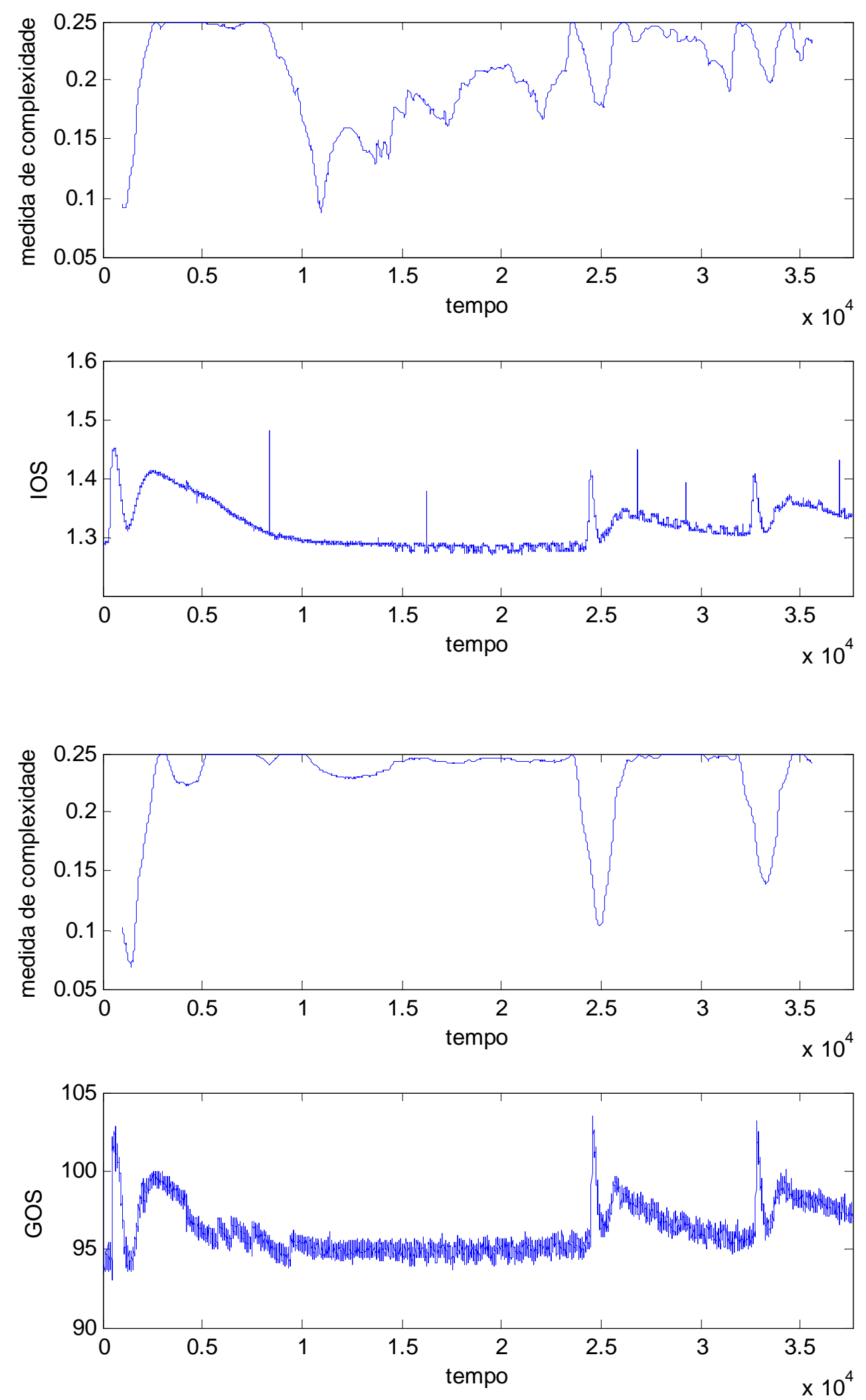

Figura 4.14 - Registros com cafeína. (a) Registro do potencial extracelular e respectivo cálculo da complexidade. (b) Registro do IOS e respectivo cálculo da complexidade. (c) Registro do GOS e respectivo cálculo da complexidade. 
Nos registros obtidos de IOS, é possível identificar os trechos relacionados aos perfis correspondentes ao potencial e a resposta da atividade metabólica, conforme descrito no capítulo 2. Para os picos relacionados com a variação do potencial, nota-se que a complexidade diminui, não sendo essa variação a responsável pelas menores medidas de complexidade. A menor complexidade calculada refere-se, muitas vezes, aos trechos entre o primeiro e o segundo componente do perfil óptico e, em outros registros, às situações em que o sinal óptico oscila em torno de valores próximos. Para o trecho do perfil relacionado à atividade metabólica, percebe-se um aumento da complexidade podendo, em alguns trechos atingir, o valor máximo da medida de complexidade, figura 4.14 (b), indicando que a influência da cafeína no fenômeno contribui para o equilíbrio entre a ordem e desordem do sistema relacionando-se com a atividade metabólica.

Para os gráficos GOS, ou seja, em microescala, é possível estabelecer a relação do potencial com o primeiro componente do perfil óptico e das respostas das atividades metabólicas com o segundo componente do perfil óptico como esperado. Para o primeiro componente do perfil que apresenta relação com a variação do potencial e para os trechos entre o primeiro e o segundo componente do perfil óptico, observa-se que a complexidade diminui, sendo esses componentes responsáveis pelos menores valores calculados da complexidade, como mostra a figura 4.14 (c), indicando que essas variações abruptas do sinal óptico contribuem para o aumento da ordem ou da desordem do sistema. Quanto ao componente relacionado à atividade metabólica, percebe-se um aumento da complexidade, sendo em muitos trechos máxima, indicando que a cafeína influência nas respostas metabólicas, produzindo um equilíbrio entre a ordem e desordem do sistema, que é mantido nos trechos após a resposta metabólica. Nesses trechos, caracterizados por uma sequência platôs, percebe-se que essas oscilações do sinal óptico, contribuem para que o equilíbrio continue prevalecendo ao longo do registro.

A diferença qualitativa entre os gráficos de complexidade em micro e macroescalas é notável, principalmente nas regiões do registro após o pico relacionado com a resposta da atividade metabólica. Nos gráficos em microescala, ou GOS, a complexidade permanece máxima nesses trechos caracterizados pela presença dos platôs, enquanto nos registros em macroescala, representado pelo 
IOS, a complexidade é máxima nos trechos da resposta metabólica e, após essas respostas, a complexidade oscila entre os valores de mínimo e máximo, com pode ser observado comparando-se as figuras 4.14 (b) e 4.14 (c).

Para alguns dos experimentos realizados, observa-se um comportamento diferente do relatado anteriormente, como mostram as figuras 4.15. Para esses perfis, percebe-se uma semelhança qualitativa entre os registros em micro e macroescalas.
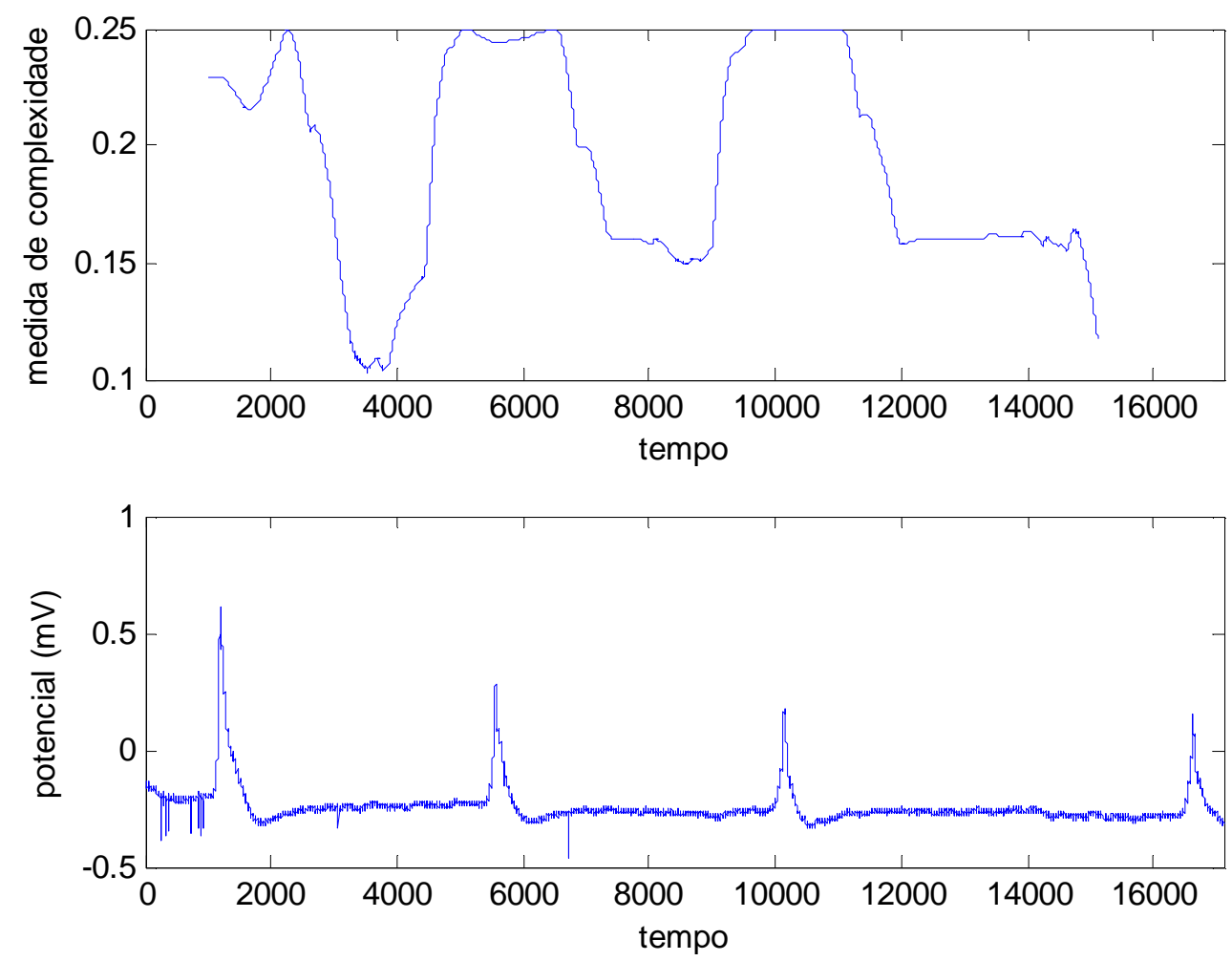

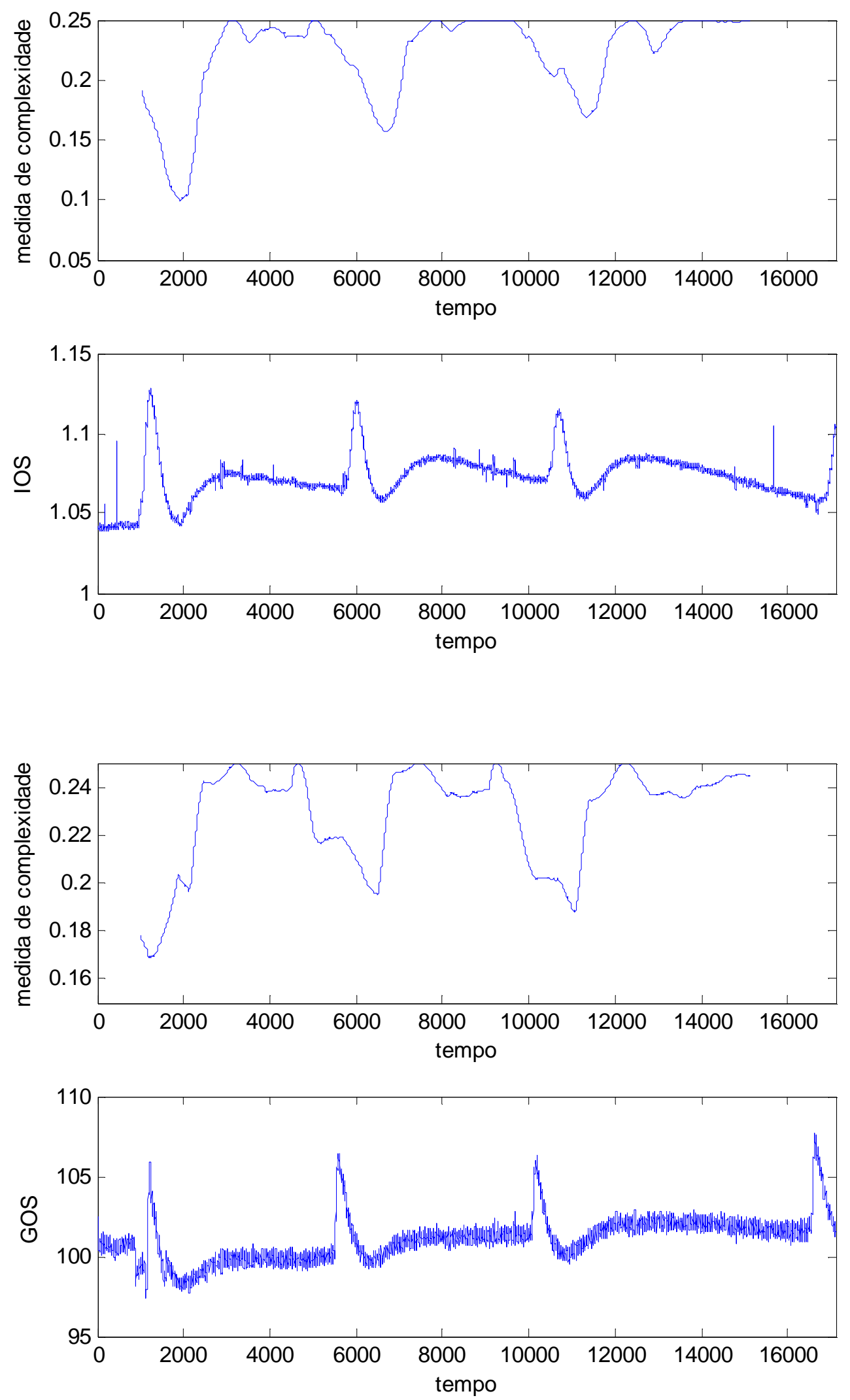

Figura 4.15 - Registros com cafeína. (a) Registro do potencial extracelular e respectivo cálculo da complexidade. (b) Registro do IOS e respectivo cálculo da complexidade. (c) Registro do GOS e respectivo cálculo da complexidade. 
Para esses experimentos, percebe-se que as maiores medidas de complexidade relacionadas aos registros de potencial, ocorrem nos trechos de variações abruptas, como nos anteriores, e que aparentemente, essas variações são responsáveis pelo equilíbrio entre a ordem, e desordem do sistema (figura 4.15 (a)). A diferença qualitativa entre os perfis está relacionada aos registros ópticos que tanto em micro quanto em macroescalas indicam que as menores medidas de complexidade estão relacionadas com o comportamento dos trechos entre 0 primeiro e o segundo componente do perfil óptico, mostrando que essas variações ópticas contribuem para o aumento da ordem ou desordem do sistema. As maiores complexidades estão relacionadas aos trechos em que o sinal óptico apresenta oscilações em torno de valores próximos, indicando que esse comportamento equilibra a ordem e a desordem do sistema (figuras 4.15 (b e c)). Como os dois registros ópticos possuem comportamento qualitativo semelhante, existe a possibilidade da análise do sistema a partir de uma visão macro, para a aferição do comportamento em microescala.

\subsubsection{Cocaína}

Para estudar as respostas do fenômeno de ondas de DA em presença de cocaína, foram realizados oito experimentos cujos registros do potencial e das medidas em micro e macroescalas foram usadas para calcular as respectivas complexidades.

Comparando-se os registros das ondas de controle e das ondas obtidas em presença de cocaína notam-se diferenças nos registros ópticos em microescalas. Dos registros obtidos, cinco deles, apresentam a sequência de platôs, descritas anteriormente, após a região relacionada às atividades metabólicas e é possível observar através das análises dos respectivos gráficos de medidas de complexidade que esse comportamento aumenta o equilíbrio entre a ordem e desordem do sistema. Os registros que não apresentam esse diferencial e que possuem o 
comportamento das ondas de controle, não possuem complexidade máxima nessas regiões, mesmo ela assumindo valores altos.

Através da comparação entre as ondas obtidas em presença de cocaína e analisando-se os registros do potencial, observa-se que, quando o potencial apresenta pequenas variações em torno de um mesmo valor, a complexidade diminui e, em muitas simulações, é possível notar que é até mínima, prevalecendo a ordem ou desordem do sistema em estudo. A complexidade aumenta quando o potencial medido apresenta pequenas variações em torno de valores diferentes e quanto mais abrupta essa variação, maior a complexidade, ressaltando-se que essa grandeza apresenta valores máximos nos picos do potencial, indicando que essa variação contribui para o equilíbrio da ordem e desordem do sistema estudado, como pode ser observado na figura 4.16 (a).
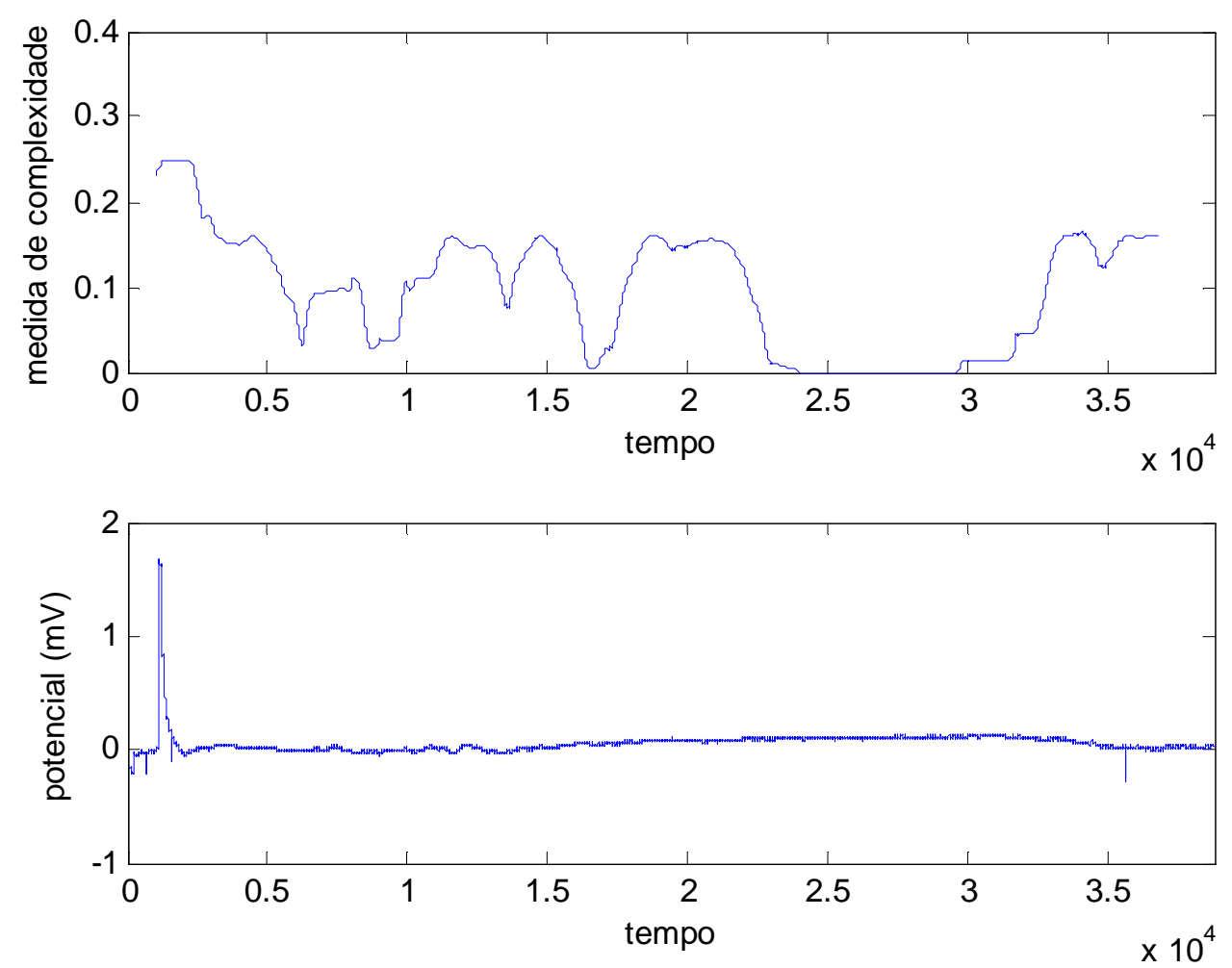

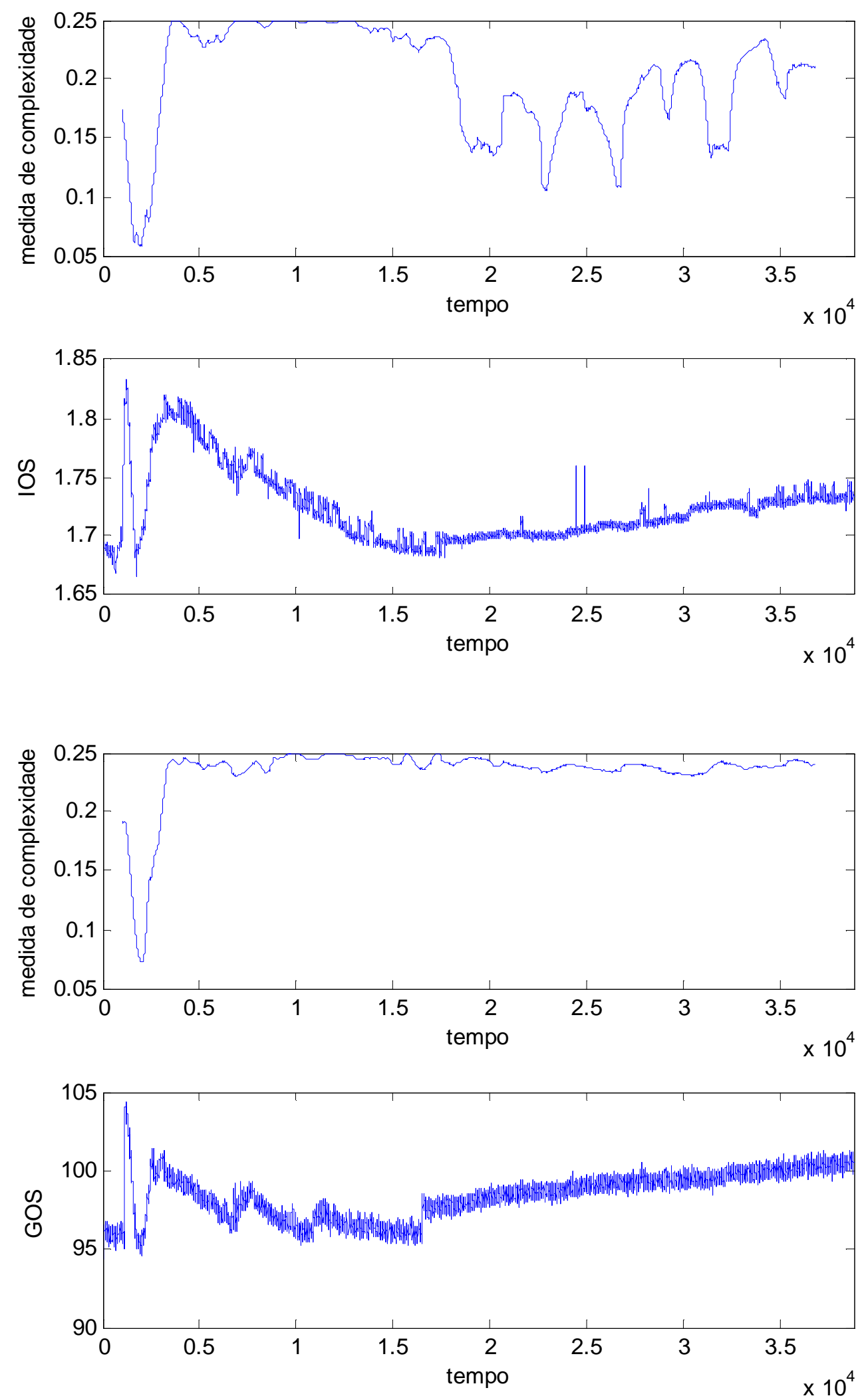

Figura 4.16 - Registros com cocaína. (a) Registro do potencial extracelular e respectivo cálculo da complexidade. (b) Registro do IOS e respectivo cálculo da complexidade. (c) Registro do GOS e respectivo cálculo da complexidade. 
Para os registros obtidos em macroescala (IOS), percebe-se que, na região do perfil relacionada com o potencial, a complexidade diminui devido às bruscas variações do sinal óptico para esse componente. Na região do perfil relacionada à atividade metabólica, em que o sinal varia em torno de valores diferentes e próximos, a complexidade é máxima indicando que há equilíbrio entre ordem e desordem do sistema. No restante do registro, em que o sinal óptico varia em torno de valores muito próximos, nota-se que há uma diminuição da medida de complexidade, indicando que essa oscilação contribui para o aumento da ordem ou desordem do sistema, figura 4.16 (b).

Para os gráficos de GOS, ou seja, dos registros em microescala, é possível identificar os perfis relacionados ao potencial e a resposta metabólica, conforme a descrição feita no capítulo 2. Para o pico relacionado ao potencial, percebe-se que o sinal óptico sofre uma brusca variação, que é traduzida por uma diminuição da medida de complexidade, caracterizando o predomínio da ordem ou desordem. No entanto, para a parte do perfil relacionada à atividade metabólica, nota-se que a variação do sinal contribui para que a complexidade seja alta e muitas vezes até máxima, indicando que a cocaína contribui para o equilíbrio entre a ordem e desordem do sistema, em resposta às atividades metabólicas, conforme mostra a figura 4.16 (c). No restante do registro, observa-se que a variação do sinal em torno de valores diferentes e muito próximos contribui para que a complexidade continue com valores altos, caracterizando uma diferença qualitativa dos registros em macroescalas.

\subsubsection{Nicotina}

Para estudar as características do fenômeno de ondas de DA em presença de nicotina foram realizados treze experimentos e adquiridos os valores das variações do potencial extracelular e dos sinais ópticos em micro e macroescalas. Com esses registros foram traçados os respectivos gráficos e suas complexidades foram calculadas. 
A análise comparativa dos registros de ondas obtidas em presença de nicotina apresenta um comportamento qualitativo diferente das ondas obtidas em presença de nicotina, anfetamina, cocaína e cafeína. Nos registros em microescalas, não ocorre a sequência de platôs descritas anteriormente. Para as ondas obtidas em presença de nicotina é possível observar que os registros nessa escala são semelhantes ao das ondas de controle e que mesmo na ausência dessa influência após a influência metabólica, a complexidade é alta e em muitos trechos é máxima.

Comparando-se os registros obtidos do potencial das ondas em presença de nicotina, observa-se que nos trechos em que ocorrem pequenas oscilações dos valores em torno de valores muito próximos, a complexidade calculada diminui. Nas regiões dos registros em que ocorrem oscilações das medidas do potencial em torno de valores diferentes e próximos, observa-se que a complexidade aumenta e é máxima em muitos trechos do registro, indicando que essas variações equilibram a ordem e desordem do sistema, figuras 4.17 (a) e 4.18 (a).
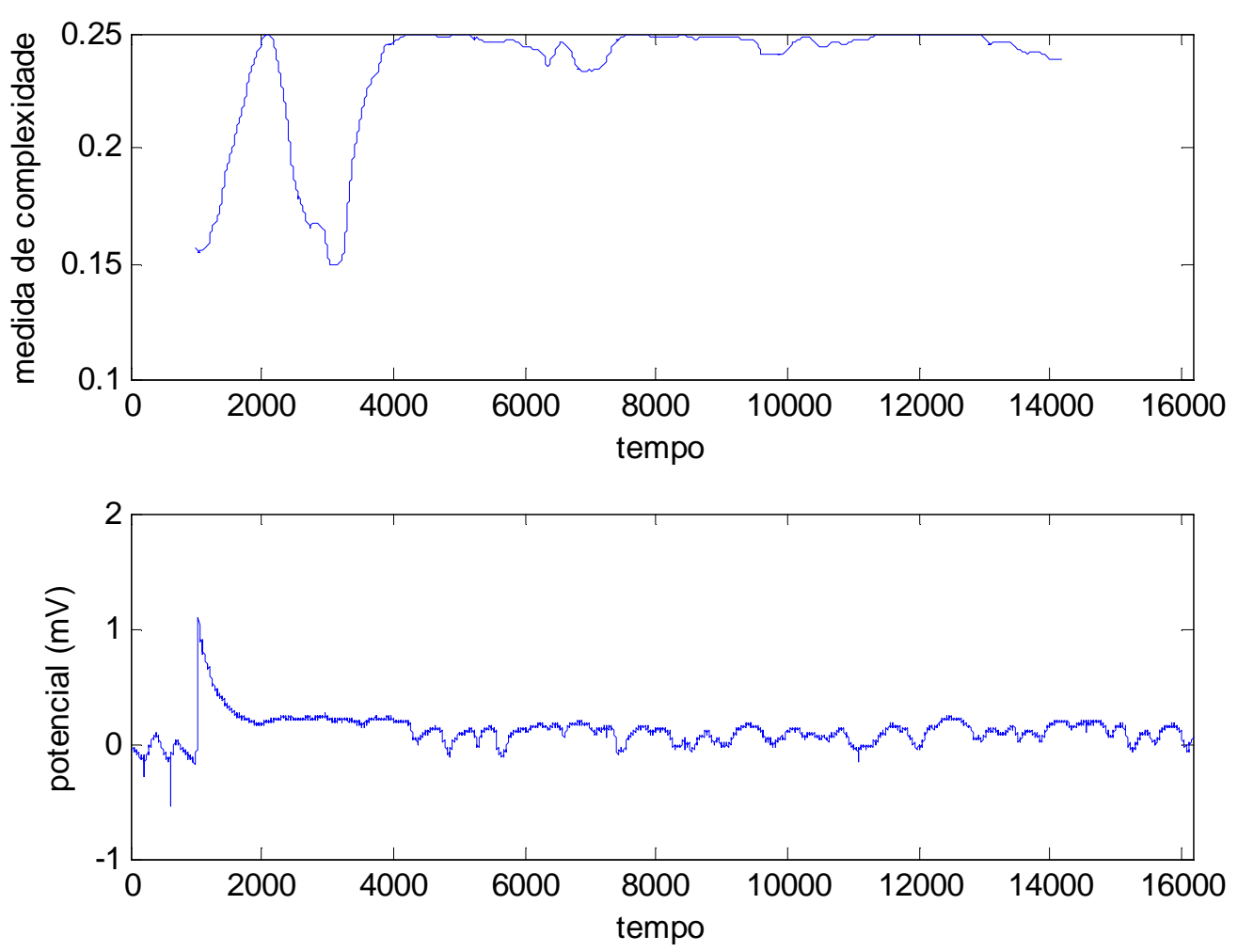

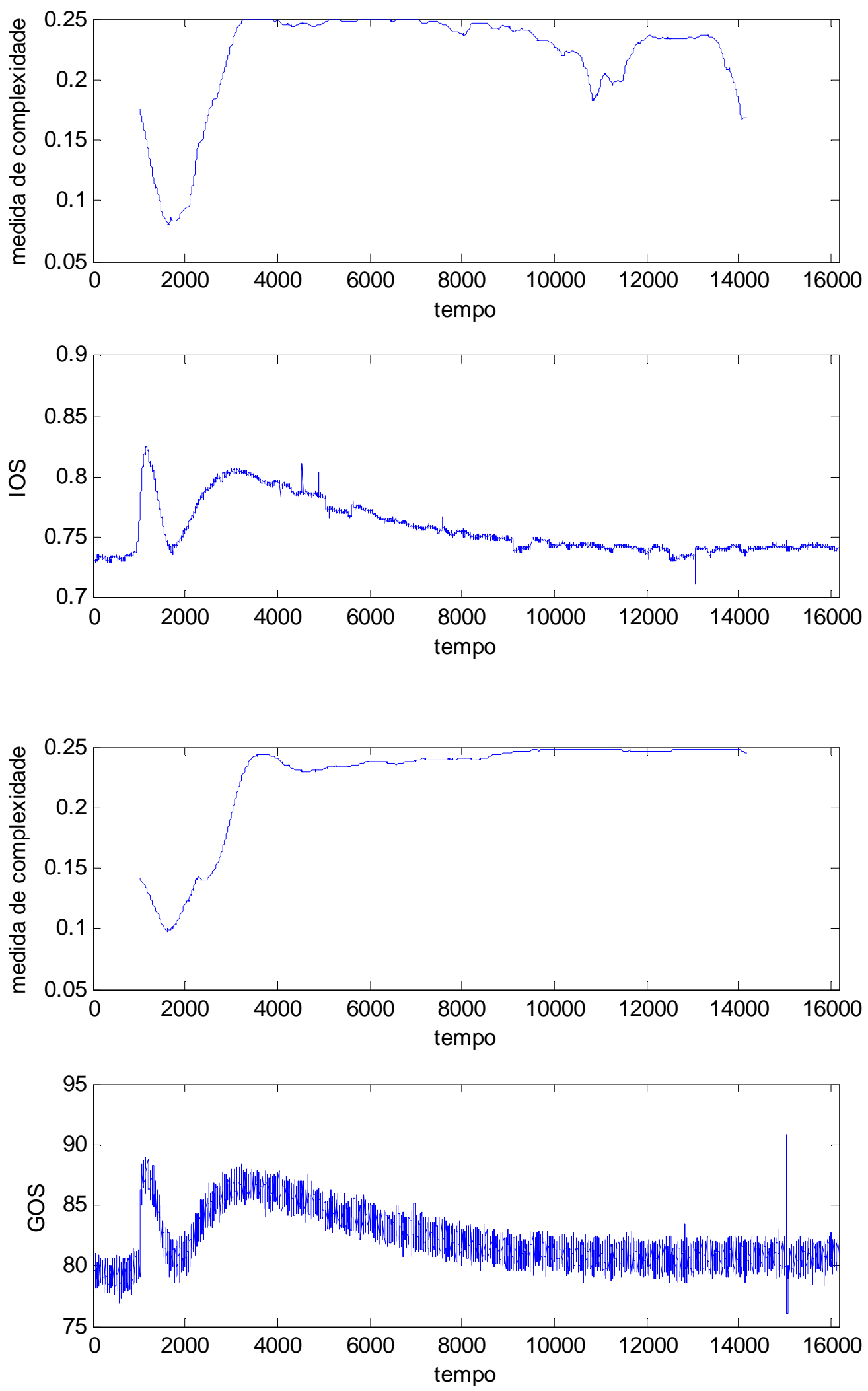

Figura 4.17 - Registros com nicotina. (a) Registro do potencial extracelular e respectivo cálculo da complexidade. (b) Registro do IOS respectivo cálculo da complexidade. (c) Registro do GOS respectivo cálculo da complexidade. 
Para a análise da influência da variação abrupta do potencial, é necessário observar o comportamento do conjunto de dados dos registros nessa região. Quando a variação abrupta da medida do potencial é precedida por um conjunto de valores que oscilam em torno de valores diferentes, observa-se que a complexidade do sistema aumenta, indicando que há equilíbrio entre ordem e desordem, como mostra figura a 4.17 (a). Por outro lado, para os registros em que a variação abrupta do potencial é precedida por um conjunto de dados que oscilam em torno de valores muito próximos, a complexidade tende a diminuir, indicando que houve predomínio de ordem ou desordem, como mostra a figura 4.18 (a). Essas análises mostram que o pico do potencial ou mudança abrupta desse sinal contribui para o aumento da complexidade.
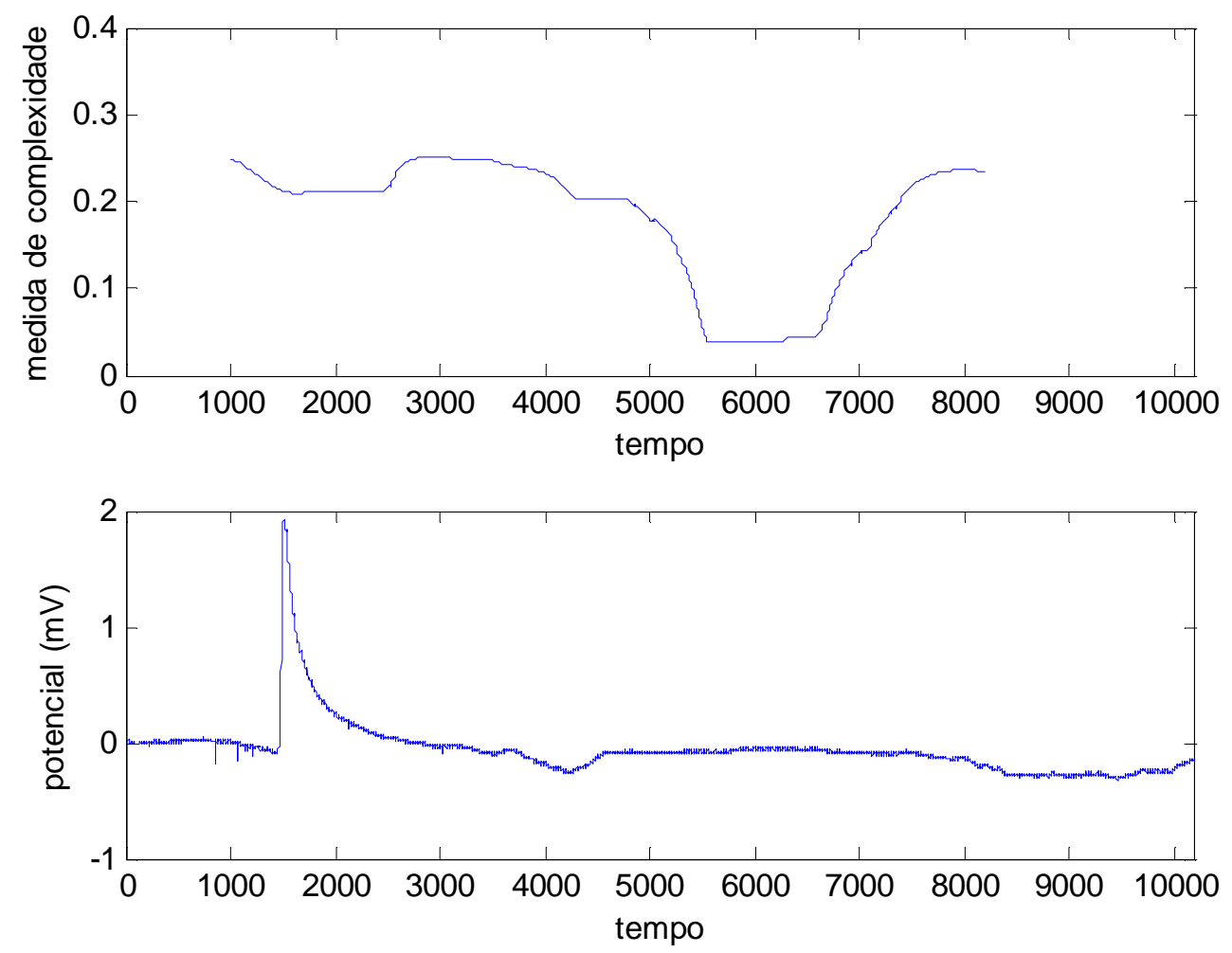

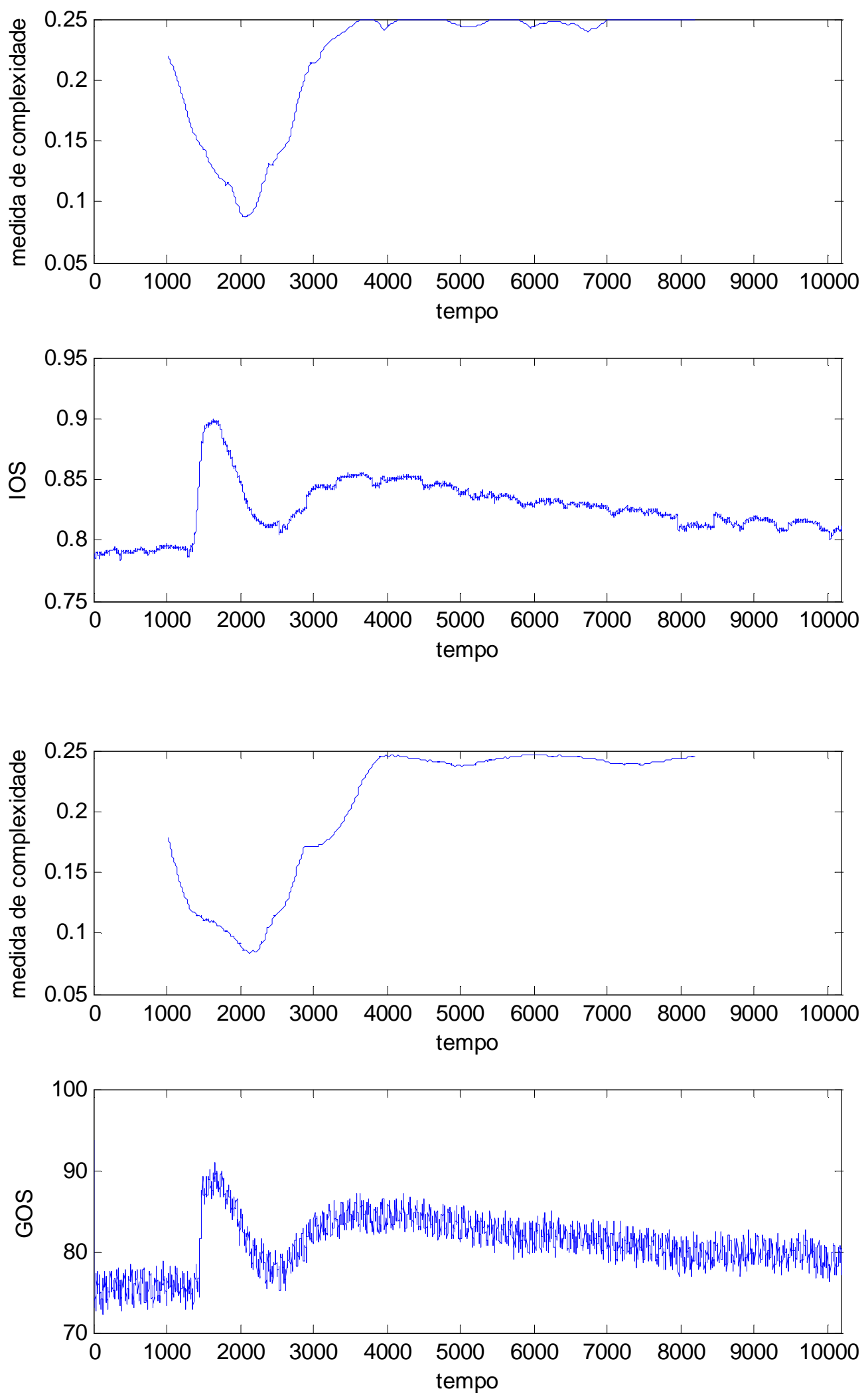

Figura 4.18 - Registros com nicotina. (a) Registro do potencial extracelular e respectivo cálculo da complexidade. (b) Registro do IOS e respectivo cálculo da complexidade. (c) Registro do GOS e respectivo cálculo da complexidade. 
Pela análise dos registros em macroescala, representados pelas figuras 4.17 (b) e 4.18 (b), percebe-se fortemente a relação do perfil registrado com o potencial e a resposta metabólica, como descrito no capítulo 2. Para a parte do perfil relacionado ao potencial, percebe-se que, quando ocorre essa variação de sinal óptico, a complexidade diminui, indicando o predomínio da ordem ou desordem. Para o perfil relacionado à atividade metabólica, percebe-se um aumento da complexidade podendo, em alguns trechos, atingir o valor máximo da medida de complexidade. Na região após a resposta metabólica, o perfil óptico é descrito por trechos cujos sinais oscilam em torno de valores diferentes e próximos que caracterizam uma complexidade alta e muitas vezes até máxima, mostrando que essa variação contribui para o equilíbrio da ordem e desordem do sistema.

Analisando-se os gráficos em microescala, também é possível observar o perfil relacionado ao potencial e à resposta metabólica. A análise dos registros sugere que a variação brusca do sinal óptico relacionado ao pico do potencial é traduzida pela diminuição da medida de complexidade e, nos trechos relacionados à atividade metabólica, em que a oscilação do sinal ocorre em torno de valores muito próximos, a complexidade é máxima, indicando que a nicotina contribui para o equilíbrio da ordem e desordem do sistema, no que se refere à resposta metabólica, como mostram as figuras 4.17 (c) e 4.18 (c).

Os registros ópticos em micro e macroescalas apresentam comportamento qualitativo semelhante, sendo confirmado pelos respectivos gráficos das complexidades calculadas.

\subsubsection{Potássio}

Para analisar a influência das respostas em presença do potássio no fenômeno de ondas de DA foram realizados quatro experimentos. Para cada experimento, foram adquiridos os valores das variações do potencial extracelular e das respostas ópticas em micro e macroescala. Para cada conjunto de dados 
concomitantes ao fenômeno, foram calculadas as respectivas medidas de complexidade.

Os registros das ondas obtidas em presença de potássio comparado com as ondas de controle apresentam diferenças qualitativas não só nos registros ópticos. Os registros do potencial apresentam, além das oscilações abruptas representadas pelos picos, as variações do sinal em torno de valores diferentes, que contribuem para que em mais regiões dos registros a complexidade seja alta e até máxima, comportamento não associado as ondas de controle.

Nos registros ópticos é possível identificar os trechos do perfil relacionados ao potencial e à resposta metabólica, como descrito no capítulo 2. A maior diferença qualitativa dos registros de potássio é devido a presença de um platô abrupto após a região relacionada com a atividade metabólica. Esse platô, que não é presente em nenhum outro registro, contribui para que a complexidade seja máxima. Os registros de potássio são caracterizados pela ausência da sequência de platôs identificados em alguns perfis obtidos em presença de outras substâncias. Diferentemente das ondas de controle e das demais analisadas, os perfis em micro e macroescalas apresentam comportamento qualitativo semelhantes sendo confirmado pelos gráficos da complexidade.

A comparação entre os registros do potencial extracelular das ondas obtidas em presença de potássio mostra que, quando os valores do potencial oscilam em torno de valores muito próximos, a complexidade diminui, permanecendo entre os valores de máximo e mínimo. A análise dos registros mostra que, quando ocorre variação dessas oscilações em torno de valores diferentes ou uma variação abrupta do potencial, a complexidade aumenta, indicando que qualquer dessas alterações do sinal contribui para o aumento do equilíbrio entre a ordem e desordem do sistema, de acordo com figura 4.19 (a). 

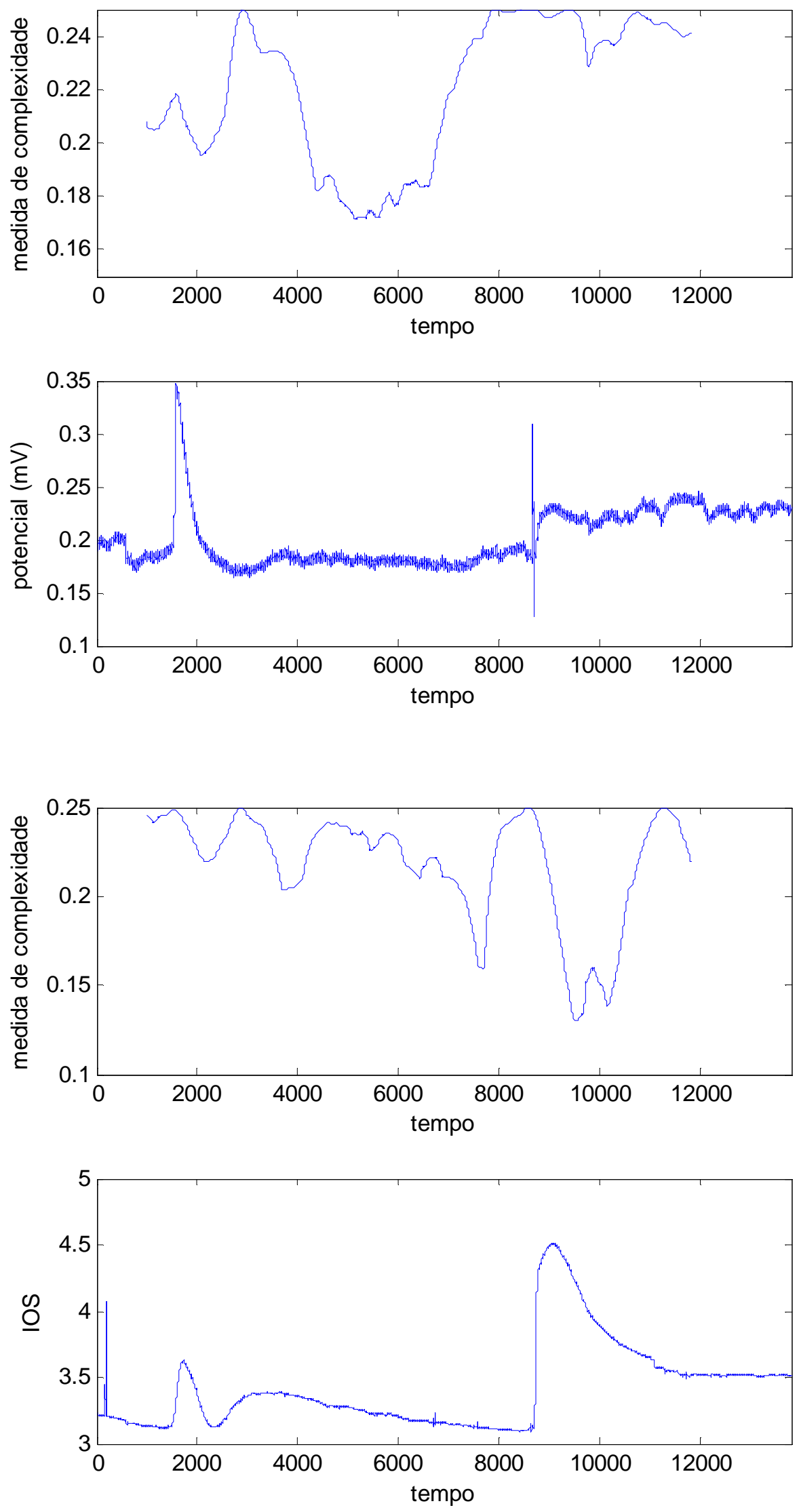

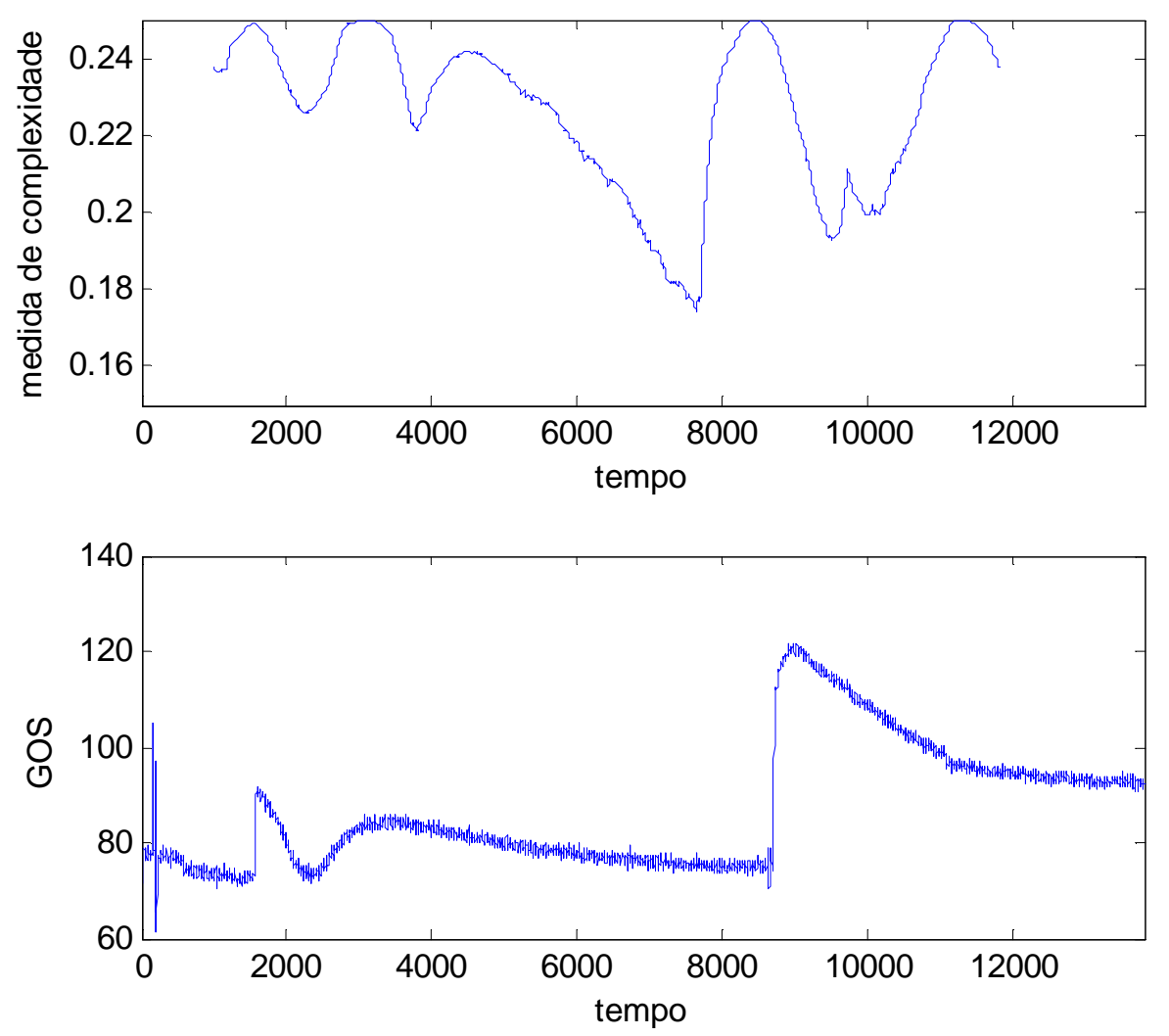

Figura 4.19 - Registros com potássio. (a) Registro do potencial extracelular e respectivo cálculo da complexidade. (b) Registro do IOS e respectivo cálculo da complexidade. (c) Registro do GOS e respectivo cálculo da complexidade.

Os perfis de onda em macro e microescalas mostram comportamentos muito semelhantes, como pode ser observado nas figuras 4.19 (b e c). Essa semelhança é confirmada analisando-se os gráficos das medidas de complexidade. A análise desses registros ópticos mostra, de forma muito clara, a relação dos registros com o potencial e com a atividade metabólica, de acordo com o capítulo 2. Para as ondas obtidas em presença de potássio, percebe-se que a sinal óptico relacionado com atividade metabólica não é tão acentuado como para outras substâncias analisadas. Para esses trechos, o sinal óptico apresenta pequenas variações em torno de valores muito próximos.

As maiores medidas de complexidade estão relacionadas aos trechos caracterizados pela variação do potencial, indicando que essa variação do sinal contribui para aumentar o equilíbrio entre ordem e desordem do sistema. Nos trechos relacionados ao metabolismo, em que o sinal varia de forma pouco abrupta, 
a complexidade apresenta valores menores, que oscilam entre o máximo e mínimo possível, e assumem, na maioria dos registros, valores intermediários, os quais indicam que houve o predomínio da ordem ou desordem no sistema, caracterizando essa diminuição da medida.

Outra observação relevante obtida através da análise é a presença de um platô, caracterizado por uma variação abrupta do sinal intrínseco que contribui para medidas de complexidade maiores. Nos registros em microescala (GOS) essa variação, juntamente com o trecho do perfil relacionado ao potencial, são responsáveis pelo equilíbrio entre a ordem e desordem, pois são os trechos que apresentam a máxima complexidade. 


\section{Conclusão}

\subsection{Introdução}

Neste capítulo serão apresentadas as conclusões obtidas das influências de cada substância estudada no fenômeno de ondas de DA. As conclusões provêm dos experimentos realizados e das análises obtidas usando a medida de complexidade para a complementação do entendimento do fenômeno. Além disso, serão apresentadas algumas perspectivas para trabalhos futuros.

\subsection{Conclusões dos cálculos de complexidade}

De acordo com os experimentos e cálculos realizados, foram obtidas as principais observações e características de cada grupo de experimento. As conclusões são baseadas nas análises comparativas de cada grupo de substâncias e da comparação desses grupos com ondas de controle Nesta seção, serão apresentadas as conclusões mais relevantes das análises realizadas.

\subsubsection{Protamina}

Para os registros das menores massas de protamina, os perfis ópticos em micro e macroescala apresentam comportamentos semelhantes para uma mesma quantidade de massa. Conclui-se que essa semelhança do perfil é aparente, e é confirmada pelas diferenças qualitativas apresentadas nos registros obtidos das medidas de complexidade. Para o experimento obtido em presença da menor massa , conclui-se que a complexidade máxima é alcançada quando há um equilíbrio entre a ordem e desordem do sistema, instantes alcançados quando os registros das 
medidas de potencial oscilam em torno de valores diferentes e próximos. Para essa mesma série temporal, conclui-se que a complexidade mínima calculada ocorre quando há uma variação abrupta do potencial. A partir das análises dos gráficos de potencial conclui-se que o aumento da massa de protamina diminui a complexidade do sistema em diversos trechos, produzindo alterações qualitativas nessas medidas. Uma conclusão importante relacionada a esse aumento de massa deve-se ao fato de que, nos trechos do registro do potencial em que esses valores oscilam pouco, a complexidade diminui, passando a assumir valores maiores e até máximos nos trechos em que ocorrem variações abruptas ou variações em torno de valores diferentes e próximos.

A análise dos registros dos perfis ópticos em micro e macroescalas, para as massas menores, permitem a conclusão de que a maior complexidade obtida do sistema é encontrada nos trechos relacionados com as respostas ao potencial, enquanto que nos trechos relacionados a atividade metabólica, em que o sinal apresenta pequenas variações de sinal, a complexidade calculada é menor, indicando que protamina em baixa quantidade de massa contribui de forma a equilibrar a ordem e desordem do sistema, no que se refere as respostas com o potencial extracelular.

Para o experimento com a maior massa, os perfis ópticos em micro e macroescalas apresentam comportamentos semelhantes para uma mesma quantidade de massa, afirmação confirmada pelos respectivos gráficos de medidas de complexidade. Observou-se que o sistema apresenta complexidade máxima nos trechos relacionados à atividade metabólica, indicando que maiores massas influenciam de forma a equilibrar a ordem e desordem do sistema em resposta as atividades metabólicas.

Para o estudo do fenômeno de ondas de DA obtidas em presença de protamina pode-se concluir que, nas duas medidas de massa de 2,0 $\mu \mathrm{g}$ e 2,5 $\mu \mathrm{g}$, o estudo do fenômeno a partir dos registros em micro e macroescala não fornecem a mesma análise qualitativa, sendo possível esse tipo de análise quando a massa de protamina passa a ser de 5,0 $\mathrm{gg}$. De forma geral, conclui-se que a medida de complexidade proposta para a análise do fenômeno contribuiu para um melhor entendimento do estudo das ondas de DA obtidas com protamina. 


\subsubsection{Ritalina}

Para os registros do potencial e das respectivas complexidades calculadas, é possível concluir que a variação abrupta do potencial, representada pelos picos, contribui para que a complexidade calculada seja máxima, indicando que essa alteração contribui para o equilíbrio entre a ordem e desordem do sistema. Pequenas variações do potencial em torno de valores diferentes contribuem para que aumente a ordem ou desordem do sistema, contribuindo para que a complexidade permaneça entre valores intermediários. O sistema permanece com complexidade mínima quando há pouca variação do potencial e assume até valores extremos, permitindo a conclusão de que a medida de complexidade proposta assume valores máximos quando o sinal varia de forma abrupta e assume valores mínimos quando a oscilação do sinal é pequena. Para o concomitante eletrofisiológico, a medida proposta contribui para que o fenômeno de ondas de DA seja entendido de forma melhor.

Para os gráficos dos registros em macroescala, é possível concluir que a dependência do potencial com o primeiro pico do perfil óptico diminui a complexidade, devido à possível ordem ou desordem ocasionada no sistema. $\mathrm{A}$ influência metabólica, caracterizada pela adição de ritalina, contribui para o aumento da complexidade, tornando-a máxima não só nesse trecho, mas nos demais pontos marcados pelo equilíbrio da ordem e desordem, descritos pela sequência de platôs.

Os gráficos das medidas de complexidade do IOS e GOS apresentam, semelhanças qualitativas para os trechos relacionados ao potencial e a influência metabólica. A medida de complexidade proposta contribui para o entendimento da DA, pois para os trechos relacionados com as variações abruptas do potencial, a complexidade apresenta valores pequenos, enquanto que para os trechos relacionados as respostas metabólicas, a complexidade assume valores máximos. 


\subsubsection{Anfetamina}

Pelos gráficos das medidas de complexidade pode-se concluir que os registros em micro e macroescalas não apresentam comportamentos qualitativos semelhantes, embora os perfis ópticos tenham algumas semelhanças. A análise dos registros permite concluir que o estudo em microescala não pode ser regido pelo estudo em macroescala. Os registros do perfil óptico em microescala mostram que a complexidade é máxima nos trechos do perfil relacionado com a atividade metabólica, dado que leva à conclusão de que a anfetamina contribui para o equilíbrio da ordem e desordem do sistema. Após esse pico, o sinal óptico permanece oscilando em torno de valores próximos, contribuindo para que a complexidade permaneça alta, embora tenha ocorrido um aumento da ordem ou desordem do sistema, visto que a complexidade diminui se comparada ao trecho anterior. Para as ondas de DA obtidas em presença de anfetamina, a medida de complexidade contribuiu para compreender a influência dessa substância no fenômeno. Na parte do registro relacionado ao potencial, marcado por uma forte variação do sinal óptico, a complexidade apresenta valores menores, indicando que essa brusca variação contribuiu para o desequilíbrio entre a ordem e desordem do sistema.

Para os registros em macroescala, conclui-se que a complexidade é máxima para os trechos do perfil relacionados com a resposta da atividade metabólica. Os valores da complexidade diminuem um pouco nos trechos cujo sinal óptico está relacionado com o sinal elétrico, permitindo a conclusão de que a anfetamina contribui para o equilíbrio da ordem e desordem do sistema nos trechos caracterizados pela atividade metabólica. Já nos trechos em que o sinal íntrisico óptico não apresenta grandes variações, indicando o predomínio da ordem ou desordem do sistema, a complexidade é minina, e chega, em algumas situações, até a assumir valores extremos.

Para os registros do potencial, conclui-se que a variação do potencial contribui para o aumento da complexidade do sistema na tentativa de tornar o sistema equilibrado entre o estado da ordem e desordem. Além disso, esse equilíbrio 
é encontrado nos trechos em que ocorrem as variações abruptas desse sinal. Quando o potencial varia muito pouco, percebe-se que a complexidade do sistema diminui, indicando que esse comportamento contribui para o predomínio da ordem ou desordem.

\subsubsection{Cafeína}

Para o estudo do fenômeno das ondas de DA obtidas em presença de cafeína os registros obtidos do potencial sugerem que a medida de complexidade aumenta com pequenas variações do potencial sendo máxima quando a variação é abrupta, indicando que esse comportamento contribui para o equilíbrio da ordem e desordem do sistema. Quando há um predomínio da ordem ou da desordem do sistema a complexidade é mínima, com trechos marcados pelas mínimas variações do potencial.

Para os gráficos em microescala (GOS), conclui-se que a complexidade máxima atingida é encontrada em resposta à atividade metabólica, mostrando que a cafeína contribui de forma a equilibrar ordem e desordem do sistema e que, após a resposta metabólica, o sistema permanece com a complexidade bem próxima do equilíbrio, indicando forte influência da cafeína. No trecho do perfil relacionado à variação do potencial, a complexidade apresenta valores baixos, indicando que houve ou predomínio da ordem ou desordem do sistema.

Para os registros em macroescala (IOS), conclui-se que a complexidade é máxima somente nos trechos relacionados à atividade metabólica, não sendo esse o comportamento observado nos gráficos em microescala. A partir dessa observação, conclui-se que não é possível analisar o comportamento em macroescala para aferir conclusões em microescala, sendo essa uma contribuição da medida de complexidade proposta para o estudo da DA. Nesses registros dos perfis em macroescala, conclui-se também que a complexidade diminui nos trechos relacionados à variação do potencial, diferenciadamente dos gráficos em microescala, mostrando que os gráficos das medidas de complexidade não 
apresentam semelhanças qualitativas. Para os registros IOS, pode-se concluir que os trechos relacionados entre o primeiro e o segundo componente óptico do perfil são os trechos que tendem a desequilibrar a ordem e desordem, pois são os que apresentam as menores complexidades calculadas.

Para os registros que possuem o mesmo comportamento qualitativo em micro e macroescalas, conclui-se que a análise em microescala não é prejudicada quando feita pelas observações em escala macroscópica. Essa peculariedade observada em tais registros pode trazer riquezas para a interpretação da influência da cafeína e seus efeitos fármaco-químico sobre os concomitantes do fenômeno de ondas de DA, que fogem do enfoque deste trabalho. Uma das características observadas para essas análises é que essas exceções foram encontradas nos registros adquiridos com menores quantidades de dados.

\subsubsection{Cocaína}

Para o estudo do fenômeno de DA sob influência da cocaína, analisando-se os registros do potencial, conclui-se que a complexidade é alterada de acordo com as variações do potencial. Quanto maior a variação do potencial em torno de valores diferentes, maior o equilíbrio entre a ordem e desordem do sistema, e maior a complexidade. Quanto maior ou menor a alteração do potencial em torno do mesmo valor de potencial, menor a medida de complexidade, prevalecendo ou a ordem ou desordem.

Os registros em micro e macroescalas possuem comportamentos qualitativos muito semelhantes, nas partes dos registros associados ao potencial e as atividades metabólicas. A diferença entre esses registros encontra-se em outros trechos. Para ambos os registros, a complexidade diminui com a variação brusca do sinal relacionado ao potencial e aumenta para os sinais relacionado as respostas metabólicas, mostrando que a cocaína aumenta o equilíbrio entre ordem e desordem, ao ser analisada a atividade metabólica.

Para o restante do registro, conclui-se que, enquanto no gráfico em 
microescala a complexidade permanece próxima do máximo, mesmo o sinal óptico oscilando em torno de valores próximos, para o estudo em macroescala (IOS), a pequena variação do sinal nessa região é suficiente para indicar que houve um pequeno aumento da ordem ou desordem sendo suficiente para provocar a diminuição da medida de complexidade, dado que mostra que os registros ópticos possuem diferenças qualitativas relevantes, mostrando a relevância do estudo do fenômeno a partir da medida de complexidade proposta.

\subsubsection{Nicotina}

As análises dos registros obtidos em presença da nicotina e dos respectivos gráficos das medidas de complexidade para ondas de DA, mostram que a complexidade máxima é encontrada para os perfis de potencial cujas oscilações ocorrem em torno de valores diferentes e próximos, permitindo a conclusão de que essas oscilações equilibram o sistema em termos de ordem e desordem. Nos trechos cujos sinais apresentam pequenas variações em torno dos mesmos valores, a complexidade calculada diminui, permitindo a conclusão de que essas pequenas oscilações aumentam a ordem ou desordem do sistema.

Para os registros ópticos, é possível concluir que as maiores medidas de complexidade são encontradas em resposta à atividade metabólica, trechos esses caracterizados por oscilações de valores em torno de valores diferentes e próximos, enquanto a menor medida é calculada nas regiões relacionadas ao potencial que são marcadas por oscilações abruptas de valores. Os registros em macro e microescalas apresentam muitas semelhanças qualitativas, indicando a possibilidade do estudo do fenômeno a partir da visão em macroescala.

\subsubsection{Potássio}

De acordo com os experimentos realizados com o potássio e com as análises 
das simulações conclui-se que pequenas variações do potencial não contribuem para o equilíbrio entre a ordem e desosordem do sistema, indicando que a complexidade não atinge valores máximos. Os valores da complexidade são máximos em trechos caracterizados pela oscilação entre valores diferentes e muito próximos. Quando a variação do potencial é abrupta, a complexidade permanece alta, não sendo, porém, máxima, permitindo a conclusão de que essa variação abrupta é um indicativo de um aumento da ordem ou desordem do sistema. Em muitos registros obtidos em presença de outras substâncias, observou-se o estado de equilíbrio entre a ordem e desordem, associado a variação abrupta do potencial. Essa diferença é um indicativo da importância da análise do fenômeno usando a medida de complexidade.

Para os sinais ópticos, conclui-se que a análise em micro e macroescalas fornecem perspectivas semelhantes visto que as medidas de complexidade e as análises são qualitativamente muito próximas, indicando a possibilidade do estudo da influência do potássio no fenômeno de ondas de DA de forma micro ou macroscópica. Para esses sinais, conclui-se que as máximas complexidades são encontradas em trechos relacionados com respostas ao potencial, enquanto que na região relacionada a respostas metabólicas, o sinal varia pouco, contribuindo para que a medida de complexidade seja menor.

Conclui-se que as ondas obtidas em presença de potássio possuem um comportamento qualitativo diferente das outras ondas analisadas. A primeira evidência dessa diferença é dada pela diferença da influência dessa substância na resposta metabólica, confirmada pelas pequenas oscilações do sinal óptico e pelas medidas da complexidade não serem máximas nessas regiões dos registros. A segunda evidência, é a presença de um platô nos registros ópticos que contribui para o aumento da complexidade, indicando a contribuição do equilíbrio entre a ordem e desordem do sistema com essa variação abrupta. 


\subsection{Perspectivas futuras}

Pelas análises dos registros obtidos com a protamina é possível perceber que quanto maior foi à massa, houve um aumento nos valores registrados para as medidas dos picos do potencial. Investigar essa relação poderia produzir ganhos relacionados à interação do produto fármaco-químico com o fenômeno de ondas de DA.

Outra investigação proveitosa poderia ser o estudo da influência do aumento da massa de 2,0 $\mu \mathrm{g}$ para 2,5 $\mu \mathrm{g}$ e a variação da complexidade calculada. Por que nos registros do potencial de menor quantidade de massa de protamina a complexidade diminui com a variação abrupta do potencial enquanto que para uma quantidade um pouco maior de massa da mesma substância, a complexidade é máxima nos instantes que antecedem e sucedem essa variação abrupta?

Além dessas sugestões de estudo para a protamina, seria oportuno um olhar detalhado para a influência da protamina em quantidade de 5,0 $\mu \mathrm{g}$ na resposta da atividade metabólica, que contribui para o equilíbrio entre a ordem e desordem do sistema e qual a influência na gênese do fenômeno.

Para os registros obtidos com a ritalina, seria interessante a investigação da ocorrência da sequência de platôs nos registros em microescala, sabe-se que essas variações do sinal contribuem para que a complexidade seja máxima, mas desconhece-se a presença dessas oscilações e suas relações com a ocorrência da depressão alastrante. Outra discussão importante seria a causa da ausência desses platôs nos registros em macroescala.

No registro do experimento realizado com ritalina, cujos resultados em micro e macroescalas apresentam semelhanças qualitativas, sugere-se a realização de novos experimentos para detalhar o ocorrido.

Assim como nos registros ópticos de microescala obtidos com a ritalina, os registros da anfetamina também apresentam a sequência de platôs, sugere-se o estudo da gênese dessas variações de sinal e, especificamente para a anfetamina, 
pode ser feita uma futura investigação da causa do sinal ser crescente após esses platôs.

Uma particularidade encontrada no trabalho, que serve para trabalhos futuros, deve-se aos experimentos realizados com cafeína. Para os registros em macroescala é possível identificar que a menor complexidade calculada está relacionada aos trechos entre o primeiro componente óptico e a resposta da atividade metabólica. A investigação desse aumento de ordem ou desordem acrescentada ao fenômeno pode trazer ricas contribuições para o estudo da influência da cafeína e a depressão alastrante. Outra discussão a ser feita é analise detalhada das exceções encontradas nos registros. Para alguns dos experimentos realizados, há semelhanças qualitativas entre os dois registros ópticos obtidos.

Para os registros obtidos com cocaína, grandes contribuições poderão ser feitas se forem investigadas a origem e as causas das sequências dos platôs nos registros em microescala. Em alguns registros, esse diferencial não é apresentado e como essa variação do sinal contribui para variar o equilíbrio entre ordem e desordem do sistema, entende-se que tal conhecimento deve favorecer a interpretação do fenômeno.

Entender por que o comportamento do sinal do potencial extracelular que precedente a variação abrupta do potencial altera o resultado da medida de complexidade pode contribuir para o estudo da influência da nicotina na propagação de ondas de DA.

A análise com potássio sugere uma investigação mais detalhada em diversos aspectos. Um deles é a descrição do único platô nos registros ópticos, qual a origem e contribuição dessa característica para o fenômeno? Outra discussão importante poderia ser feita através do estudo comparativo do perfil óptico relacionado ao primeiro componente óptico, pois esse trecho relacionado com o potencial apresenta um tempo de ocorrência maior. Qual a relação entre esse tempo e a interação da substância com o fenômeno? Por que os registros ópticos em micro e macroescalas são semelhantes para o experimento com potássio?

O presente texto pretende ser uma contribuição para o estudo do fenômeno de ondas de DA em retina na perspectiva de que a medida de complexidade 
estudada fornecesse um entendimento melhor da depressão alastrante. Uma grande contribuição do estudo do fenômeno de ondas de DA, usando-se a medida de complexidade proposta, seria a possibilidade da análise de Fourier nos trechos em que a complexidade assumiu valores mínimos, na perspectiva de descobrir se esse comportamento da medida é consequência do predomínio da ordem ou da desordem do sistema. Se nesses trechos marcados pela baixa complexidade, o predomínio for à ordem do sistema, poderia se propor um estudo detalhado da influência da substância em ordenar o sistema e de como esse padrão de ordem se estabelece. Se o predomínio for da desordem, poder-se-ia propor um estudo da influência de dinâmica não linear e as medidas de complexidades.

Analisando-se os registros GOS percebe-se que, frequentemente os experimentos com algumas substâncias influenciam o sistema de forma diferenciada. Essa indicação é evidenciada no trecho do perfil óptico após a relação com a atividade metabólica. Sugere-se o estudo detalhado dessa influência para essas substâncias, na perspectiva de entender por que essa variação de sinal influencia quase todos os experimentos, de forma a contribuir para o equilíbrio entre a ordem e desordem do sistema, aumentando a complexidade. Entender biologicamente essa interação pode trazer contribuições para o estudo da autoorganização do sistema. 


\section{Referências Bibliográficas}

BEGGS, J. M.; PLENZ, D. Neuronal avalanches are diverse and precise activity patterns that are stable for many hours in cortical slice cultures. The Journal of Neuroscience, v. 24, n. 22, p. 5216 - 5229, jun. 2004.

BENNET, C. H. How to define complexity in physics, and why. In: Complexity, Entropy and the physics of information. Addison-Wesley, 1990. p. 137-148.

CAMPBELL- BORGES, Y. C.; PIQUEIRA, J. R. C. Complexity Measure: A quantum information approach. International Journal of Quantum Information, v. 10, n. 4, p. 1250047-1-1250047-19, jun. 2012.

De MATTOS, S. H. V. L; PIQUEIRA, J. R. C.; VASCONCELOS-NETO, J; ORSATTI, F. M. Measuring q-bits in three-trophic level systems. Ecological Modelling, v. 200, n. 1- 2, p. $183-188$, jan. 2007.

Do CARMO, R. J.; MARTINS-FERREIRA, H. Spreading depression of Leão probed with íon-selective microelectrodes in isolated chick retina. Anais da Academia Brasileira de Ciências, v. 56, n. 4, p. 401 - 421, dez. 1984.

DUARTE, M. A. Uma técnica para o estudo do sinal óptico intrínseco da depressão alastrante em retina de aves. Universidade Estadual de Campinas, Faculdade de Engenharia Elétrica e de Computação, Tese de Doutorado, 2000.

FELDMAN, D. P.; CRUTCHFIELD, J. P. Measures of statistical complexity: Why? Physics Letters A, v. 238, n.4-5, p. 244 - 252, fev. 1998.

FERNANDES De LIMA, V. M., SCHELLER, D.; TEGTMEYER, F.; HANKE, W.; SCHLUE, W. R. Self-susteined spreading depressions in the chicken retina and short-term neuronal-glial interactions within the gray matter neuropil. Brain Research, v. 614 , p. 45 - 51, jan. 1993.

FERNANDES De LIMA, V. M.; HANKE, W. Excitation in central grey matter : the retinal spreading depression. Progress in Retinal and Eye Research, v. 16, n. 4, p. 657-690, 1997. 
FERNANDES De LIMA, V. M.; GOLDERMANN, M.; HANKE, W. The retinal spreading depression. Aachen : Shaker, 1999.

GORELOVA, N. A.; BURES, J. Spiral waves of spreading depression in isolated chicken retina. Journal of Neurobiology, v. 14, n. 5, p.353 - 363, set. 1983.

GOURAS, P. Spreading depression of activity in amphibian retina. The American Journal of Physiology, v. 195, n.1, p. 28 - 32, set. 1958.

GRAFSTEIN, B. Mechanism of spreading cortical depression. Journal of Neurophysiology, v. 19, n. 2, p.154 - 171, mar. 1956.

GROSSMAN, R. G.; SEREGIN, A. Glial-Neural interaction demonstrated by the injection of $\mathrm{Na}^{+}$and $\mathrm{Li}^{+}$into cortical glia. Science, v. 195, n. 4274, p. $196-198$, jan. 1977.

LANDSBERG, P. T. Can entropy and "order" increase together? Physics Letters, v. 102 A, n. 4, p.171-173, mai. 1984.

LANDSBERG, P. T.; SHINER, J. S. Disorder and complexity in an ideal nonequilibrium Fermi gas. Physics Letters A, v. 245, n.3 - 4, p. 228 - 233, ago. 1998.

LEÃO, A. A. P. Spreading depression of activity in the cerebral cortex. Journal of Neurophysiology, v. 7, n. 6, p. 359 - 390, nov. 1944a.

LEÃO, A. A. P. Pial circulation and spreading depression activity in cerebral cortex. Journal of Neurophysiology, v.7, n. 6, p. 391 - 396, nov. 1944b.

LEÃO, A. A. P. Further observations on the spreading depression activity in the cerebral cortex. Journal of Neurophysiology, v. 10, n. 6, p. 409 - 414, nov. 1947.

LÓPEZ-RUIZ, R.; MANCINI, H. L.; CALBET, X. A statistical measure of complexity. Physics Letters A, v. 209, n.5-6, p. 321-326, dez. 1995. 
MARTINS-FERREIRA, H.; De OLIVEIRA CASTRO, G.; STRUCHINER, C. J.; RODRIGUES, P. S. Circling spreading depression in isolated chicken retina. Journal of Neurophysiology, v. 37, n. 4, p. 773 - 783, jul. 1974.

MARTINS-FERREIRA, H.; NEDERGAARD, M.; NICHOLSON, C. Perspectives on spreading depression. Brain Research Reviews, v. 32, n. 1, p. 215 - 234, mar. 2000.

MILNER, P. M. Note on possible correspondence between the scotomas of migraine and spreading depression of Leão. EEG Clinical Neurophysiology, v. 10, p. 705, n. 4, nov. 1958.

PEIXOTO, N. L. V. A depressão alastrante na retina. Universidade Estadual de Campinas, Faculdade de Engenharia Elétrica e de Computação, Dissertação de Mestrado, 1997.

PIQUEIRA, J. R. C.; De MATTOS, S. H. V. L.; VASCONCELOS-NETO, J. Measuring complexity in three-trophic level systems. Ecological Modelling, v. 220, n. 3, p. 266271 , fev. 2009.

PIQUEIRA, J. R. C.; De MATTOS, S. H. V. L. Note on LMC complexity measure. Ecological Modelling, v. 222, n. 19, p. 3603 - 3604 out. 2011.

PIQUEIRA, J. R. C.; NAHAS, T. R. O sonho de Bernouilli. Estudos avançados (USP. Impresso), v. 25, n. 72, p. 289 - 301, 2011.

PIQUEIRA, J. R. C.; MORTOZA, L. P. D. Brazilian exchange rate complexity: Financial crises effects. Communications in Nonlinear Science and Numerical Simulation, v. 17, n. 4, p. 1690 - 1695, abr. 2012.

PIQUEIRA, J. R. C.; De LIMA, V. M. F.; SIEBER, M.; HANKE, W. Tasaki 's membrane model and the spread of excitation waves in the CNS: insights from intrinsic optical and field potentials. Physica D (submetido).

SHANNON, C. E. A mathematical theory of communication. The Bell System Technical Journal., v. 27, n. 3, p. 379 - 423, 623 - 656 jul./out. 1948. 
SHINER, J. S.; DAVISON, M.; LANDSBERG, P. T. Simple measure for complexity. Physical Review E, v. 59, n. 2, p. 1459 - 1464, fev. 1999.

VAN HARREVELD, A., Two mechanisms for spreading depression in the chicken retina. Journal of Neurobiology, v. 9, n. 6, p. 419 - 431, nov. 1978.

WACKERBAUER, R.; WITT, A.; ATMANSPACHER, H.; KURTHS, J.; SCHEINGRABER, H. A comparative classification of complexity measures. Chaos, Solitons \& Fractals, v. 4, n. 1, p. 133 - 173, jan. 1994. 